UNIVERSIDADE DE SÃO PAULO

ESCOLA DE ENFERMAGEM

CASSIMIRO NOGUEIRA JUNIOR

POLÍTICAS PÚBLICAS PARA PREVENÇÃO E CONTROLE DE IRAS: CONCEPÇÃO DE UM MODELO EXPLICATIVO PARA SUA ESTRUTURAÇÃO 


\section{POLÍTICAS PÚBLICAS PARA PREVENÇÃO E CONTROLE DE IRAS: CONCEPÇÃO DE UM MODELO EXPLICATIVO PARA SUA} ESTRUTURAÇÃO

Tese apresentada ao Programa de Pós-Graduação em Enfermagem (PPGE) da Escola de Enfermagem da USP (EEUSP) para a obtenção do título de Doutor em Ciências.

Área de Concentração: Cuidado em Saúde.

Orientadora: Prof. ${ }^{a}$ Dr. ${ }^{a}$ Maria Clara Padoveze. 
AUTORIZO A REPRODUÇÃO E DIVULGAÇÃO TOTAL OU PARCIAL DESTE TRABALHO, POR QUALQUER MEIO CONVENCIONAL OU ELETRÔNICO, PARA FINS DE ESTUDO E PESQUISA, DESDE QUE CITADA A FONTE.

Assinatura:

Data:

\section{Catalogação na Publicação (CIP) \\ Biblioteca "Wanda de Aguiar Horta" \\ Escola de Enfermagem da Universidade de São Paulo}

Nogueira Junior, Cassimiro

Políticas públicas para prevenção e controle de IRAS: concepção de um modelo explicativo para sua estruturação / Cassimiro Nogueira Junior. São Paulo, 2018.

$131 \mathrm{p}$.

Tese (Doutorado) - Escola de Enfermagem da Universidade de São Paulo.

Orientadora: Prof. ${ }^{a}$ Dr. ${ }^{a}$ Maria Clara Padoveze

Área de concentração: Cuidado em Saúde

1. Política de saúde. 2. Infecção hospitalar. 3. Controle de infecções. 4. Enfermagem. I. Título.

Ficha catalográfica elaborada por Fabiana Gulin Longhi Palacio (CRB-8: 7257) 
Nome: Cassimiro Nogueira Junior

Título: Políticas Públicas para Prevenção e Controle de IRAS: Concepção de um modelo teórico para sua estruturação

Tese apresentada ao Programa de Pós-Graduação em Enfermagem (PPGE) da Escola de Enfermagem da USP (EEUSP) para a obtenção do título de Doutor em Ciências.

Aprovado em:

\section{Banca Examinadora}

Prof. Dr. (a):

Instituição:

Julgamento:

Prof. Dr. (a):

Instituição:

Julgamento:

Prof. Dr. (a):

Instituição:

Julgamento:

Prof. Dr. (a):

Instituição:

Julgamento:

Prof. Dr. (a):

Instituição:

Julgamento: 


\section{DEDICATÓRIA}

"Quando a liberdade é deixada intacta, o amor cresce infinitamente." Osho

Aos que mais amo nesta vida, aos que me fazem voar, me lançam ao infinito e além... Acreditam... mesmo nos momentos mais difíceis. Incentivam... mesmo quando parece impossível:

Hélder, meu melhor amigo, meu companheiro de vida - pelo ombro, por ser minha base, por me apoiar e ensinar a cada dia, por estar sempre ao meu lado e nunca me deixar desistir...

Meu amado e saudoso Pai - que tenho certeza esteve sempre presente... sei que seu carinho será eterno... mesmo não tendo sua presença física, sei que você vibra onde estiver com minhas conquistas...

Minha amada Mãe - pelo olhar que acolhe, pela doçura que me envolve, pela saudade sempre presente...

Meus irmãos Mônica, Átila e Tiago - pelo abraço caloroso, pelo sorriso, pelo carinho...

À família que Deus me proporcionou, minhas amadas cunhadas Fabiany e Caroliny, meus sogros Siomaria e Silvano - por me receberem como filho, pelo apoio e pela vibração.

Amo vocês infinitamente! 


\section{AGRADECIMENTOS}

À Deus por guiar meus passos e proporcionar tantas realizações, nunca me deixando resistir.

À Prof ${ }^{a}$ Dr $^{\mathrm{a}}$ Maria Clara por acreditar em meu potencial e colaborar para o meu desenvolvimento pessoal e profissional

Ao Conselho Nacional de Desenvolvimento Científico e Tecnológico (CNPq), pelo apoio a concretização desta pesquisa.

Ao Dr. Fernando Otaiza (Chile), Dr. Mitchell Schwaber (Israel) e Magda Miranda (Brasil) pela recepção, contribuição e por tornar realidade este estudo.

As equipes do Ministério da Saúde do Chile, de Israel e da Agência Nacional de Vigilância Sanitária - ANVISA (Brasil) pela acolhida, por me permitir conhecer suas atividades e por colaborar com esta pesquisa.

Às equipes dos hospitais chilenos $\mathrm{e}$ israelenses visitados, pela atenção e receptividade.

As amigas de pós-graduação e que ficarão para sempre em minha vida, Débora Melo e Amanda Maciel, por tornarem suas presenças especiais apoiando-me quando precisei.

Aos queridos amigos do Controle de Infecção do Hospital Alemão Oswaldo Cruz: Cristiane Schimitt, Ligia Abraão, Ícaro Boszczowski e Márcia Baraldi pelos desabafos, pelos conselhos e pelo apoio.

Á equipe de Qualidade e Segurança do Hospital Alemão Oswaldo Cruz por aturarem meus desesperos, pelos incentivos, pelo convívio diário. Em especial ao Dr. Fernando Colombari, por me permitir concluir este estudo e às amadas Eliener e Ana Paula, pelos conselhos, pelo ombro amigo, pela torcida. 
Aos amigos do Hospital Municipal Dr. Mario Gatti - Campinas/SP e Universidade Paulista - UNIP pelas liberações e pelo apoio.

Aos amigos de ontem, de hoje e de sempre... por me divertirem e tornarem minha vida mais leve: Flávio Reis, Rodrigo Valente, Luiz Benoliel, Gabriela Vasconcelos, Murilo Costa, Anderson Queiroz...

Aos colegas de pós-graduação, aos professores e a Universidade Estadual de Campinas (UNICAMP) por contribuir e estimular o adensamento teórico em minha trajetória e apoiar a finalização deste estudo.

Aos colegas do subgrupo de pesquisa de Vulnerabilidade pela colaboração na construção do modelo explicativo e nas discussões deste estudo. 
“Toda mudança positiva - todo salto para um nível maior de energia e consciência envolve um ritual de passagem. A cada subida para um degrau mais alto na escada da evolução pessoal, devemos atravessar um período de desconforto, de iniciação. Eu nunca conheci uma exceção". 


\section{RESUMO}

Nogueira-Júnior C. Políticas Públicas para Prevenção e Controle de IRAS: Concepção de um modelo explicativo para sua estruturação. [tese] São Paulo: Escola de Enfermagem; 2018.

Introdução: As infecções relacionadas à assistência à saúde (IRAS) constituem um problema de interesse global por seu impacto para a segurança dos cuidados em saúde. Consequentemente, demandam a implantação de políticas públicas eficazes para sua prevenção e controle. Uma manifestação concreta das políticas públicas é o estabelecimento e manutenção de programas nacionais específicos para a prevenção e controle de IRAS. Objetivo: O objetivo do estudo foi analisar e comparar a implantação dos programas nacionais de prevenção e controle de IRAS no Brasil, Chile e Israel. Métodos: Trata-se de um estudo de caso descritivo e exploratório que utilizou o modelo do triângulo de análise de políticas de saúde para comparar o contexto, o processo, o conteúdo e os atores destes programas governamentais. Os dados foram coletados entre 2014 e 2017 em três fases: Fase I - acesso às páginas eletrônicas dos programas nos países selecionados; Fase II - visita à sede do programa nacional e Fase III - construção do modelo teórico explicativo. Resultados: Elementos comuns entre os três países foram identificados permitindo a proposição de um modelo teórico explicativo constituído de dois núcleos: núcleo de formação composto por três componentes estratégicos (gerador de necessidade, formador de alternativas e promotor do interesse social); e núcleo de desenvolvimento e sustentabilidade dos programas - composto por outros quatro componentes estratégicos (gerador de decisão, gerador de sustentação, gerador de renovação e patrocinadores do processo). Conclusão: $O$ modelo proposto contribui na compreensão dos fatores que podem influenciar o progresso de um programa nacional de IRAS, fornecendo reflexões sobre elementos para o estabelecimento de programas em países nos quais ainda estão incipientes.

Palavras-chave: Política de Saúde, Infecção Hospitalar, Controle de Infecções,

Programa de Controle de Infecção Hospitalar, Programas Governamentais, Enfermagem. 


\begin{abstract}
Nogueira-Júnior C. Public Policies for Prevention and Control of HAI: Design of an explanatory model for its composition. [thesis] São Paulo: Escola de Enfermagem; 2018.
\end{abstract}

Background: Healthcare-associated infections (HAls) are a global concern due to the impact on healthcare safety. Consequently, they demand the implementation of effective public policies for their prevention and control. A concrete manifestation of public policies is the establishment and maintenance of specific national programs for the prevention and control of IRAS. Aim: The objective of this study was to analyze and compare the implementation of national programs for the prevention and control of HAls in Brazil, Chile, and Israel. Methods: It is a descriptive and exploratory case study that used the triangle of health policy analysis to compare the context, the process, the content and the actors of these government programs. Data were collected between 2014 and 2017 in three phases: Phase I - access to the electronic pages of the programs in the selected countries; Phase II - visit to the headquarters of the national program and Phase III - construction of the theoretical explanatory model. Results: The triangle of health policy analysis was used to compare the context, process, and content of national HAl prevention and control programs. Common elements identified among the three countries led to the proposal of an explanatory theoretical model constituted of two nuclei: formation nuclei - composed of three strategic components (necessity generator, alternatives generator and promoter of social interest); and development \& sustainability nuclei - composed of four other strategic components (decision generator, sustainability generator, renewal generator and process sponsors). Conclusion: The proposed model contributes to understanding the factors that can influence the progress of a national HAI program, providing insights into the elements for establishing programs in countries where they are still inceptive.

Key words: Health Policy, Cross Infection, Infection Control, Hospital Infection Control Program, Government Programs, Nursing. 


\section{LISTA DE ILUSTRAÇÕES}

Figura 1 - Representação esquemática das etapas de seleção dos países para a inclusão no estudo. São Paulo. 2018.

Figura 2 - O triângulo de análise de políticas de saúde. São Paulo. 2018.

Figura 3 - Etapas da análise dos dados coletados no estudo. São Paulo. 2018.

Figura 4 - Representação esquemática da linha do Tempo do Programa Nacional de Prevenção e Controle de Infecção do Brasil, segundo as fases de formação, consolidação, padronização, monitoramento \& avaliação. São Paulo. 2018.

Figura 5 - Representação esquemática da linha do Tempo do Programa Nacional de Prevenção e Controle de Infecção do Chile, segundo as fases de formação, consolidação, padronização, monitoramento \& avaliação. São Paulo. 2018.

Figura 6 - Representação esquemática da linha do Tempo do Programa Nacional de Prevenção e Controle de Infecção e Resistência Microbiana de Israel, segundo as fases de formação, consolidação, padronização, monitoramento \& avaliação. São Paulo. 2018.

Figura 7 - Modelo Teórico Explicativo da formação dos Programas Nacionais de Prevenção e Controle de IRAS. São Paulo. 2018. 


\section{LISTA DE QUADROS}

Quadro 1 - Principais Legislações pertinentes aos Programas Nacionais de Prevenção e Controle de Infecção do Brasil, Chile e Israel. São Paulo. 2018.

Quadro 2 - Indicadores Epidemiológicos dos Programas de Prevenção e Controle de Infecção do Brasil, Chile e Israel. São Paulo. 2018.

Quadro 3 - Conteúdo Sumarizado dos Programas Nacionais de 77 Prevenção e Controle de Infecção no Brasil, Chile e Israel, segundo os elementos: objetivos, foco, equipe, atividades e resultados. São Paulo. 2018.

Quadro 4 - Principais atores envolvidos na elaboração dos programas nacionais de prevenção e controle de IRAS no Brasil, Chile e Israel. São Paulo. 2018.

Quadro 5 - Núcleos, componentes e elementos da formação, desenvolvimento e manutenção de programas nacionais de prevenção e controle de IRAS. São Paulo. 2018. 


\section{LISTA DE TABELAS}

Tabela 1 - Indicadores sociais, demográfico e de saúde no Brasil. São 55 Paulo. 2018.

Tabela 2 - Indicadores sociais, demográfico e de saúde no Chile. São 60 Paulo. 2018.

Tabela 3 - Indicadores sociais, demográfico e de saúde em Israel. São 64 Paulo. 2018. 


\section{LISTA DE ABREVIATURAS E SIGLAS}

$\mathrm{ABIH}-$

AMECIH -

ANIVSA -

APEC -

APECIH -

BRICS -

CDT -

CECIRAS -

CJM -

CNCIRAS -

$\mathrm{CNPq}-$

CRE -

DEIS -

ECDC -

EEUSP -

ESBL -

EUA -

G20 -

IBGE -

ICS -
Associação Brasileira dos Profissionais em Controle de Infecção Hospitalar

Associação Mineira de Epidemiologia e Controle de Infecções

Agência Nacional de Vigilância Sanitária

Cooperação Econômica Ásia-Pacífico

Associação Paulista de Epidemiologia e Controle de Infecção

Relacionada à Assistência à Saúde

Acrônimo que se refere aos países membros fundadores do grupo econômico: Brasil, Rússia, Índia e China

Clostridium Difficile Toxin

Comissão Estadual de Controle de Infecções Relacionadas a Assistência em Saúde

Congresso Judaico Mundial

Comissão Nacional de Controle das Infecções Relacionadas à Assistência à Saúde

Conselho Nacional de Desenvolvimento Científico e Tecnológico

Enterobactérias resistentes aos carbapenêmicos

Departamento de Estadísticas e Información de Salud

Centro Europeu de Prevenção e Controle de Doenças

Escola de Enfermagem da Universidade de São Paulo

Betalactamases de Espectro Extendido

Estados Unidos da América

Grupo dos 20

Instituto Brasileiro de Geografia e Estatística

Infecção da Corrente Sanguínea 


\begin{tabular}{|c|c|}
\hline IPCS/CVC - & $\begin{array}{l}\text { Infecção Primária de Corrente Sanguínea relacionada a Cateter } \\
\text { Venoso Central }\end{array}$ \\
\hline IRAS - & Infecções Relacionadas à Assistência à Saúde \\
\hline ITU/SVD - & $\begin{array}{l}\text { Infecção do Trato Urinário relacionada a Sonda Vesical de } \\
\text { Demora }\end{array}$ \\
\hline MCTI - & Ministério da Ciência, Tecnologia, Inovações e Comunicações \\
\hline Mercosul - & Mercado Comum do Sul \\
\hline MRSA - & Staphylococcus Aureus resistente a Meticilina \\
\hline MS - & Ministério da Saúde \\
\hline OCDE - & Organização para a Cooperação e Desenvolvimento Econômico \\
\hline OEA - & Organização dos Estados Americanos \\
\hline OEI- & Organização de Estados Ibero-americanos \\
\hline OMC - & Organização Mundial do Comércio \\
\hline OMS - & Organização Mundial da Saúde \\
\hline ONU - & Organização das Nações Unidas \\
\hline OPAS - & Organização Pan-Americana da Saúde \\
\hline PAV - & Pneumonia Associada à Ventilação Mecânica \\
\hline PNPCIRAS - & $\begin{array}{l}\text { Programa Nacional de Prevenção e Controle de Infecção } \\
\text { Relacionada à Assistência à Saúde }\end{array}$ \\
\hline $\mathrm{PNCl} / \mathrm{PNClH}-$ & Programa Nacional de Controle de Infecção \\
\hline RENISS - & $\begin{array}{l}\text { Rede Nacional para Investigação de Surtos e Eventos Adversos } \\
\text { em Serviços de Saúde }\end{array}$ \\
\hline RM - & Resistência Microbiana \\
\hline SINAIS - & $\begin{array}{l}\text { Sistema Nacional de Informação para o Controle de Infecções } \\
\text { em Serviços de Saúde }\end{array}$ \\
\hline $\mathrm{SNC}-$ & Sistema Nervoso Central \\
\hline US & stema Unico de Saúde \\
\hline
\end{tabular}


UTI - $\quad$ Unidade de Terapia Intensiva

VE - $\quad$ Vigilância Epidemiológica

VRE - $\quad$ Enterococos resistentes à Vancomicina 


\section{SUMÁRIO}

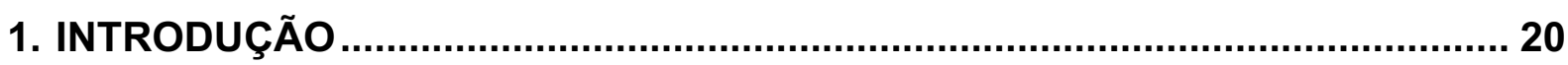

2. OBJETIVOS

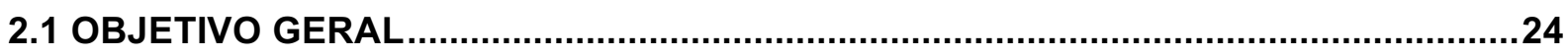

2.2 OBJETIVOS ESPECÍFICOS............................................................................24

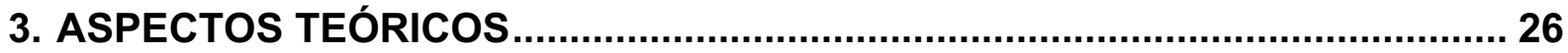

3.1 POLÍTICAS PÚBLICAS: CONCEITOS E DEFINIÇÕES ..............................................26

3.1.1 A formulação e análise de Políticas Públicas....................................................................28

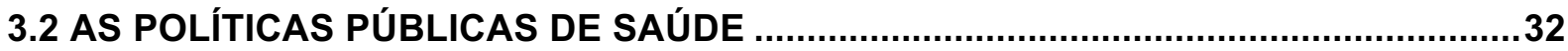

3.3 A PREVENÇÃO E O CONTROLE DE IRAS COMO UMA POLÍTICA PÚBLICA DE

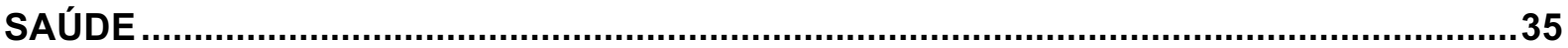

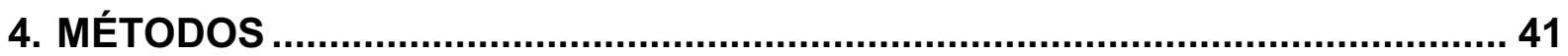

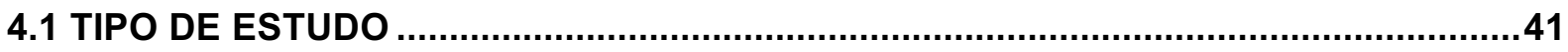

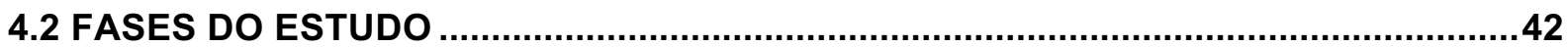

4.3 CENÁRIO - SELEÇÃO DAS UNIDADES DE ANÁLISE .......................................42

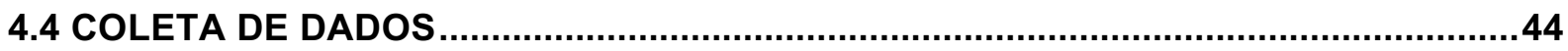

4.4.1 Fase I - Pesquisa Bibliográfica e Documental sobre os Programas Governamentais.. 44 4.4.2 Fase II - Visita a sede dos Programas Governamentais de Prevenção e Controle de IRAS

4.4.3 Fase III - Construção de um Modelo Teórico Explicativo das Políticas Públicas de

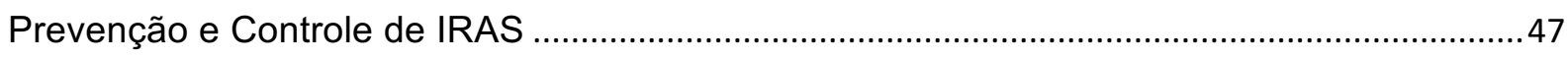

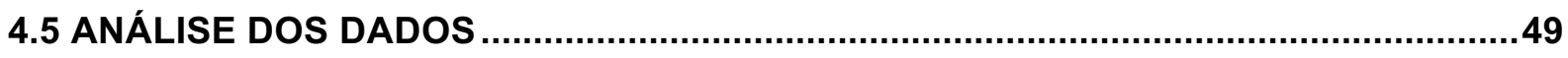

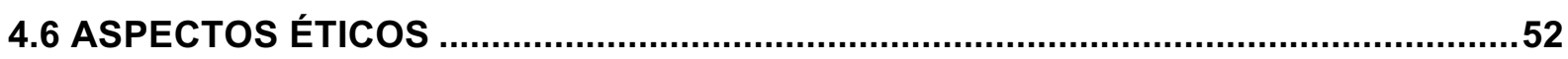

4.7 FINANCIAMENTO DO PROJETO E APOIO AO DESENVOLVIMENTO DA

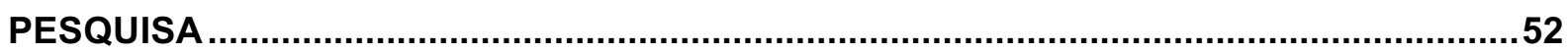

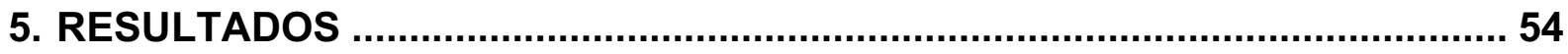

5.1 ESTUDO DE CASO 1 - O PROGRAMA NACIONAL DE PREVENÇÃO E CONTROLE

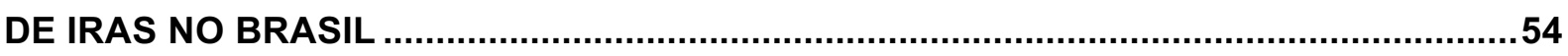

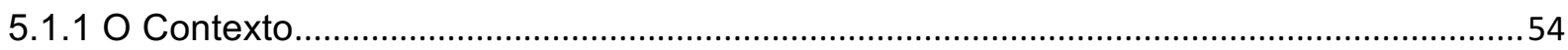

5.1.2 O Processo de desenvolvimento do Programa Nacional .....................................................57 
5.2 ESTUDO DE CASO 2 - O PROGRAMA NACIONAL DE PREVENÇÃO E CONTROLE

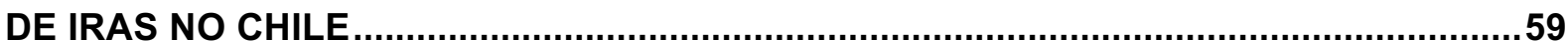

5.2.1 O Contexto

5.2.2 O Processo de desenvolvimento do Programa Nacional ..................................................61

5.3 ESTUDO DE CASO 3 - O PROGRAMA NACIONAL DE PREVENÇÃO E CONTROLE

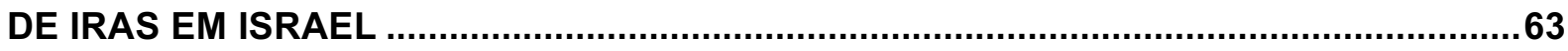

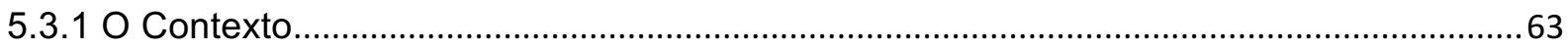

5.3.2 O Processo de desenvolvimento do Programa Nacional .................................................65

5.4 O CONTEÚDO DOS PROGRAMAS NACIONAIS DE PREVENÇÃO E CONTROLE DE IRAS 67

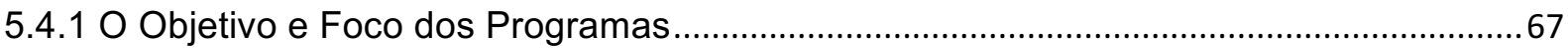

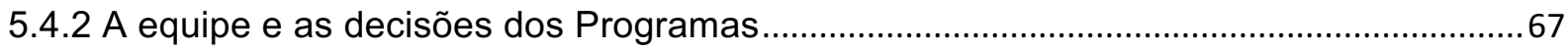

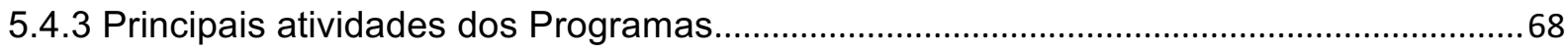

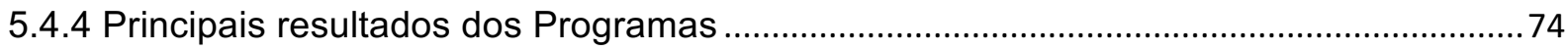

5.5 PAREAMENTO DE CASOS: ELEMENTOS DAS POLITICAS PÚBLICAS PARA

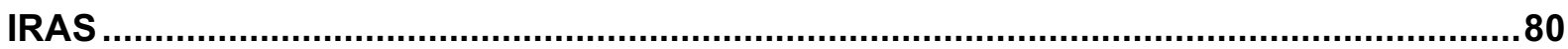

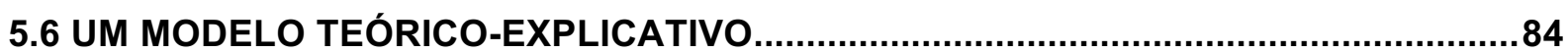

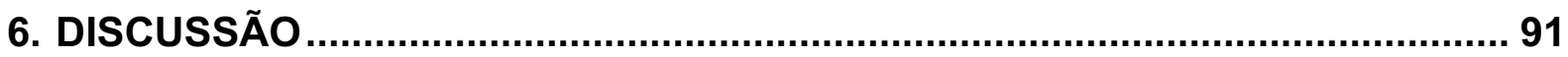

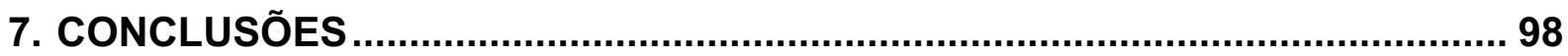

7.1 IMPLICAÇÕES PARA A PRÁTICA E PARA A PESQUISA ….....................................99

7.2 SUGESTÕES PARA TRABALHOS FUTUROS ......................................................99

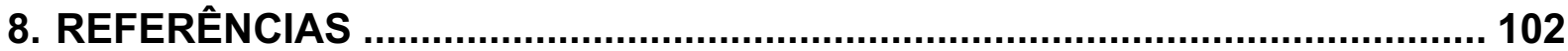

APÊNDICE A - CARTA CONVITE

APÊNDICE B - PROGRAMAS DA VISITA AO CHILE...............................................114

APÊNDICE C - PROGRAMA DA VISITA A ISRAEL

APÊNDICE D - PROGRAMA DA VISITA AO BRASIL .............................................120

APÊNDICE E - INSTRUMENTO DE COLETA DE DADOS ...........................................123

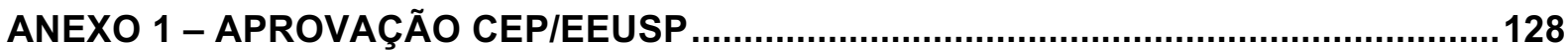




\section{INTRODUÇÃO}

As infecções relacionadas à assistência à saúde (IRAS) constituem um fenômeno histórico e social decorrente da evolução tecnológica da assistência à saúde e da epidemiologia. Esta ocorrência provoca diversos impactos assistenciais, econômicos e jurídicos, representando uma importante causa de morbimortalidade e um dos principais desafios para melhoria da qualidade assistencial nos dias atuais (Stone et al., 2005; Rodrigues, 2010; Allegranzi et al., 2011; Padoveze e Fortaleza, 2014).

São ocorrências resultantes do processo assistencial, ou seja, não estavam presentes e nem mesmo em incubação no momento da admissão do paciente, podendo se manifestar durante uma internação ou após a alta. Representam um dos principais eventos adversos dos cuidados em saúde, afetando pacientes tanto em hospitais como em outros serviços ambulatoriais. Sua prevenção e controle requer uma estrutura mínima que inclui a organização de uma comissão de controle e vigilância constante, até recursos básicos para higiene de mãos, esterilização, análise microbiológica de espécimes clínicas, entre outros (Allegranzi et al., 2017; Fortaleza et al., 2017).

Dados norte-americanos estimam que a cada ano aproximadamente dois milhões de pessoas sejam acometidas por IRAS nos Estados Unidos (EUA), sendo que destes, em torno de noventa mil terminam em morte. Os custos com esta assistência chegam a aproximadamente 6,5 milhões de dólares por ano, elevando consideravelmente os gastos com os cuidados em saúde (Stone et al., 2005; Klevens et al., 2007; Allegranzi et al., 2011; Zimlichman et al., 2013). Nos países em desenvolvimento a carga de IRAS nos serviços de saúde é ainda mais alta (Allegranzi et al., 2011). Especialmente no Brasil, um estudo conduzido entre 2011 e 2013 em 152 hospitais encontrou uma prevalência global de IRAS em torno de 10,8\% (Fortaleza et al., 2017).

O seu efetivo combate demanda o comprometimento dos gestores dos serviços de saúde em melhorar a vigilância e incorporar práticas qualificadas de controle e 
prevenção (Allegranzi et al., 2011). A implantação de programas de controle de infecção aliado a estratégias multimodais que incluam: orientações técnicas, treinamento e educação, estrutura adequada para a vigilância e monitoramento contínuo, componentes mínimos para o combate desta ocorrência (Storr et al., 2017).

Todavia, estas práticas de prevenção e controle não devem ficar restritas somente aos serviços de saúde. Torna-se imprescindível a expansão desta discussão para uma lógica social, entendendo o fenômeno como um problema de ordem pública que exige a interferência do Estado para a garantia da segurança e qualidade nos cuidados em saúde (Lacerda et al., 1996; Lacerda e Egry, 1997; Exworthy, M., 2008; Cardo et al., 2010).

É necessário implantar e desenvolver políticas públicas de saúde para que a prevenção e controle das IRAS se estabeleçam de forma ampla (Mckibben et al., 2005; Stone et al., 2005; Cardo et al., 2010). Isto implica ações planejadas e sustentadas pelo Estado para intervir neste problema atual, provocando mudanças efetivas que conduzam melhorias no contexto assistencial (Cardo et al., 2010; Schraiber, 2012). Ou seja, alocar recursos e desenvolver planos que possam intervir em condições que impactam a redução deste evento (Gilson et al., 2008; Walt et al., 2008; Bowman et al., 2012; Birkland, 2014).

Neste contexto, estudiosos apontam que é imprescindível organizar programas governamentais de prevenção e controle de IRAS como estratégia para a qualidade do cuidado em saúde. O estabelecimento e manutenção destes programas específicos para a prevenção e controle de IRAS são manifestações das políticas públicas. Os programas nacionais, assim como os institucionais, devem estar embasados em evidências cientificas, treinamento, vigilância e monitoramento dos resultados. Esta estratégia, além de reduzir custos assistenciais, amplia a cultura de segurança do paciente (Stone et al., 2005; Cardo et al., 2010; Nogueira Junior, C. et al., 2014; Storr et al., 2017).

Órgãos internacionais têm alertado os governantes sobre a importância destes programas, estimulando o seu desenvolvimento. Como exemplo, a União Europeia por meio do European Centre for Disease Prevention and Control (ECDC) tem buscado fomentar a vigilância de IRAS em seus países membros; e a Organização Mundial da Saúde (OMS), por meio da Aliança Mundial para a Segurança do Paciente 
vem despertando o comprometimento das nações no desenvolvimento de políticas públicas para segurança do paciente (Bristol, 2005; World Health Organization, 2008; Allegranzi et al., 2017; Storr et al., 2017).

Como resultado deste processo, algumas ações governamentais de controle e prevenção de IRAS têm avançado. Entretanto, muitos países ainda precisam progredir, pois apresentam ações insuficientes, ou mesmo, permanecem inertes na constituição destes programas nacionais (Allegranzi et al., 2011; Nogueira Junior, C. et al., 2014; Allegranzi et al., 2017).

O desenvolvimento e a implantação de políticas públicas não é um simples processo que se estabelece de forma linear. É influenciado pelos mais variados interesses e relações de poder, que pré existem a sua formação e que muitas vezes tornam este processo desarticulado e impreciso (Exworthy, M., 2008; Buse et al., 2012). Portanto, o desencadeamento e consequente sustentação destes programas dependem da confluência positiva de fatores, que englobam desde a evidência e preocupação com o problema por macro gestores até o estabelecimento de uma rede de serviços estruturada em todos os subsistemas de saúde (Secchi, 2010; Buse et al., 2012)

Esta base estruturada está representada pelas recomendações da OMS no âmbito do controle e prevenção de infecção (Storr et al., 2017). Contudo, estas recomendações contêm apenas componentes técnicos operacionais. Ainda não estão claros fatores políticos e estratégicos que conduzem o sucesso desta política pública. Ainda são desconhecidos os fatores que influenciam positivamente e negativamente o processo de criação, desenvolvimento e manutenção destes programas nacionais na esfera governamental em diferentes cenários.

Neste sentido, esquemas de interpretação e estudos de casos podem colaborar com esta prática. A análise detalhada das interfaces destes programas e a identificação de elementos que foram fundamentais ao seu desenvolvimento podem nortear a concepção de modelos estratégicos para responder indagações classicamente propostas sobre como e porque determinadas decisões governamentais são tomadas (Souza, 2006; Secchi, 2010; Buse et al., 2012). 


\section{OBJETIVOS}

\subsection{OBJETIVO GERAL}

Construir um modelo explicativo para a formação de programas nacionais de prevenção e controle de IRAS.

\subsection{OBJETIVOS ESPECÍFICOS}

1. Descrever a trajetória histórica de formação dos programas governamentais de prevenção e controle de IRAS em países com reconhecida tradição e/ou em processo de ascensão nesta área.

2. Caracterizar e comparar os modelos de implantação dos programas governamentais de prevenção e controle de IRAS em países definidos, considerando seu conteúdo, contexto e processo.

3. Construir uma matriz explicativa dos modelos analisados para a formação, desenvolvimento e manutenção dos programas governamentais de prevenção e controle de IRAS. 


\section{ASPECTOS TEÓRICOS}

\subsection{POLÍTICAS PÚBLICAS: CONCEITOS E DEFINIÇÕES}

A sociedade moderna é composta por um corpo social que apresenta distintos papéis determinados pelas diversas características e interesses de seus membros. Esta diferenciação social faz com que as inter-relações entre os indivíduos se tornem complexas, apresentando divergências de pensamento, ideias e opiniões. Neste cenário, para a sobrevivência e progresso da humanidade, torna-se imprescindível a resolução dos conflitos de forma pacífica e ordenada pelos diferentes grupos sociais, o que chamamos de política (Schmitter, 1982; Rua, 1998; Rodrigues, 2010).

A política é uma ação inerente à práxis humana, "engloba um conjunto de atividades que, de alguma maneira, faz referência ao Estado" (Rodrigues, 2010). Corresponde a um conjunto de ações que motiva diversos procedimentos formais e informais que vão determinar relações de poder. Este conceito faz referência principalmente aos conflitos concernentes aos bens públicos, no qual estas ações determinam decisões e alocações de recursos públicos, o que denominamos Políticas Públicas (Rua, 1998; Rodrigues, 2010).

As políticas públicas estão compreendidas em uma área do conhecimento e envolvem ações executadas pelo Estado que vão determinar implicações em um meio social. Constituem parte das estratégias do governo na tomada de decisão para a resolução de grandes questões públicas (Souza, 2006; Rodrigues, 2010; Schraiber, 2012).

Como área do conhecimento as políticas públicas derivam do campo da ciência política, ganhando efetivo destaque científico e autonomia a partir da segunda metade do século $X X$. Nas três últimas décadas, este campo do conhecimento obteve um rápido crescimento com o fortalecimento de diversos estudos, principalmente nos EUA (considerado precursor do processo científico) e na Europa (Souza, 2006; Frey, 2009; Rodrigues, 2010).

Nos EUA, o foco das pesquisas esteve voltado para o processo de estruturação das políticas públicas, com ênfase nas atividades do governo, enquanto na Europa, a área se desenvolveu focalizando seus estudos no papel do Estado e das organizações 
que o compõe (Souza, 2006; Rodrigues, 2010). No Brasil, os estudos sobre políticas públicas são mais recentes (década de 1990) e pontuais, destacando políticas setoriais específicas com predomínio na análise de estruturas e instituições (Frey, 2009).

Basicamente, o desenvolvimento desta área considera quatro autores como seus principais fundadores: Laswell (EUA - década de 1930) - que utilizou o termo "policy analysis" (análise da política pública) integrando esta ciência com a prática do governo; Simon (EUA - década de 1950) - que discutiu e analisou a atuação racional dos "policy makers" (decisores políticos) como algo limitado por informações, tempo, interesse entre outros; Lindblom (EUA - década de 1950) - que incorporou novas variáveis na análise e formulação de políticas públicas, considerado a imprevisibilidade política nos diferentes contextos; e Easton (EUA - década de 1960) - que considerou a política pública como um sistema (Fischer e Miller, 2006; Frey, 2009).

Contudo, por ser uma área recente do conhecimento cientifico, dependendo do referencial teórico adotado divergências conceituais sobre alguns posicionamentos básicos podem estar presentes. Como por exemplo: a implantação destas ações é exclusiva do setor publico, sem a participação da esfera privada?; a omissão do governo frente a um problema pode ser considerada uma política pública?; política pública é uma macrodiretriz estratégica, na qual os planos, programas e projetos são apenas elementos do processo? (Secchi, 2010).

Independente desta dissensão, de um modo geral, as ações deliberadas pelas políticas públicas pretendem atuar no encontro de um problema público atual e transformar esta realidade social em um objetivo comum entre os diferentes grupos e atores sociais envolvidos. Todavia, este é um conceito subjetivo, pois um problema só se torna público quando apresenta uma situação coletiva relevante, representando impactos para uma quantidade ou qualidade evidente de pessoas (Secchi, 2010).

A aplicação das políticas públicas é transversal, ou seja, estas ações podem ser operacionalizadas em diversas áreas ou setores de interesse do Estado, como: saúde, educação, segurança, gestão, meio ambiente, habitação, entre outros. E a instrumentalização deste processo pode ocorrer por meio de diversas ferramentas, 
como: programas, projetos, leis, campanhas, entre outros (Walt et al., 2008; Secchi, 2010; Buse et al., 2012).

Para fins deste estudo, será tomado como conceito de política pública "aquilo que o governo escolhe fazer ou não fazer" (Dye, 2013). Estas ações fazem referência sobre a capacidade do governo na tomada de decisão e na implementação de ações frente a determinadas circunstâncias para alcançar um objetivo.

Este conceito incorpora as ações estratégicas propostas, assim também como a inércia do governo posta em determinadas situações. De modo geral, entende-se que as políticas públicas buscam responder indagações classicamente propostas, como: quem ganha com estas ações?; por quê são ou foram determinadas?; em que contexto se estabeleceram?; e, quem está envolvido e faz a diferença neste processo? (Fischer e Miller, 2006; Walt et al., 2008; Frey, 2009; Secchi, 2010; Buse et al., 2012; Dye, 2013).

\subsubsection{A formulação e análise de Políticas Públicas}

O entendimento acerca da constituição das políticas públicas como ação ou inação pública envolve uma série de decisões que determinarão as consequências de todo este processo (Rodrigues, 2010). Esta articulação política não é uma simples conduta, implica na habilidade de influenciar outros para o alcance dos objetivos desejados, projetando atividades que determinem a transformação de um contexto social (Rodrigues, 2010; Buse et al., 2012).

O processo político (policy process) é representado por relações de poder que instituem ações em um contexto que pré existe a sua concepção, sendo articuladas durante o desenvolvimento da sociedade. Por este motivo, frequentemente não existe um começo ou um fim para a articulação política, mas somente um meio. As intenções e ações, assim como a formulação e implantação destas, são procedimentos de difícil distinção, o que torna o entendimento do processo político, muitas vezes, desconectado e confuso (Exworthy, M., 2008).

Alguns autores, dentro deste campo, criaram modelos que buscam direcionar a elaboração das políticas públicas e a análise deste processo político. Estes modelos variam em sua forma, contudo, todos tem o propósito de buscar um amplo 
entendimento da situação, respondendo questões clássicas sobre o posicionamento do governo durante sua administração (Souza, 2006; Secchi, 2010).

A análise de uma política pública envolve níveis que incluem o funcionamento e a estrutura administrativa do governo, a tomada de decisão, a implementação de ações e as relações entre o Estado e a sociedade. O objetivo de um processo analítico é compreender a realidade de uma política pública e o processo de mudança, produzindo importantes referências para orientar sua estruturação e progresso (Secchi, 2010; Dye, 2013; Araújo e Rodrigues, 2017).

Um analista de política pública, dependendo de sua perspectiva ideológica, pode realizar a análise de uma política a partir de diferentes perspectivas, que incluem: o estudo do seu conteúdo, a análise do processo de elaboração, dos resultados, da avaliação da política pública, entre outros (Secchi, 2010; Dye, 2013; Araújo e Rodrigues, 2017).

Neste âmbito, os modelos tradicionais de análise possuem diferentes focos (Souza, 2006; Secchi, 2010), como:

- tipos de políticas públicas - uma tipologia elaborada por Lowi que pressupõe processos políticos variados de acordo com o tipo de política pública implementada;

- o incrementalismo - no qual Lindblom assinala que as decisões dos governos são incrementais e pouco substanciais;

- o ciclo de políticas públicas - um ciclo de decisões formado por fases que constitui um processo dinâmico e de conhecimento;

- o modelo "garbage can" ou lata de lixo - que cita a incerteza do processo político, sem um ponto de início ou fim, no qual temos variados problemas com poucas soluções;

- a coalizão de defesa - que menciona a política pública como subsistemas relativamente estáveis articulados com eventos sociais, que colidem com valores, crenças e ideais;

- as arenas sociais - que colocam as políticas públicas como problemas evidenciados pela conjuntura social demandando intervenções;

- o modelo do "equilíbrio interrompido" - que acreditam que a política pública surge quando a estabilidade cede espaço a instabilidade; 
- modelos influenciados pelo "novo gerencialismo público" e "ajuste fiscal" - no qual a busca de eficiência com a definição de regras claras é a premissa da formulação de políticas públicas;

- entre outros.

$\mathrm{Na}$ análise específica de políticas de saúde, existem ideias variadas. Seu foco central pode estar direcionado para a alocação de recursos, para a definição das estratégias e planejamento de ações, para as relações profissionais, entre outros. Todavia, independente do objetivo e aplicação, o conhecimento do contexto e relações políticas que determinaram sua formação, desenvolvimento e conteúdo são essenciais para uma ampla compreensão do cenário (Buse et al., 2012).

A análise de políticas de saúde vem avançando, causando interesse no conhecimento das estratégias desenvolvidas e nos fatores de sucesso destas ações (Buse et al., 2012; Blank e Burau, 2013). No Brasil, a Saúde Coletiva, como campo científico estruturado e estruturante de práticas e conhecimentos a respeito do "objetivo" saúde e suas interfaces, engloba esta análise de políticas de saúde como um dos seus espaços de formação disciplinar (Nunes e Universidade Estadual De Campinas, 2006; Vaitsman et al., 2013). Além deste, expõe uma compreensão mais abrangente da saúde pública, incluindo outras grandes áreas de conhecimento como as ciências sociais e humanas, a epidemiologia e a avaliação de tecnologias em saúde.

No contexto de análise das "políticas, planejamento e gestão em saúde", o campo da saúde coletiva busca produzir conhecimento tendo como base de investigação o posicionamento político de uma sociedade e o reflexo deste nos saberes e práticas (Paim e Teixeira, 2006). Este arcabouço teórico incorpora debates que dão apoio à compreensão do homem com seu meio e assim, proporciona abertura à interdisciplinaridade e consequente transformação do sistema de saúde de um país (Nunes e Universidade Estadual De Campinas, 2006; Vaitsman et al., 2013; Velloso et al., 2016).

Para esta pesquisa, a subárea de política e planejamento em saúde foi adotada como referencial e eixo na Saúde Coletiva. Este campo tem incorporado rico quadro conceitual e ampliado às discussões para além de orçamento, organização e legislação sanitária de um sistema de saúde. Engloba estudos sobre as condições de 
saúde da população e o papel do Estado e suas relações com a sociedade na definição de ações e prioridades (Nunes e Universidade Estadual De Campinas, 2006; Paim e Teixeira, 2006).

Para isto, modelos específicos já consagrados na literatura podem ser aplicados nesta exploração, como o modelo de triângulo de políticas de saúde. Este modelo é aplicável em diferentes contextos (países de renda alta, média e baixa) e busca analisar sistematicamente o conteúdo da política de saúde, o seu processo de formação e como o poder foi utilizado. É uma metodologia simples para um conjunto complexo de fatores e inter-relações que não podem ser analisadas separadamente (Buse et al., 2012).

É fato que, independente do modelo adotado para análise, o processo político por abranger vários atores e diferentes níveis de decisões na distinção "do que se pretende fazer" e "do que de fato se faz", se coloca com um processo extremante complexo e de difícil análise. As políticas públicas abarcam amplas atividades direcionadas ao alcance de resultados desejados e, que, por isso, envolvem múltiplos subprocessos de formulação, implementação e avaliação que necessitam ser desvendados e interpretados em qualquer investigação (Souza, 2006). 


\subsection{AS POLÍTICAS PÚBLICAS DE SAÚDE}

A área da saúde é uma área complexa e problemática para a definição de políticas públicas, especialmente nas definições regulatórias e redistributivas. Compõe parte importante da economia por absorver grandes investimentos para atender demandas sociais através do cuidado em saúde. Estas atividades habitualmente se inserem em um contexto com problemas e conflitos singulares e que, com a incorporação de tecnologia, crescimento/envelhecimento populacional e outros fatores, tem se tornado uma das discussões mais significativas da agenda política de um país (Buse et al., 2012; Blank e Burau, 2013).

Segundo a Organização Mundial da Saúde (OMS), as políticas de saúde são ações formadas por instituições oficiais em torno das principais questões, necessidades e recursos que afetam o campo da saúde de um país. Seu planejamento exige uma definição criteriosa de prioridades e parâmetros de ação que vão impactar diretamente na capacidade produtiva do Estado, do mercado e da sociedade em geral (World Health Organization, 1998). Como qualquer outra política pública, sua estruturação não é simples e nenhum país no mundo está livre das controvérsias e dificuldades que a acompanham (Blank e Burau, 2013).

O conceito de saúde hoje adotado pela OMS busca abandonar um pensamento hegemônico, ainda presente no campo da medicina, que se baseia exclusivamente na dimensão técnico-científica desta área. Este novo pensamento considera as práticas em saúde antes de tudo como prática social e não apenas técnica, influenciadas por diferentes determinantes. Consequentemente, a formação das políticas nesta área não se limita aos aspectos biológicos dos indivíduos, mas exige o reconhecimento da influência de uma conjuntura política, social, econômica, cultural, entre outras (Paim e Teixeira, 2006; Exworthy, Mark, 2008; Fleury e Ouverney, 2008; World Health Organization, 2011a; Buse et al., 2012; Schraiber, 2012).

Por sua magnitude de definição e intervenção, a formulação destas políticas exige um diagnóstico crítico e extenso. Muitos analistas políticos se atêm ao conceito e propósito das ações, procurando apenas explicitar estratégias e resultados. Contudo, este conteúdo não deve ser isolado. É preciso reconhecer o contexto cultural, econômico, e estrutural deste planejamento; entender o processo de 
elaboração e as fases que o constituem; e quem são os atores envolvidos, identificando-os e compreendendo suas relações na elaboração destas propostas (Buse et al., 2012).

$\mathrm{Na}$ verdade, em todos os setores do Estado existem dimensões do campo da saúde. Logo, as áreas, interesses e atores envolvidos na elaboração destas políticas se tornam múltiplos, coexistindo uma estrutura heterogênea de relações de poder e negociação, que vão determinar o foco das intervenções e das implicações deste processo (Buse et al., 2012; Blank e Burau, 2013).

À vista disso, as ações políticas do Estado na saúde interferem nas condições básicas de existência da sociedade. Constituindo diferentes formatos e modalidades, estas ações buscam, de certo modo, intermediar uma rede de relações entre o Estado, a sociedade e o mercado, buscando integração e sociabilidade entre eles (Paim e Teixeira, 2006; Fleury e Ouverney, 2008; Viana et al., 2013).

Dependendo da sua composição, dos envolvidos e do contexto no qual se insere, as implicações políticas e os reflexos deste processo serão variados. E poderão conduzir formas diversas de compreensão das ações de saúde: como medida de caridade, benefício adquirido ou usufruto de um direito de cidadania (Fleury e Ouverney, 2008).

Em síntese, as políticas públicas de saúde explicitam as intenções do Estado sobre a qualidade de vida da população, tornando manifesta suas estratégias, prioridades e valores de acordo com as necessidades e desejos de um meio social (Paim e Teixeira, 2006). Este cenário, portanto, apresenta-se como um rico espaço para conhecimento e análise das relações de poder e sua consequente interferência na estruturação, reprodução e propósito destas ações (Fleury e Ouverney, 2008).

Deste modo, a inserção de modelos de análise destas políticas torna-se uma atividade essencial para a área da saúde pública. $O$ desenvolvimento de pesquisas relevantes e a compreensão ampliada do desenvolvimento e impacto destas ações fortalecem a estratégia, encorajam parcerias e elevam sua eficiência e eficácia, contribuindo com a alocação de recursos e a tomada de decisão baseada em evidências (Institute of Medicine, 2002). 
Para este estudo, a relação entre Estado e sociedade será explorada por meio de uma unidade de análise que são programas nacionais de prevenção e controle das IRAS, manifestação concreta de políticas públicas de saúde específicas e positivas frente a esta preocupação social. Na literatura científica não está evidente se as ações públicas de combate às IRAS são efetivas em países que não há estes programas estruturados. Por este motivo, o conjunto destas ações, denominado programa, será apontada como condição de sucesso nas intervenções do Estado para a transformação de um problema público: o efetivo combate destas infecções. 


\subsection{A PREVENÇÃO E O CONTROLE DE IRAS COMO UMA POLÍTICA PÚBLICA DE SAÚDE}

As IRAS representam um dos eventos adversos mais comuns decorrentes dos cuidados em saúde. Um fenômeno histórico e social resultante da evolução tecnológica e assistencial em saúde. Acomete milhares de pessoas em todo mundo, sendo causa significante de morbimortalidade principalmente na área hospitalar, com amplo impacto na qualidade de vida das pessoas (Lacerda e Egry, 1997; Stone et al., 2005; Padoveze e Fortaleza, 2014; Allegranzi et al., 2017).

A ocorrência deste evento pode ser percebida durante a internação hospitalar, após a alta, ou mesmo no atendimento ambulatorial, domiciliar e laboratorial, suscitando inúmeros impactos, que incluem: aumento do tempo de permanência hospitalar e prolongamento do tratamento; situações geradoras de incapacidade como disfunções físicas e estresse emocional; aumento da resistência dos microrganismos a antimicrobianos; elevação nos custos com os cuidados em saúde e mortes (Allegranzi et al., 2011; Weber et al., 2016).

Estima-se que um em cada dez pacientes desenvolvam infecções associadas aos cuidados em saúde. Entre pacientes críticos esta estimativa sobe para cerca de $30 \%$. Dados de revisões sistemáticas apontam para mais de 4,1 milhões de pacientes acometidos por IRAS todos os anos na Europa e 1,7 milhões nos EUA. Entretanto, a carga global destas infecções ainda é desconhecida pela dificuldade na obtenção de dados confiáveis. Nos países em desenvolvimento este cenário ainda é obscuro e fragmentado, mais de $60 \%$ não possuem informações e muitos estudos, conduzidos com recursos limitados, apontam taxas variadas de prevalência $(5,7 \%-19,1 \%)$ (Allegranzi et al., 2011). No Brasil, a prevalência global de IRAS estimada por um grupo de pesquisadores foi de 10,8\% (Fortaleza et al., 2017).

Os impactos individuais repercutem na sociedade com a redução da força de trabalho e de produção, sobrecarregando as organizações e o Estado e consequentemente interferindo diretamente no financiamento e sustentabilidade do sistema. Na Europa são estimadas perdas financeiras com IRAS em torno de 7 bilhões de euros/ano e nos EUA em torno de 4,5 a 6,5 bilhões de dólares/ano (Stone et al., 2005; Allegranzi et al., 2011; Nogueira Junior, C. et al., 2014; Padoveze e Fortaleza, 
2014). Trata-se, portanto, de um sério problema para a saúde pública mundial, que torna sua prevenção e controle uma condição fundamental para a segurança e qualidade na assistência em saúde.

Há algumas décadas, para a redução sistemática dos danos decorrentes deste fenômeno, os serviços de saúde têm organizado programas de controle e prevenção de IRAS (PCPIRAS), estabelecendo a vigilância epidemiológica como um dos eixos centrais das suas ações de prevenção e controle. Estudos corroboram que a formação destes programas nos serviços de saúde reduz em mais de $30 \%$ a ocorrência destas infecções (Haley et al., 1980; Haley et al., 1985; Garner et al., 1988; Allegranzi et al., 2011).

A transmissão de IRAS é multifatorial e por este motivo sua prevenção e controle devem levar em consideração tanto os aspectos do paciente, quanto aspectos do cuidado em saúde, da gestão dos serviços e do uso de técnicas assépticas pelos profissionais de saúde (Lacerda e Egry, 1997; Collins, 2008)

Neste contexto, os programas institucionais devem compor equipes interdisciplinares para a definição das ações, incluindo a participação de diferentes profissionais e áreas do hospital (gestão, farmácia, laboratório, enfermagem, médicos, entre outros). Minimamente, o escopo das ações do programa deve abranger: o combate à resistência microbiana; o uso de técnicas limpas e assépticas nas intervenções e práticas de higiene e limpeza ambiental; estratégias para aprimorar e incentivar a higiene de mãos; a provisão de profissionais em número suficiente para o cuidado e estimular a uso adequado de equipamentos de proteção individual; fortalecimento de lideranças; a utilização de práticas baseadas em evidência, e a estruturação de sistemas de vigilância epidemiológica (Collins, 2008; Allegranzi et al., 2017; Storr et al., 2017).

A estruturação do sistema de vigilância epidemiológica (VE) das IRAS é a base das ações de prevenção e controle das IRAS. Um sistema de VE desenvolvido adequadamente revela a carga destas infecções nos serviços de saúde, norteando o planejamento das demais ações com identificação de áreas e condições prioritárias (Haley et al., 1980; Cardo et al., 2010; Nogueira Junior, C. et al., 2014).

Todavia, os serviços de saúde estão imersos em uma conjuntura social, econômica, política e ambiental que exerce forte influência no processo assistencial e 
consequentemente no sistema de saúde, ou seja, não atuam de forma isolada. De tal modo, as intervenções sistemáticas de combate as IRAS não devem ser restritas ao âmbito institucional, nas ações situadas no plano dos cuidados em saúde (micropolítica). É necessário expandir esta discussão, na trama da macropolítica, projetando modelos para as complexas situações do cuidado em saúde. Os países devem organizar programas no nível governamental, definindo atividades, recursos, normas e procedimentos para o amplo conhecimento do fenômeno, norteando a tomada de decisão e a transformação da prática assistencial (Stone et al., 2005; Allegranzi et al., 2011; Nogueira Junior, Cassimiro et al., 2014; Padoveze e Fortaleza, 2014).

Neste rumo, alguns países espelhando-se na experiência dos serviços de saúde, incorporaram programas nacionais de prevenção e controle de IRAS (Nogueira Junior, C. et al., 2014; Nogueira Junior, Cassimiro et al., 2014). Contudo, esta é uma realidade ainda distante para muitas nações, principalmente países em desenvolvimento (de baixa e média renda) que, muitas vezes, sequer contam com estrutura mínima em seus serviços para garantir higiene básica durante a assistência (Allegranzi et al., 2011).

Alguns órgãos internacionais têm estimulado a conscientização dos governantes sobre a importância destas ações. Como principal exemplo, a Organização Mundial da Saúde (OMS) estabeleceu em 2004 a Aliança Mundial para a Segurança do Paciente criando diretrizes e estratégias para incentivar o desenvolvimento de políticas públicas e ações para segurança do paciente. $\mathrm{O}$ compromisso global dispôs a busca por práticas baseadas em evidências como uma das principais medidas para a segurança e qualidade nos cuidados em saúde, tendo o combate às IRAS como um objeto central da estratégia (World Health Organization, 2008).

Também, outras agências e sociedades internacionais como a Association for Professionals in Infection Control and Epidemiology (APIC) ${ }^{a}$, a Society for Healthcare Epidemiology of America (SHEA) ${ }^{\mathrm{b}}$, o Centers for Disease Control and Prevention

\footnotetext{
${ }^{a}$ https://apic.org/

${ }^{\mathrm{b}}$ https://www.shea-online.org/
} 
$(C D C)^{c}$ e o European Centre for Disease Control $(E C D C)^{d}$ tem enfatizado a importância do combate às IRAS, convocando os estados e países para o desenvolvimento de ações constantes e vigilância para a redução máxima da incidência destas infecções (Cardo et al., 2010).

A formação de sistemas de vigilância de IRAS, e consequentemente a formação de programas neste contexto não é algo simples (Nogueira Junior, C. et al., 2014). Poucas experiências bem-sucedidas se consolidaram, demonstrando a complexidade deste cenário. É necessário oportunizar discussões aprofundadas sobre o assunto ampliando espaços de investigação de estratégias e estruturação de metodologias para o desenvolvimento destes programas governamentais em diferentes realidades.

A OMS, em 2009 (Seto et al, 2010; World Health Organization, 2011b), por meio de um grupo internacional de experts, estabeleceu um guia técnico com os componentes mínimos para a formação de programas de prevenção e controle de IRAS, tanto no nível institucional (hospitais de cuidados agudos) quanto governamental. Este guia consiste na base operacional para estruturar um programa. O guia foi recentemente atualizado, com revisão do conjunto de mecanismos para prevenir ameaças reais e futuras para a saúde publica mundial. Seu objetivo central é contribuir para o desenvolvimento de protocolos nacionais e planos de ação para a prevenção e controle de infecção e resistência microbiana em diferentes realidades (Storr et al., 2017).

O guia apresenta a base técnica de um programa nacional de controle e prevenção de IRAS, provendo recomendações baseadas em evidências e consenso. A partir do documento de 2009, um extenso trabalho que incluiu uma revisão sistemática identificou oito componentes essenciais, sendo que deste seis são aplicáveis aos programas nacionais: organização do programa, orientações e normas técnicas, educação e treinamento, vigilância das infecções, estratégias multimodais para implantar ações, monitoramento e auditoria de práticas e retroalimentação (Storr et al., 2017).

\footnotetext{
${ }^{\mathrm{c}}$ https://www.cdc.gov/

${ }^{\mathrm{d}}$ https://ecdc.europa.eu/en
} 
Estas recomendações já estão consolidadas e são relevantes para orientar e avaliar o conteúdo básico de um programa. Entretanto, a dimensão política da implantação de um programa com inclusão desta temática na agenda governamental ainda precisa ser explorada.

Neste sentido, além da base operacional, outros aspectos ainda merecem ser avaliados do ponto de vista de políticas públicas: o nível de priorização dado pelos países e o comprometimento das autoridades com a prevenção de IRAS; a inserção destes programas no contexto do sistema de saúde; a mobilização de recursos e a manutenção das estratégias e ações na agenda governamental; as questões econômicas, sociais e culturais, entre outras.

Estes aspectos referem-se às questões administrativas e políticas. Devem ser extraídos da experiência dos que, de alguma forma, obtiveram êxito na operacionalização de um programa nacional. O estudo destes casos e a concepção de esquemas para interpretá-los podem permitir viabilizar a apreensão do entendimento da experiência, do conhecimento já alcançado generalizando os achados para outras realidades (Souza, 2006; Secchi, 2010; Buse et al., 2012; Denzin e Lincoln, 2017).

Este espaço de investigação pode trazer o reconhecimento de importantes elementos na formação, desenvolvimento e manutenção dos programas nacionais de IRAS e ampliar a capacidade de análise e avaliação destes, abrindo espaço para o debate da sistematização e articulação política, ainda fragilmente investigados. Tal ação pode ampliar o conhecimento e favorecer a estruturação de programas governamentais em cenários nos quais eles ainda estão inexistentes, norteando práticas de um cuidado de qualidade, com visíveis impactos para a saúde coletiva.

Assim, foi proposto este estudo para analisar e comparar a formação, implantação e desenvolvimento de programas governamentais de prevenção e controle de IRAS em países selecionados, destacando os principais elementos que conduziram seu progresso. Esta investigação buscou caracterizar o processo de formação das políticas publicas de IRAS identificando aspectos comuns, tendências e desafios. E, deste modo, esquematizar um modelo explicativo que norteie a formação destes programas em outras realidades. 
4 MÉTODOS 


\section{MÉTODOS}

\subsection{TIPO DE ESTUDO}

Os programas nacionais de prevenção e controle de IRAS constituem um objeto dinâmico e complexo que engloba um grande espectro de atividades interrelacionadas. Por estas características, exigem uma compreensão ampliada do seu desenvolvimento. A presente pesquisa consiste em um estudo de caso, tipo descritivo e exploratório, com abordagem qualitativa, que utilizou o modelo do triângulo de análise de política de saúde (Walt e Gilson, 1994) para a investigação dos programas nacionais de prevenção e controle de IRAS.

A unidade de análise de caso definida foi o programa governamental de prevenção e controle de IRAS de países selecionados. O modelo de estudo de caso por ser eminentemente qualitativo é um método aplicável para a descrição complexa e ampliada das experiências e fenômenos relacionados à implantação destes programas governamentais. O modelo procura captar "como" e "por quê" algumas estratégias se estabeleceram, permitindo compreender as experiências, o conhecimento produzido e a possibilidade de generalização para outras realidades (Denzin e Lincoln, 2017).

Estudiosos mencionam que a apreciação e a comparação de casos individuais podem ser empregues para a construção de princípios e elementos universais. A comparação de casos permite a identificação de atividades regulares e comuns entre diferentes contextos, assim como, suas discordâncias, circunscrevendo fatos sociais em um conjunto de relações de causa e efeito (Schneider e Schmitt, 1998; Gonzalez, 2008)

A abordagem qualitativa trabalha com o ambiente natural dos acontecimentos como fonte de seus dados, compondo um universo de significados, motivos, aspirações, crenças, valores e atitudes, que não podem ser reduzidos à operacionalização de variáveis. Nesta abordagem, o pesquisador busca elementos significativos ao seu estudo, procurando compreender os valores culturais e as representações de determinado grupo social; as relações estabelecidas pelos atores sociais; e a avaliação das políticas públicas e sociais tanto do ponto de vista de sua 
formulação, aplicação técnica, como dos usuários a quem se destina (Lüdke e André, 1986; Minayo et al., 2013).

\subsection{FASES DO ESTUDO}

A pesquisa foi desenvolvida por meio de três fases:

$\checkmark$ Fase I - Pesquisa Bibliográfica e Documental sobre os Programas Governamentais;

$\checkmark$ Fase II - Visita à sede dos Programas Governamentais de Prevenção e Controle de IRAS;

$\checkmark$ Fase III - Construção de um Modelo Explicativo dos Programas Governamentais de Prevenção e Controle de IRAS.

Cada fase utilizou técnicas complementares de coleta de dados para possibilitar o acesso às informações relevantes para a pesquisa. Cabe ressaltar, que as fases não ocorreram de modo isolado e sequencial, em alguns momentos do estudo houve confluências das mesmas para a construção e desconstrução de conceitos estruturados, segundo o modelo do Triângulo de análise de Políticas Públicas de Saúde (Walt e Gilson, 1994).

\subsection{CENÁRIO - SELEÇÃO DAS UNIDADES DE ANÁLISE}

O estudo foi desenvolvido entre 2014 e 2017, em países com tradição na prevenção e controle de IRAS no âmbito governamental e/ou em processo de ascensão nesta área, respeitando critérios de inclusão e exclusão.

O cenário de estudo foi pré-definido a partir de:

$\checkmark$ um estudo preliminar que analisou sistemas de vigilância epidemiológica de IRAS em âmbito nacional por meio de revisão de literatura e consultas a páginas eletrônicas de diferentes países, tendo em perspectiva de que estes sistemas são reflexos da maturidade dos programas governamentais de prevenção e controle de IRAS. Foram acessadas páginas com informações em língua inglesa, espanhola e portuguesa. Nesta etapa, foram pré-selecionados 11 países: Alemanha, Argentina, 
Austrália, Brasil, Chile, Colômbia, Estados Unidos, Holanda, Inglaterra, Israel e Uruguai.

$\checkmark$ e um "Ciclo de Debates em Políticas Públicas para a Prevenção e Controle de IRAS e Segurança do Paciente" realizado pela Universidade de São Paulo (USP) no ano de 2014 (Levin e Padoveze, 2015) que visou identificar informações relevantes para a identificação de critérios de inclusão no estudo.

A partir da pré-seleção, foram então definidos os critérios de inclusão no estudo, a saber: história na prevenção e controle de IRAS no nível governamental; existência de um programa nacional para prevenção e controle destas infecções; aprovação do gestor nacional do programa para uma visita a sua sede; possibilidade de comunicação em português, inglês ou espanhol. Após a aplicação dos critérios de inclusão foram selecionados seis países: Austrália, Brasil, Chile, Estados Unidos, Inglaterra e Israel.

Considerando a disponibilidade logística e financeira do pesquisador para realizar as visitas na sede dos programas, ainda foram excluídos três países do grupo dos selecionados, sendo incluídos e visitados três países: Brasil, Chile e Israel (Figura 1).

Figura 1 - Representação esquemática das etapas de seleção dos países para a inclusão no estudo. São Paulo. 2018.

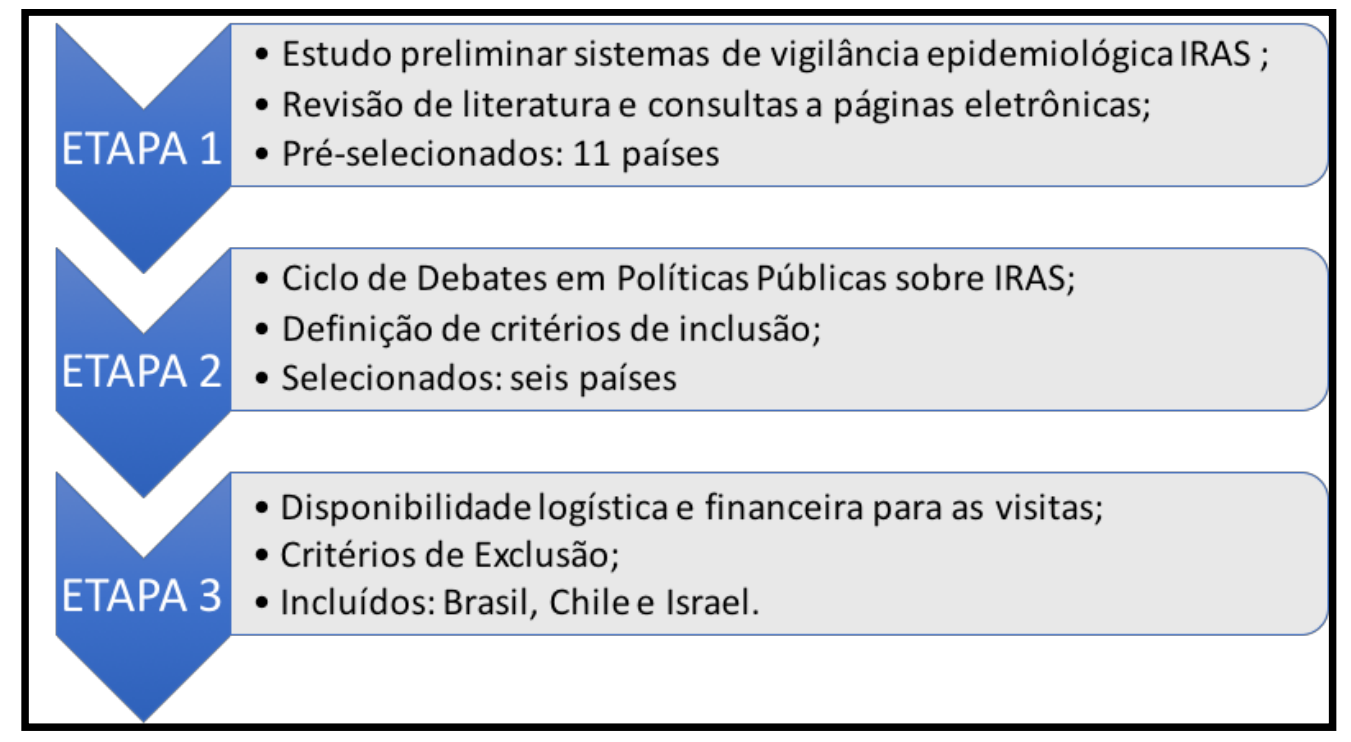




\subsection{COLETA DE DADOS}

\subsubsection{Fase I - Pesquisa Bibliográfica e Documental sobre os Programas Governamentais}

A fase inicial do estudo explorou informações relevantes sobre a origem e 0 desenvolvimento do programa nacional de prevenção e controle de IRAS. Esta fase ocorreu entre 2014 e 2017, e objetivou a aproximação do pesquisador com informações relevantes sobre o contexto de cada país (política, economia, sistema de saúde) e sobre a formação e evolução do programa nacional de prevenção e controle de IRAS, revelando e complementando informações sobre os eventos centrais, principais marcos históricos e estratégias implantadas.

Para esta etapa da pesquisa foram utilizadas as seguintes técnicas de coleta de dados:

$\checkmark$ pesquisa bibliográfica - consulta às publicações que abordaram a temática investigada (livros, artigos, teses, pesquisas, entre outros);

$\checkmark$ pesquisa documental - consulta às páginas eletrônicas governamentais dos países e de outros órgãos governamentais em busca de acesso a documentos públicos de interesse da pesquisa (leis, resoluções, relatórios, pareceres, entre outros).

\subsubsection{Fase II - Visita a sede dos Programas Governamentais de Prevenção e Controle de IRAS}

Esta fase ocorreu entre os anos de 2015 e 2016 e abrangeu o aprofundamento da investigação sobre a implantação dos programas governamentais de IRAS nos países selecionados. O objetivo desta etapa foi elucidar detalhes da criação e consolidação dos programas e ampliar o acesso às informações sobre a origem e evolução desta estratégia.

Nesta etapa, o pesquisador realizou uma visita à sede de cada programa nacional. A imersão na realidade proposta foi conduzida para propiciar a interpretação 
e compreensão das dinâmicas que envolvem esta política. Para isto, foi solicitada autorização formal aos gestores do programa nacional dos países previamente selecionados por meio de carta convite (Apêndice A). A proposta de programa de visita foi baseada nos objetivos do presente estudo, e foi validada previamente pelas equipes de cada país (Apêndices B, C e D). O programa incluiu a participação em reuniões, debates, eventos, visitas aos serviços de saúde do país e outras atividadeschave do programa nacional de prevenção e controle de IRAS, segundo seus coordenadores.

As visitas foram realizadas nos meses de março de 2016 (Chile), setembro de 2016 (Israel) e março de 2017 (Brasil). As atividades governamentais do programa foram acompanhadas e observadas pelo pesquisador por cinco dias no Chile e Israel e por dois dias no Brasil. As atividades do programa nacional brasileiro foram acompanhadas somente por dois dias por se tratar do país de residência do pesquisador, que já conhecia o programa nacional de controle e prevenção de IRAS e estava inserido em pesquisas relacionadas ao mesmo.

Nesta fase da pesquisa, para nortear a coleta de dados durante as visitas, foi elaborado um instrumento (Apêndice $E$ ) constituído de três conjuntos de questões (contexto, processo e conteúdo) baseado no triângulo de análise de política de saúde (Walt e Gilson, 1994). O Ciclo de Políticas Públicas (Secchi, 2010) foi utilizado nesta etapa exclusivamente para apoiar a elaboração do conjunto de questões sobre o processo de construção dos programas governamentais de IRAS, com o objetivo de obter maiores detalhes sobre os acontecimentos.

O ciclo de políticas públicas proposto primariamente por Lasswell, na década de 1950, compõe um modelo para observar e entender a estratégia adotada como política pública (Secchi, 2010). Há críticas ao modelo, pois a real dinâmica ou vida de uma política pública não é linear. Contudo, por ser um esquema didático tornou-se um recurso apropriado para organizar a coleta de dados sobre o processo e atores sociais, favorecendo a obtenção de riqueza nas informações.

As fases estruturadas buscam retratar uma sucessão de componentes do processo político-administrativo, que estão representadas em uma sequência lógica, que na prática normalmente se apresentam desordenadas (Secchi, 2010).

Segue o modelo utilizado (Secchi, 2010): 
- Etapa 1 - Identificação e Formação de Agenda - identificar aspectos históricos do reconhecimento das IRAS como problema de saúde pública; caracterizando sua inserção na agenda política do país.

- Etapa 2 - Escopo - caracterizar o conteúdo do programa governamental: seus objetivos e estratégias prioritárias, processo de elaboração e definição do eixo central do programa e mecanismos utilizados para a implementação de ações.

- Etapa 3 - Tomada de Decisão - compreender a estrutura governamental e o modelo de tomada de decisão do programa.

- Etapa 4 - Implementação e Impactos - caracterizar o processo de implementação do programa, com identificação dos principais marcos históricos e impactos gerados pelo programa.

- Etapa 5 - Avaliação - identificar as potencialidades da política pública em cada realidade: critérios utilizados para avaliar resultados, principais indicadores, e processo de melhoria contínua utilizados.

- Etapa 6 - Análise de Lacunas - identificar fragilidades e principais deficiências do programa e também as perspectivas, desafios e tendências do programa.

A coleta dos dados durante as visitas não ocorreu de forma sequencial ao instrumento proposto. O instrumento apenas serviu de guia para a obtenção dos dados, que foram obtidos à medida que a visita prosseguia e as atividades foram desenvolvidas. Durante a visita, o pesquisador realizou revisão das informações obtidas e no último dia, o mesmo direcionou a coleta de dados para as questões do instrumento ainda não contempladas.

Nesta fase, para a coleta de dados foram utilizadas as seguintes técnicas:

$\checkmark$ Observação - aproximação, registro e contato com as atividades e profissionais envolvidos com os programas nacionais de controle e prevenção de infecção.

$\checkmark$ Pesquisa documental - acesso a documentos oficiais do programa nacional de controle e prevenção de IRAS que não estavam disponíveis em meio eletrônico e que são de interesse da pesquisa (leis, resoluções, relatórios, pareceres, entre outros). 


\subsubsection{Fase III - Construção de um Modelo Teórico Explicativo das Políticas Públicas de Prevenção e Controle de IRAS}

Esta compreende a última fase do estudo. Após a coleta e observação dos resultados, o processo indutivo progrediu com sua classificação e pareamento das informações obtidas. O conjunto de dados obtidos foi confrontado com teorias de análise de políticas públicas.

Com a triangulação e pareamento dos dados, segundo o método proposto, foram identificadas semelhanças e divergências entre os cenários. Essa abordagem possibilitou destacar elementos norteadores da formação, desenvolvimento e manutenção dos programas.

Esta fase exigiu raciocínio lógico e científico para subsidiar a associação/ interrelação dos resultados obtidos. Para isto, outras teorias de análise de políticas públicas apoiaram reflexões e novas interpretações dos resultados. Reuniões e debates entre os pesquisadores a partir de questões norteadoras foram realizadas para reforçar o processo reflexivo e a apreensão dos cenários e, então, observar os construtos de análise e suas relações em um modelo explicativo. As principais questões norteadoras utilizadas durante os debates estão listadas a seguir:

1) Janela política: Como o problema impulsionou ações governamentais? Qual o suporte político, econômico e cultural recebido?

2) Norteadores da estratégia: Quais os marcos norteadores do programa?

3) Implantação: Como foi negociada a disseminação e manutenção do programa? Como foram tomadas as decisões?

4) Atores: Quais os atores envolvidos e o seu papel neste processo? Qual sua capacidade de influência?

5) Impulsionadores e desaceleradores: Quais situações/eventos impulsionaram ou retardaram o processo? Qual sua relação com a estratégia?

6) Sustentação: Quais aspectos foram cruciais para sustentar e fortalecer a estratégia ao longo do tempo?

Esta reflexão ocorreu em vários encontros entre os pesquisadores e conduziu a elaboração de um modelo explicativo com o propósito de orientar a formação desta estratégia em outras realidades. Esta concepção do modelo considerou duas 
dimensões (Arredondo e Meléndez, 1992; Weiss, 1997; Trostle et al., 1999; Elias e Patroclo, 2005; Oliveira e Teixeira, 2013):

- DIMENSÃO TEÓRICA traz a fundamentação científica do modelo. A dimensão é representada pelo referencial teórico que aborda as IRAS como problema de saúde pública e os componentes mínimos para a formação de programas governamentais de prevenção e controle de IRAS. Esta dimensão está contemplada em dois eixos:

a) Estrutural - definição clara do problema e a necessidade de intervenção no nível governamental (justificativa para os programas).

b) Operacional - definição das condições mínimas necessárias para o desenvolvimento desta política pública (componentes mínimos do programa);

A dimensão teórica já se encontra consolidada através do guia técnico publicado pela Organização Mundial da Saúde. Especialistas no assunto conduziram um extenso trabalho discutindo a importância dos programas institucionais e governamentais, consolidando componentes essenciais, baseados em evidências, para sua composição (Allegranzi et al., 2011; Storr et al., 2017). Por este motivo, o estudo não vai se aprofundar nesta dimensão teórica, que é citada como parte fundamental no modelo proposto. O foco principal deste modelo, proposto nesta investigação, foi a dimensão explicativa detalhada a seguir.

- DIMENSÃO EXPLICATIVA / INDUTIVISTA construída a partir dos casos paradigmáticos estudados. Na análise dos casos foram identificados os principais elementos de formação e desenvolvimento dos programas. Estão dimensão foi representada por dois eixos:

a) Estratégico - apresentação de um esquema para articulação dos programas, seus principais núcleos, elementos e relação com os atores envolvidos neste processo (modelo esquemático);

b) Sistêmico - discussão da inserção do modelo no sistema político, econômico e de saúde dos países. Reflexões sobre questões macro que também podem influenciar a formação, desenvolvimento e manutenção desta política pública, expondo possíveis conflitos e riscos para o sucesso da estratégia (aspectos políticos, econômicos e do sistema de saúde). 
O eixo estratégico e sistêmico foi representado por meio de diagramas, símbolos e definição de conceitos, procurando criar um modelo inteligível que possa nortear a elaboração destes programas e conduzir reflexões sobre sua inserção em um sistema de saúde. O diagrama foi construído e discutido entre os pesquisadores de maneira sistemática. Posteriormente, foi apresentado em algumas reuniões com profissionais que atuam no âmbito do controle de infecção como forma de examinar a compreensão do esquema e corrigir possíveis ambiguidades, lapsos e lacunas de entendimento.

\subsection{ANÁLISE DOS DADOS}

Para a análise dos casos, foi utilizado o triângulo de análise de políticas públicas de saúde (Figura 2) (Walt e Gilson, 1994), que consiste em uma abordagem simplificada das inter-relações complexas, tendo como foco não apenas o conteúdo da política, mas também seu contexto e processo, além de assumir os atores sociais como fatores centrais desta conjuntura. Esta triangulação ajuda a explorar de forma sistemática a política pública de saúde minimizando o risco da omissão de aspectos fundamentais na análise deste objeto de estudo (Buse et al., 2012).

Figura 2 - O triângulo de análise de políticas de saúde. São Paulo. 2018.

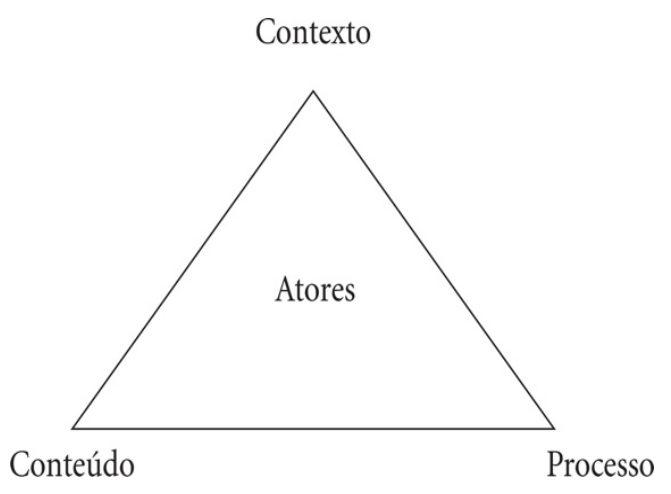

Fonte: Walt e Gilson, 1994

A descrição do processo evolutivo dos programas governamentais seguiu a proposta de Padoveze et al (2017) organizando as ocorrências temporais segundo as fases de formação, consolidação, padronização, monitoramento \& avaliação. Ou seja: 
Formação - desenvolvimento de técnicas e práticas de prevenção e infecção; Consolidação - propostas iniciais dos programas, entrada do problema na agenda governamental e políticas dos países; Padronização - estabelecimento das legislações (normas e regulamentos) das ações do programa no nível governamental; e Monitoramento \& Avaliação - formação completa do programa, incluindo mecanismos de avaliação dos resultados (Padoveze et al., 2017).

Após a triangulação, para o pareamento dos casos, comparação do contexto, processo e conteúdo dos programas analisados, foram empregados outros dois métodos de análise (Figura 3), como seguem:

1) descritivo-comparativo - para a triangulação foi realizada a descrição do contexto, processo e conteúdo dos programas governamentais de IRAS nos cenários selecionados, posteriormente estas informações foram pareadas para a comparação. Este método levou em consideração a descrição dos fatos e fenômenos em cada realidade, buscando uma compreensão aprofundada dos elementos que se destacaram em cada cenário (Lakatos e Marconi, 2010).

2) descritivo-analítico - em um segundo momento, as informações foram categorizadas com base em seus atributos. Categorias foram criadas a partir da associação e dissensão de elementos, levando em consideração o modelo de análise proposto (Walt e Gilson, 1994). Posteriormente, foram identificados elementos norteadores desta prática, discutindo-os à luz de teorias de políticas públicas. Este método favoreceu a transferabilidade dos resultados para outros potenciais cenários, possibilitando a formação de novos referenciais teóricos. Além disso, exigiu reflexão do pesquisador sobre os dados analisados, com a identificação de fatores que interferiram no objeto em questão (Lakatos e Marconi, 2010). Por fim um modelo teórico explicativo foi estabelecido. 
Figura 3 - Etapas da análise dos dados coletados no estudo. São Paulo. 2018.

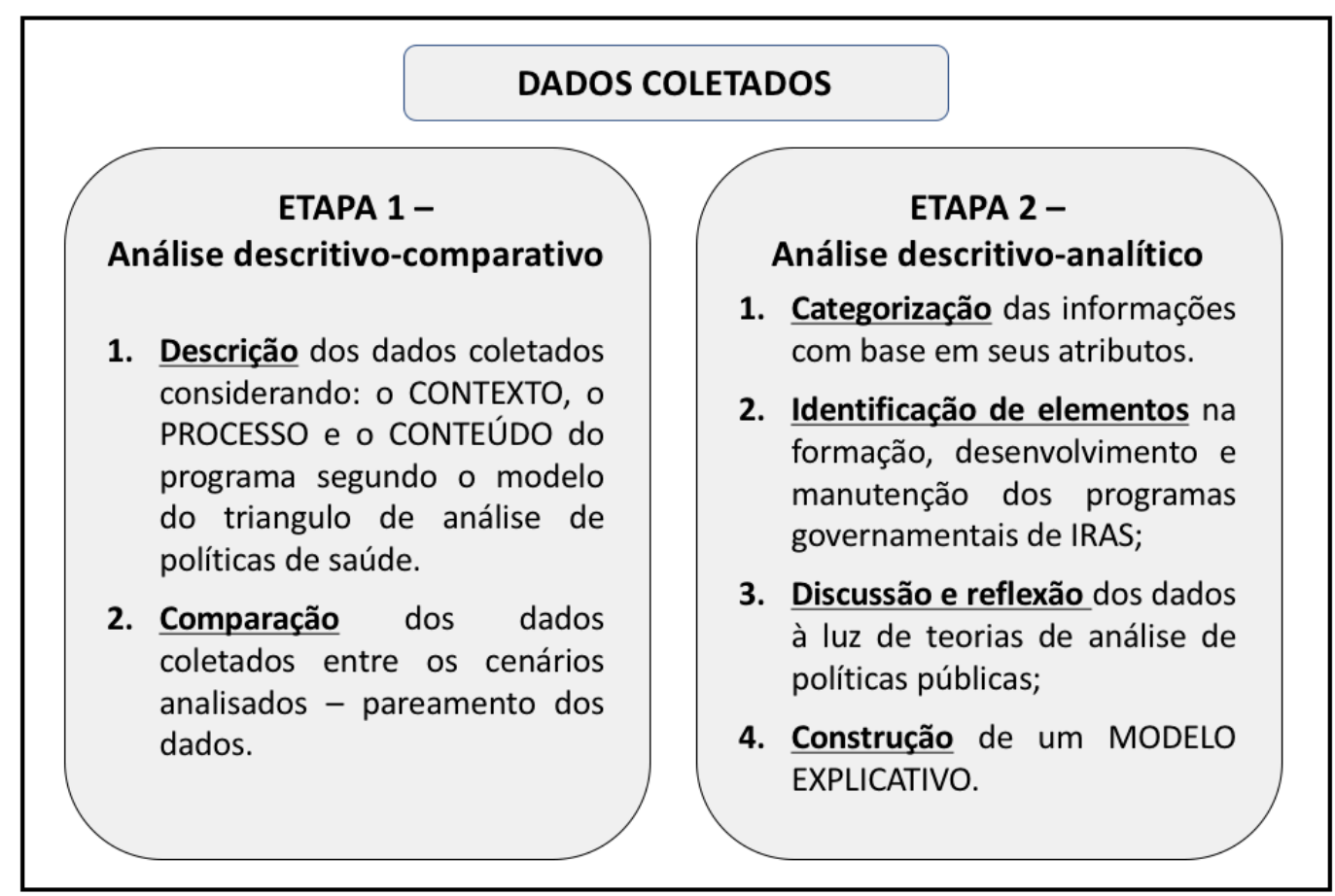

A principal intenção deste processo indutivo (observação, categorização e associação) foi a formulação de um modelo explicativo que apoiasse a estruturação dos programas governamentais de prevenção e controle de IRAS em outras realidades. Este construto parte do pressuposto que as relações sociais resultam de um complexo contexto sistêmico e que a compreensão deste pode evidenciar aspectos comuns que são inerentes a realidades distintas.

Os modelos teórico-explicativos constituem em uma representação conceitual, compacta e esquemática de um objeto, fenômeno ou sistema. O modelo trabalha com concepções do objeto de estudo de modo a tornar compreensível um evento complexo (Bunge, 1974; Oliveira e Teixeira, 2013; Peters, 2014). Estes modelos, construídos indutivamente, devem ser colocados à prova através de processos dedutivos para compor o denominado ciclo interativo de teorização (Carlile e Christensen, 2004). Este estudo se ateve apenas a construção do modelo, o processo de validação do mesmo deve ser objeto de pesquisas futuras. 


\subsection{ASPECTOS ÉTICOS}

O estudo foi submetido à apreciação ética do Comitê de Ética em Pesquisa da Escola de Enfermagem da Universidade de São Paulo (EEUSP) e foi aprovado em 01 de fevereiro de 2016 com o parecer $n^{\circ} 1.400 .148$ (Anexo 1). Após a aprovação foi iniciado o contato com os gestores dos programas de prevenção e controle de IRAS nos países selecionados para prosseguir com a segunda fase da coleta de dados visita à sede dos programas.

\subsection{FINANCIAMENTO DO PROJETO E APOIO AO DESENVOLVIMENTO DA PESQUISA}

Os custos do estudo foram financiados pelo Ministério da Ciência, Tecnologia e Inovação - MCTI e Conselho Nacional de Desenvolvimento Científico e Tecnológico - CNPq, através do Processo n ${ }^{\circ} 460783$ / 2014-9, como parte integrante do projeto: "Desenvolvimento de Tecnologias para Apoio a Políticas Públicas em Prevenção e Controle de Infecções Relacionadas à Assistência à Saúde". 


\section{RESULTADOS}

A partir da perspectiva do triângulo de análise de políticas de saúde a descrição do contexto, processo e conteúdo dos programas nacionais de controle e prevenção de IRAS observados nos países é apresentada a seguir. Também foram destacados os principais atores envolvidos neste processo em cada país.

\subsection{ESTUDO DE CASO 1 - O PROGRAMA NACIONAL DE PREVENÇÃO E CONTROLE DE IRAS NO BRASIL}

\subsubsection{O Contexto}

O Brasil é uma República Federativa formada por 26 Estados e um Distrito Federal, e mais de 5.570 municípios, todos com governo próprio e relativa autonomia (Brasil, 1988; Ibge, 2016). O sistema político é composto por diversos partidos e o país é governado pelo poder executivo, chefiado pelo presidente. Sua organização político-administrativa é composta pela União, Estados e Municípios (Brasil, 1988). O seu território possui dimensão continental e está subdividido em cinco regiões. É o maior país da América Latina e o quinto maior do mundo em área territorial (IBGE, 2016). Estima-se que sua população ultrapasse os 208 milhões de habitantes (IBGE, 2016). Uma população com grande diversidade étnica, fortemente influenciada pelos diferentes povos que a constituíram (Paim et al., 2011).

Sua economia está entre as dez maiores do mundo (FMI, 2017). É membro de importantes organizações político-econômicas como a Organização das Nações Unidas (ONU), Grupo dos 20 (G20), Grupo Político de Cooperação - BRICS (Brasil, Rússia, Índia, China e África do Sul), Organização dos Estados Americanos (OEA), Organização dos Estados Ibero-americanos (OEI), Mercado Comum do Sul (Mercosul) entre outros (CIA, 2017). Contudo, possui amplas desigualdades regionais e sociais, decorrentes da má distribuição de renda e acesso a educação e saúde, entre outros (Tabela 1) (IBGE, 2011; Paim et al., 2011). 
O modelo atual de assistência a saúde surgiu com a Constituição de 1988, que definiu este bem social como um direito de todos e um dever do Estado. Neste período, foi instituído o Sistema Único de Saúde (SUS), tendo como princípios universalidade, equidade, integralidade, descentralização, participação da comunidade, entre outros. O sistema se subdivide nos subsetores público e privado. A população é livre para transitar entre estes, de acordo com sua condição financeira e de acesso. O subsetor público é governado por três níveis de governo: o federal, o estadual e o municipal. O sistema conquistou muitos avanços, investindo em tecnologia, capacitação de profissionais, ciência e tecnologia, entre outros, ampliando a conscientização sobre o direito a saúde no país (Paim et al., 2011; Mendes, 2013).

Tabela 1 - Indicadores sociais, demográfico e de saúde no Brasil. São Paulo. 2018.

\begin{tabular}{|c|c|}
\hline Indicador & Resultado (Ano) \\
\hline População Total & 208 milhões de habitantes (Projeção 2017) \\
\hline Taxa Global de Fecundidade & 1,72 filhos por mulher (2015) \\
\hline Esperança de Vida ao Nascer & 75,44 anos $(2015)$ \\
\hline Taxa de Mortalidade Infantil & 13,82 óbitos/1000 nascidos vivos (2015) \\
\hline Taxa de Mortalidade Geral & 6,08 óbitos / 1000 habitantes (2015) \\
\hline Leitos Hospitalares & $2,42 / 1000$ habitantes $(2010)$ \\
\hline Coeficiente de Gini & $0,515-10^{\circ}$ país mais desigual no mundo (2015) \\
\hline IDH* $^{*}$ & $0,755-79^{\circ}$ posição ranking mundial (2015) \\
\hline PIB $^{* \star}$ per capta & 8.528 US\$ \\
\hline \% PIB Gasto com Saúde & $9,7 \%$ PIB \\
\hline
\end{tabular}

Fonte: instituto Brasileiro de Geografia e Estatística (IBGE) e United Nations Statistics Division, National Accounts Main Aggregates Database, Basic Data Selection, New York, 2016. Acesso em: janeiro, 2017.

Segundo consulta ao Cadastro Nacional de Estabelecimentos de Saúde CNES em 2017, o país conta com um total de 6160 hospitais divididos pelas cinco regiões, que disponibilizam aproximadamente 495 mil leitos. Em 2010, foram apontados 2,42 leitos por mil habitantes, um número que vem reduzindo a cada ano. A maior concentração de serviços de saúde esta na região sudeste (Brasil, 2017).

Na década de 1960 houve a criação da primeira comissão para a prevenção e controle de IRAS em um hospital brasileiro (Padoveze e Fortaleza, 2014). No fim da 
década de 1980 uma crescente conscientização dos profissionais de saúde sobre o problema foi evidenciada e muitas comissões de controle de infecção foram criadas (Padoveze e Fortaleza, 2014).

Este movimento beneficiou a formação de massa critica no país e as primeiras iniciativas governamentais foram constituídas com a promulgação de uma lei que obrigou os hospitais brasileiros a formarem comissões de prevenção e controle de infecções. Neste mesmo período, com o financiamento da Organização Panamericana de Saúde (OPAS) um curso foi promovido capacitando profissionais para disseminarem conhecimento em torno do fenômeno em questão (Lacerda et al., 1996; Padoveze e Fortaleza, 2014).

Em 1985, o primeiro presidente eleito democraticamente após o fim do regime de ditadura militar morreu supostamente em decorrência de IRAS. Acentuou-se um processo de inspeções sanitárias em hospitais para identificar a conformidade à legislação vigente (Nogueira Junior, C. et al., 2014; Padoveze e Fortaleza, 2014). No final da década de 1980, importantes associações de profissionais foram formadas, como: a Associação Paulista de Epidemiologia e Controle de Infecção relacionada à Assistência à Saúde $(\mathrm{APECIH})^{\mathrm{e}}$ - que se iniciou como núcleo de estudos no ano de 1982 e foi transformada em associação no ano de 1987; a Associação Mineira de Estudos em Controle de Infecção Hospitalar (AMECIH $)^{\text {f }}$; e a Associação Brasileira dos Profissionais em Controle de Infecção Hospitalar $(A B I H)^{g}$. Estas associações possibilitaram a capacitação de profissionais, por meio de cursos básicos e eventos.

O Programa Nacional de Controle de Infecções Hospitalares (PNCIH) foi instituído em 1988, marcando a entrada deste tema na agenda formal do governo. As primeiras ações documentadas referem-se a centros de treinamento e atividades educativas com material didático apoiado pelo Ministério da Saúde. Os resultados subsequentes são pouco documentados (Nogueira Junior, C. et al., 2014; Padoveze e Fortaleza, 2014).

\footnotetext{
e http://www.apecih.org.br/

f ameci.org.br/

${ }^{\mathrm{g}} \mathrm{http}: / /$ www.abih.net.br/institucional/
} 


\subsubsection{O Processo de desenvolvimento do Programa Nacional}

O desenvolvimento do programa é marcado por decisões ligadas a esfera do Ministério da Saúde até o fim da década de 1990, quando a Agência Nacional de Vigilância Sanitária (ANVISA) assumiu as atribuições. Não há relatos documentados de amplo envolvimento da sociedade civil no seu processo de desenvolvimento (Figura 4) (Lacerda et al., 1996; Nogueira Junior, C. et al., 2014; Padoveze e Fortaleza, 2014).

A consolidação do programa no cenário nacional percorreu mais de duas décadas, nas quais as ações foram escassamente documentadas. As tentativas de operacionalização do programa no final da década de 1990 começam a ganhar forma com a gestão da ANVISA e reestruturação das atividades do programa (Nogueira Junior, C. et al., 2014; Padoveze e Fortaleza, 2014). Iniciativas pontuais foram programadas, como: a Rede Nacional de Monitoramento da Resistência Microbiana em Serviços de Saúde e a Rede Nacional para Investigação de Surtos e Eventos Adversos em Serviços de Saúde (RENISS) (Nogueira Junior, C. et al., 2014).

O primeiro projeto para um sistema de vigilância epidemiológica de IRAS foi instituído no ano de 2005 (SINAIS - Sistema Nacional de Informações para o Controle de Infecções em Serviços de Saúde), porém, não obteve sucesso. Na década seguinte, foi realizado um diagnóstico situacional do programa nacional e das comissões estaduais. Nessa mesma década, foi implantado um novo sistema de vigilância de IRAS, com padronização de critérios de vigilância, definição de metas e ações estratégicas. Este sistema de vigilância de IRAS brasileiro concentrou-se em seu início em hospitais com leitos de Unidade de Terapia Intensiva (UTI), visando o monitoramento das infecções primárias da corrente sanguínea. Os primeiros resultados foram publicados, embasando a reformulação de novas metas e ações estratégicas (Nogueira Junior, C. et al., 2014; Padoveze e Fortaleza, 2014; Anvisa, 2016b).

Atualmente, a vigilância é dirigida a todos os hospitais, independente do número de leitos de UTI, e escopo da vigilância também foi ampliado para pneumonias associadas a ventilação mecânica, infecções do trato urinário e infecções de sitio cirúrgico (Anvisa, 2016b). 
Figura 4 - Representação esquemática da linha do Tempo do Programa Nacional de Prevenção e Controle de Infecção do Brasil, segundo as fases de formação, consolidação, padronização, monitoramento \& avaliação*. São Paulo. 2018.

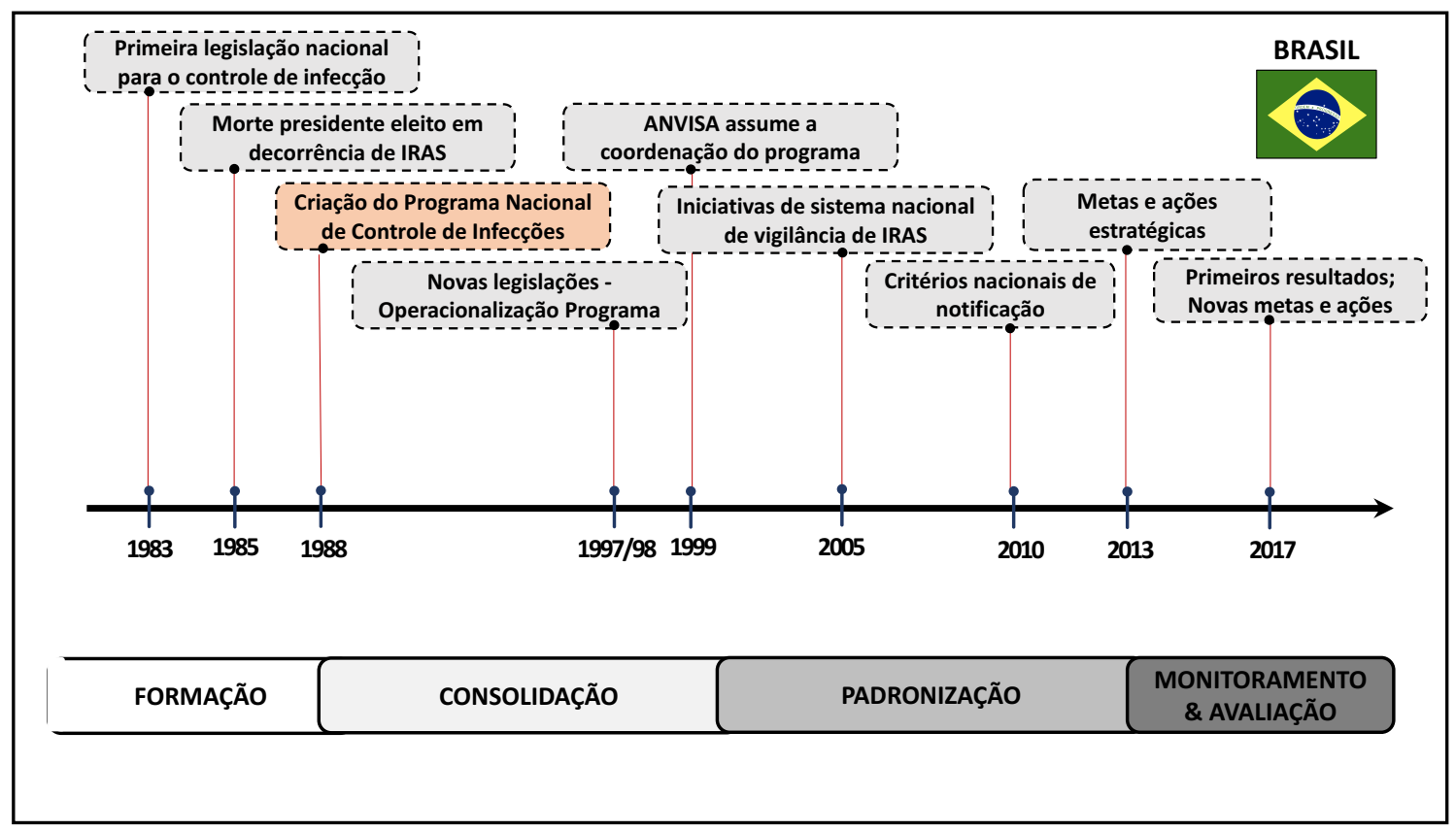

\section{Legenda:}

ANVISA - Agência Nacional de Vigilância Sanitária

IRAS - Infecção relacionada à assistência à saúde

* Padoveze MC, Melo S, Bishop S, Poveda VB, Fortaleza C. Public policies on healthcare-associated infections: a Brazil and UK case study. Rev Saude Publica. 2017; 51:119. 


\subsection{ESTUDO DE CASO 2 - O PROGRAMA NACIONAL DE PREVENÇÃO E CONTROLE DE IRAS NO CHILE}

\subsubsection{O Contexto}

O Chile é uma República Democrática, composta por 15 regiões, 54 províncias e 346 comunas (municípios). O Presidente, eleito democraticamente, é o chefe do poder executivo. O parlamento é composto pelo Senado e pela Câmara de Deputados. O seu território com ampla extensão territorial no sentido norte sul é estreito no sentido leste oeste. Sua população em torno de 17,3 milhões de habitantes possui composição étnica basicamente formada por ameríndios e espanhóis (Chile, 2017; CIA, 2017; FMI, 2017).

É um dos países mais estáveis e prósperos da América do Sul. Está entre as cinco maiores economias da América Latina. Sua economia é predominantemente de mercado, caracterizada por significativa desigualdade na distribuição de renda (Chile, 2017; FMI, 2017). Participa de importantes blocos comerciais como: Organização Mundial do Comércio (OMC), Cooperação Econômica da Ásia e do Pacífico (APEC), Mercosul, entre outras (Chile, 2017; FMI, 2017).

O Sistema Nacional de Serviços de Saúde Chileno é misto, tanto no financiamento como na prestação, tendo como parte da responsabilidade o setor público, responsável pela cobertura de $80 \%$ da população, e parte do setor privado (Tabela 2) (Labra, 2001; Becerril-Montekio et al., 2011). A lei de Garantias Explícitas em Saúde busca assegurar acesso, oportunidade e qualidade dos cuidados em saúde (Labra, 2001). Segundo o Departamento de Estadísticas e Información de Salud (DEIS), em 2015 o país contava com 404 hospitais e clínica, dos quais 189 são hospitais públicos, e 25.334 leitos hospitalares no setor público. Em 2010, foram registrados 2,0 leitos hospitalares por mil habitantes. A maior concentração de serviços de saúde está na região da capital Santiago (Chile, 2015). 
Tabela 2 - Indicadores sociais, demográfico e de saúde no Chile. São Paulo. 2018.

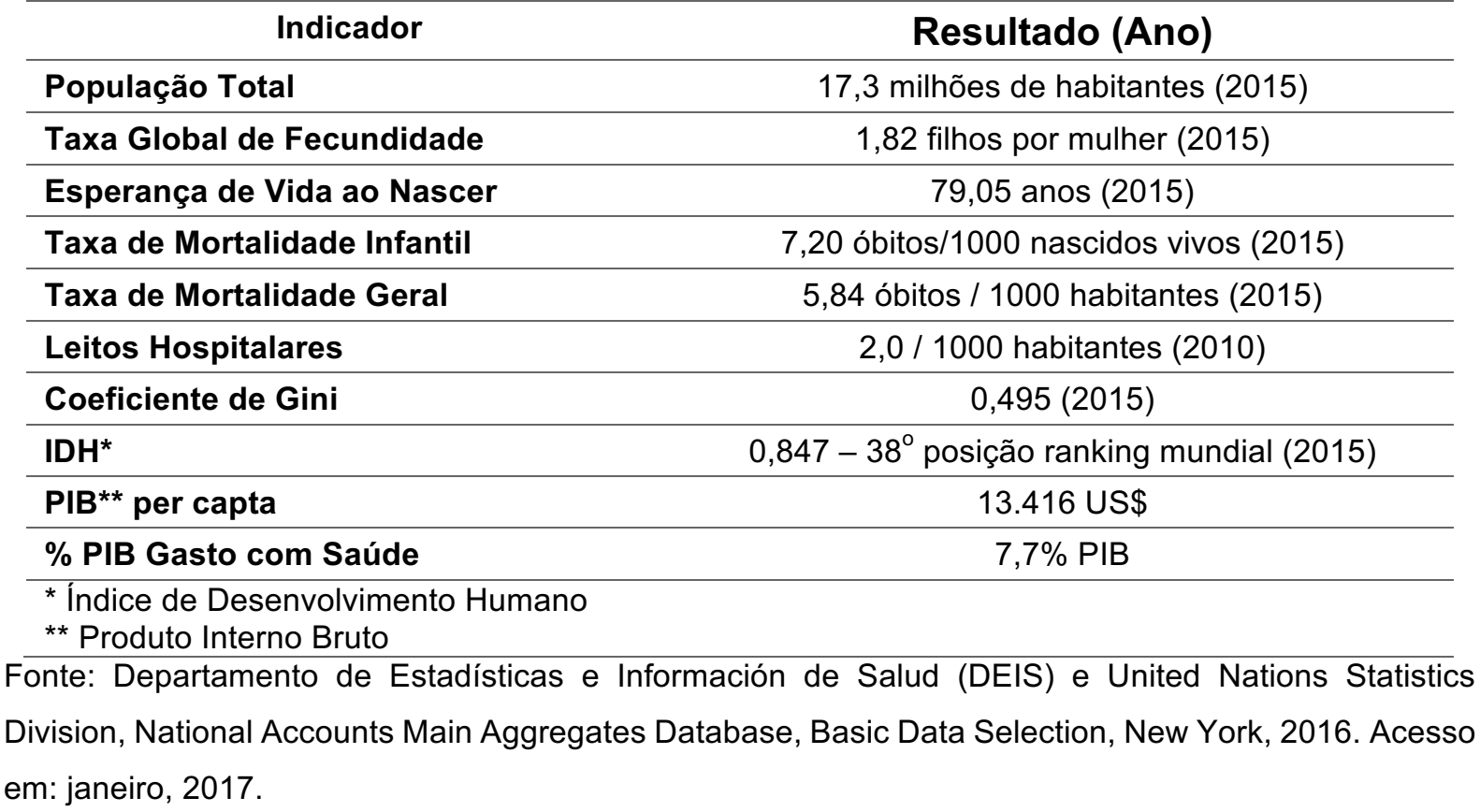

Antes da década de 1980, no âmbito governamental, inexistia as ações expressivas para o controle de infecção. A concentração das ações estava no âmbito institucional, focado no manejo de surtos, saneamento básico, estudos de portadores e medidas de isolamento.

O Programa Nacional de Controle de Infecção foi criado no inicio da década de 1980. Em decorrência de três surtos simultâneos de IRAS no país, em um curto período de tempo e com cobertura da imprensa, o Ministro da Saúde estruturou uma equipe de trabalho para atuar no controle das IRAS. As primeiras legislações foram promulgadas e o programa nacional iniciou suas atividades (Chile, 1998). Nos primeiros anos, a estratégia recebeu apoio da Organização Panamericana de Saúde (OPAS), com incorporação de conhecimento e assessoria externa nos moldes da Joint Comission International, conquistando importantes resultados, que veio a tornar o país uma referência para o controle e prevenção de IRAS em âmbito governamental (World Health Organization, 2017). 


\subsubsection{O Processo de desenvolvimento do Programa Nacional}

As decisões iniciais para a composição do programa partiram do Ministro da Saúde. Uma liderança médica foi selecionada, assumindo a supervisão das ações do programa desde a década de 1980, coordenando todas as atividades e decisões do programa até os dias atuais. Este profissional buscou se qualificar em torno da temática, em instituições nacionais e internacionais. Não há relatos de intenso envolvimento da sociedade civil na criação do programa (Figura 5). A Sociedade Chilena de Controle de Infecção e Epidemiologia Hospitalar ${ }^{h}$, formada em 1997, teve um papel importante na fase de consolidação do programa contribuindo para a promoção e difusão das boas práticas de prevenção e controle de infecção.

O programa se consolidou na década de 1980, compondo um primeiro sistema de vigilância passivo. Em 1987, a eclosão da epidemia de AIDS elevou a preocupação com a prevenção de infecções ocupacionais e transmissão iatrogênica do HIV, provocando uma reestruturação do sistema nacional para a vigilância ativa em todos os hospitais do país. O foco neste período esteve voltado para a consolidação das ações de prevenção e controle de infecção (Chile, 1998).

Em meados da década de 1990, a padronização dos critérios de vigilância foi efetivada e o sistema de vigilância foi reestruturado para um sistema ativo e seletivo. O programa nacional produz recomendações e regulações baseadas em evidências para a prevenção de IRAS que são aplicadas nos setores privados e públicos. No período entre 2006 e 2007, o sistema de vigilância foi informatizado. Ainda na década de 1990, a avaliação periódica dos hospitais tornou-se um dos pilares da estratégia. Por meio de uma ferramenta com componentes mínimo do programa, aplicada por um grupo de profissionais treinados e delegados pelo MS, fortaleceu a supervisão local para o alcance de bons resultados (Chile, 1998). Em 2012, 80\% dos hospitais chilenos cumpriam $90 \%$ dos componentes mínimos do programa. No mesmo ano, a lei que regula os direitos dos pacientes tornou obrigatório que todo serviço de saúde do país tenha controle de infecção de acordo com os princípios e recomendações nacionais.

Os resultados do programa permitiram identificar fragilidades e aspectos que podem ser melhorados como, surtos prolongados e frequentes taxas elevadas de

\footnotetext{
${ }^{\mathrm{h}} \mathrm{http}: / /$ www.sociedad-iih.cl/
} 
IRAS. A organização do sistema de vigilância e a implantação de medidas específicas de prevenção e controle de infecção foram revisadas, norteando a capacitação de especialistas e avaliadores e a incorporação de estudos de sensibilidade da vigilância por meio de prevalência pontual.

Figura 5 - Representação esquemática da linha do Tempo do Programa Nacional de Prevenção e Controle de Infecção do Chile, segundo as fases de formação, consolidação, padronização, monitoramento \& avaliação*. São Paulo. 2018.

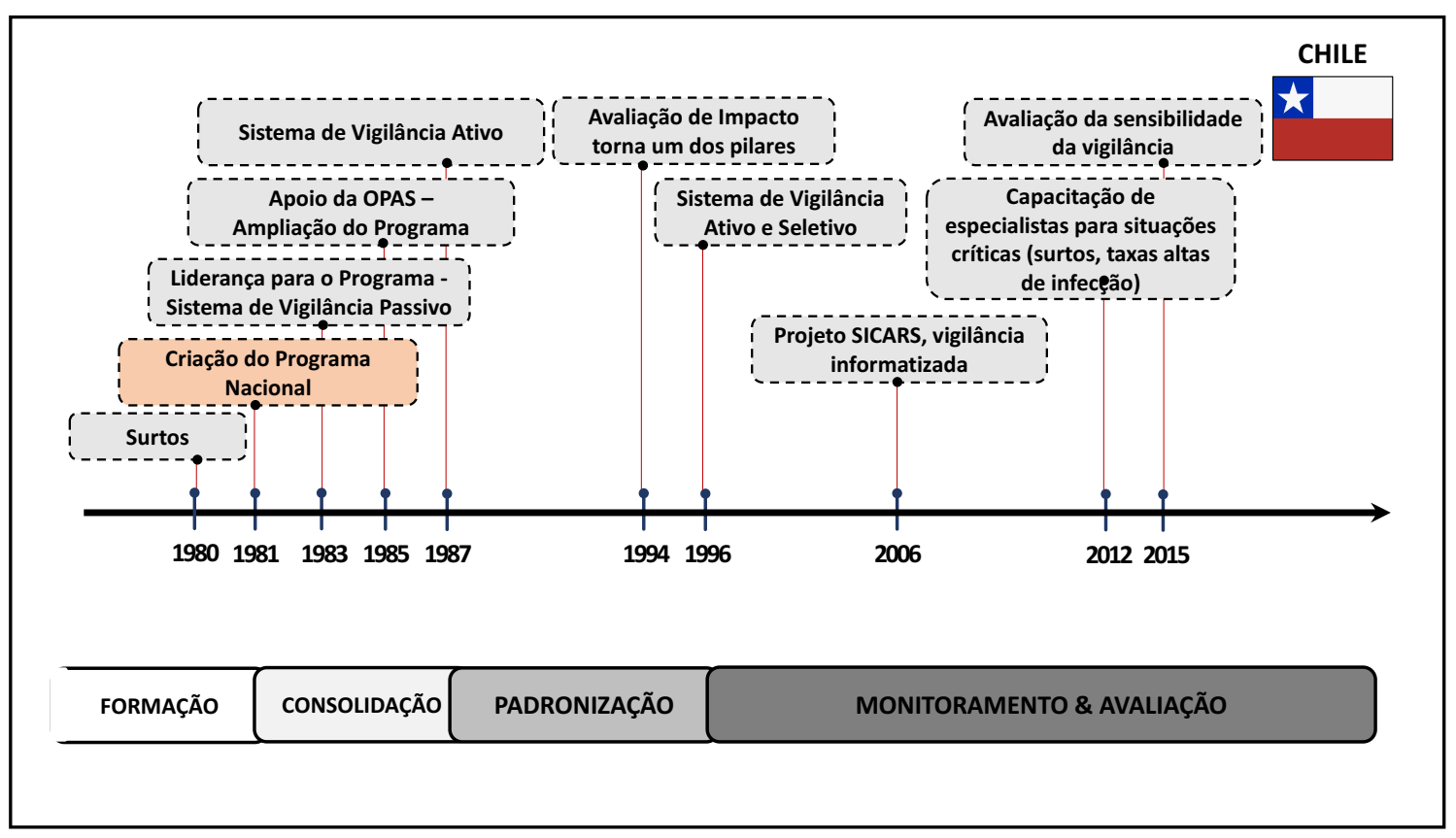

\section{Legenda:}

SICARS - Sistema de Indicadores de Calidad y Atención y Resultados Sanitarios OPAS - Organização PanAmericana de Saúde

* Padoveze MC, Melo S, Bishop S, Poveda VB, Fortaleza C. Public policies on healthcare-associated infections: a Brazil and UK case study. Rev Saude Publica. 2017; 51:119. 


\subsection{ESTUDO DE CASO 3 - O PROGRAMA NACIONAL DE PREVENÇÃO E CONTROLE DE IRAS EM ISRAEL}

\subsubsection{O Contexto}

Israel é uma democracia parlamentar republicana fundamentada no sufrágio universal e na representação proporcional. Seu sistema de governo está alicerçado em leis básicas decretadas por seu parlamento, o Knesset. O território do país é alongado e estreito, totalizando uma área de $27.800 \mathrm{~km}^{2}$, que inclui as linhas do cessar-fogo e o autogoverno da palestina. Sua população foi estimada em 2015 em mais de oito milhões de pessoas, composta em sua maioria por judeus e uma pequena parcela de árabes (Cia, 2017; Israel, 2017b; The World Bank, 2017).

É uma das economias mais avançadas do sudoeste da Ásia. Os altos investimentos em educação transformaram o seu perfil econômico em uma economia moderna de mercado com indústrias e tecnologia fortemente desenvolvidas. O país faz parte dos blocos econômicos: Organização Mundial do Comércio (OMC), Organização para a Cooperação e Desenvolvimento Econômico (OCDE) e Congresso Judaico Mundial (CJM)(CIA, 2017; Israel, 2017b; OECD, 2017; The World Bank, 2017).

O sistema de saúde israelense é universal, financiado por tributos que estão vinculados aos rendimentos dos cidadãos. A provisão de serviços de saúde é de responsabilidade de quatro planos de saúde sem fins lucrativos: Clalit, Maccabi, Meuhedet e Leumit (Rosen et al., 2015). Os níveis de saúde israelenses podem ser comparados a outros países desenvolvidos, apesar do percentual gasto com saúde ser baixo (Tabela 3) (Rosen et al., 2015; Balicer et al., 2017). O país conta com 30 hospitais públicos com 15 mil leitos aproximados e 296 instituições de longa permanência com 25 mil leitos, que juntos totalizam aproximadamente 40 mil leitos, aproximadamente 3,1 leitos/ 1000 habitantes (Israel, 2017a; Schwaber e Carmeli, 2017). 
Tabela 3 - Indicadores sociais, demográfico e de saúde em Israel. São Paulo. 2018.

\begin{tabular}{|c|c|}
\hline Indicador & Resultado (Ano) \\
\hline População Total & 8,547 milhões de habitantes (2016) \\
\hline Taxa Global de Fecundidade & 3,09 filhos por mulher (2015) \\
\hline Esperança de Vida ao Nascer & 82,4 anos $(2015)$ \\
\hline Taxa de Mortalidade Infantil & 3,98 óbitos/1000 nascidos vivos (2015) \\
\hline Taxa de Mortalidade Geral & 5,30 óbitos / 1000 habitantes (2015) \\
\hline Leitos Hospitalares & 3,4 / 1000 habitantes $(2011)$ \\
\hline Coeficiente de Gini & $0,360(2015)$ \\
\hline IDH $^{*}$ & $0,894-18^{\circ}$ posição ranking mundial $(2015)$ \\
\hline PIB $^{* *}$ per capta & 37.129 US $\$$ \\
\hline \% PIB Gasto com Saúde & $7,2 \% \mathrm{PIB}$ \\
\hline $\begin{array}{l}\text { * Índice de Desenvolvimento Hu } \\
\text { ** Produto Interno Bruto }\end{array}$ & \\
\hline
\end{tabular}

Desde a década de 1980, o país já possuía uma base formada por profissionais controladores de infecção, que formaram associações promovendo eventos, atualização e discussões regulares em torno desta temática (Schwaber e Carmeli, 2017). Cabe ainda ressaltar que alguns profissionais detinham formação específica em controle e prevenção de IRAS em instituições de ensino fora de Israel.

O programa nacional de prevenção e controle de IRAS em Israel surge em 2007, a partir de uma demanda social para controle de surtos de Klebsiella pneumoniae resistentes aos carbapenêmicos. Durante um encontro israelense de controladores de infecção em fevereiro de 2007 foi percebida a situação em todo o país e reportado ao Diretor Geral do Ministério da Saúde de Israel. Esta medida estimulou a formação de uma força tarefa no âmbito nacional para a contenção do problema, convertendo posteriormente no programa nacional de prevenção e controle de infecção e resistência microbiana (Schwaber et al., 2011; Schwaber e Carmeli, 2014; Schwaber e Carmeli, 2017). 


\subsubsection{O Processo de desenvolvimento do Programa Nacional}

Após a formação da força tarefa, as primeiras ações do programa envolveram: a publicação de guias técnicos em prevenção e controle de enterobacterias resistentes a carbapenêmicos; a busca por mais informações, com a estruturação de um sistema de vigilância; a regulação da formação de comissões de controle de infecção nos hospitais; e a supervisão destas práticas com visitas recorrentes aos serviços de saúde (Figura 6) (Schwaber et al., 2011).

Em 2008, foi padronizado o método de vigilância ativa no país e ampliada o escopo da vigilância no país para instituições de longa permanência. No ano seguinte, foram regulamentadas novas diretrizes para tratamento e notificação das infecções causadas por enterobacterias resistentes aos carbapenêmicos (CRE) e enterococos resistentes à vancomicina (VRE) e outras legislações.

Entre os anos de 2010 a 2013, os primeiros resultados nacionais do programa foram divulgados (Schwaber et al., 2011), as comissões de controle e prevenção de infecção nos hospitais tornaram-se obrigatórias. Foram ainda publicados novos guias técnicos ampliando a abrangência da vigilância para outras topografias infecciosas (infecções de corrente sanguínea, trato urinário).

Os resultados da análise dos primeiros cinco anos de intervenção foram publicados em 2014 (Schwaber e Carmeli, 2014) e as diretrizes para diagnóstico laboratorial, notificação e prevenção de infecções causadas por CRE foram atualizadas em 2016.

O programa israelense foi constituído no âmbito do Ministério da Saúde (MS). A equipe que atua na prevenção e controle de IRAS no âmbito do Ministério da Saúde possui experiência e capacitação específica para IRAS. Todas as decisões são tomadas no âmbito ministerial com a participação de membros da sociedade civil, por meio de reuniões com a equipe ministerial (Schwaber e Carmeli, 2017). 
Figura 6 - Representação esquemática da linha do Tempo do Programa Nacional de Prevenção e Controle de Infecção e Resistência Microbiana de Israel, segundo as fases de formação, consolidação, padronização, monitoramento \& avaliação*. São Paulo. 2018.

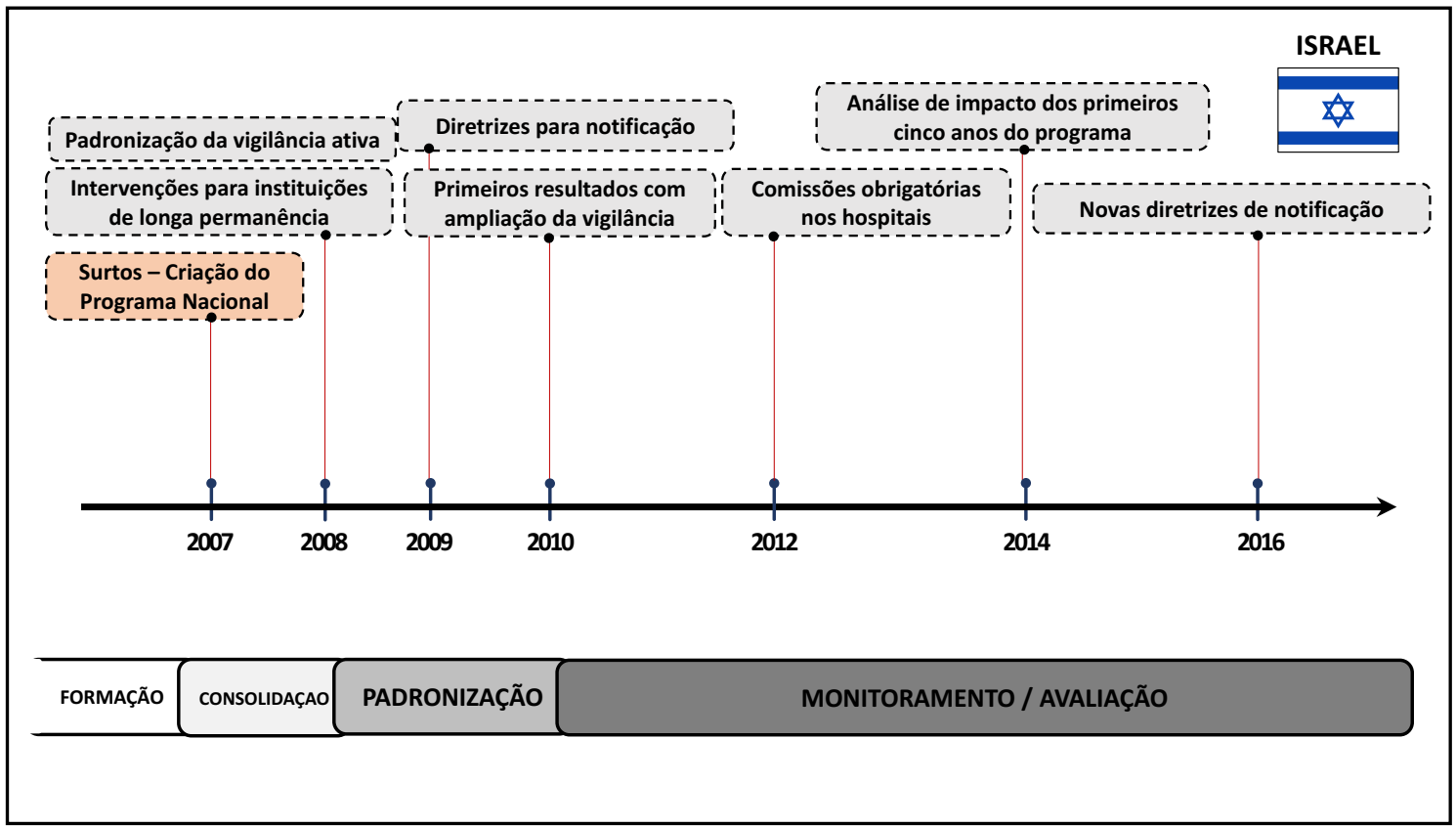

* Padoveze MC, Melo S, Bishop S, Poveda VB, Fortaleza C. Public policies on healthcare-associated infections: a Brazil and UK case study. Rev Saude Publica. 2017; 51:119. 


\subsection{O CONTEÚDO DOS PROGRAMAS NACIONAIS DE PREVENÇÃO E CONTROLE DE IRAS}

O conteúdo dos programas de IRAS está detalhado nos Quadros 1, 2 e 3.

\subsubsection{O Objetivo e Foco}

Embora, o foco central do programa nacional dos três países seja a prevenção e o controle de infecções, os objetivos globais de cada um deles variam dependendo do contexto analisado.

Todos os programas objetivam a redução das IRAS nos serviços de saúde. No Chile, ainda há um importante destaque para a preocupação com o impacto financeiro desta ocorrência, acrescentando a redução dos custos associados como parte deste objetivo. Em Israel, o programa intensifica e destaca a contenção da resistência microbiana (Quadro 1).

Brasil e Chile também destacam objetivos específicos para o programa. No Brasil são reforçadas a consolidação do sistema nacional de vigilância, a redução da incidência de IRAS prioritárias, e a prevenção e controle da disseminação da resistência microbiana. No Chile, os objetivos específicos reforçam a redução da incidência de IRAS associadas a procedimentos invasivos, surtos e exposição ocupacional, a redução da transmissão de infecção ocupacional, a elevação da eficiência e sensibilidade do sistema de vigilância e o custo benefício das atividades de prevenção e controle, e a redução dos custos associados às IRAS.

O foco do programa nos três países inclui os hospitais de cuidados agudos, instituições de maior ocorrência destas infecções. O programa israelense amplia o foco para as instituições de longa permanência e o programa chileno coloca no escopo do programa estabelecimentos que prestam assistência direta ao paciente.

\subsubsection{A equipe e as decisões dos Programas}

O programa brasileiro é coordenado por uma equipe exclusivamente dedicada ao mesmo, composta por sete profissionais especialistas, que incluem enfermeiros, farmacêuticos e estatístico. As decisões do programa são compartilhadas com a 
Comissão Nacional de Controle e Prevenção de IRAS (CNCIRAS), que é composta por membros da sociedade civil e do governo. Por conta da organização político administrativa do país, as decisões regionais são autônomas e são livres para ocorrer respeitando a macro diretriz definida pelo nível nacional. Estas decisões ficam sob a responsabilidade das Comissões Estaduais de Controle e Prevenção de IRAS (CECIRAS).

No Chile, a equipe ministerial é composta por dois médicos e duas enfermeiras e contam com o apoio de outras instâncias governamentais para a supervisão das atividades do programa. Todas as decisões do programa são compartilhadas, quando pertinente, com outras áreas do governo. Há interface com o nível regional nas ações de avaliação dos programas locais.

No contexto israelense a equipe do programa é composta por médicos, enfermeiros, epidemiologistas, microbiologistas e equipe de suporte para a análise de dados. O planejamento das ações do programa conta com a colaboração de outros profissionais de controle e prevenção de infecção dos serviços hospitalares israelenses e com profissionais que atuam em outras áreas do ministério. A formação das decisões e planejamento ministerial são responsabilidades da equipe do governo.

\subsubsection{Principais atividades}

Todos os programas publicam guias técnicos e normativas para prevenção controle e vigilância de infecções (Quadro 1), possuem um sistema nacional de vigilância de IRAS (Quadro 2) como pilar central de suas ações e divulgam periodicamente relatórios de resultados. O programa chileno ainda incorpora a avaliação da sensibilidade da vigilância por meio de estudos pontuais de prevalência.

No Brasil, por ser um país de dimensão continental, há um destaque, dentro das suas atividades principais, para as ações de assessoria às comissões estaduais na implantação das atividades de prevenção e controle de IRAS. Chile e Israel possuem ainda a avaliação dos serviços de saúde como um pilar estruturado do programa que, embora com metodologias distintas, busca observar como as práticas recomendadas estão sendo implantadas. Também nestes dois países, o treinamento e a formação de profissionais são ações definidas no escopo do programa. 
Quadro 1 - Principais Legislações pertinentes aos Programas Nacionais de Prevenção e Controle de Infecção do Brasil, Chile e Israel. São Paulo. 2018.

\begin{tabular}{|c|c|}
\hline \multicolumn{2}{|c|}{ LEGISLAÇÕES DO BRASIL } \\
\hline LEGISLAÇÃO & ASSUNTO \\
\hline $\begin{array}{l}\text { Resolução RDC 50, de } 21 \text { de fevereiro de } 2002 \text {, atualizada } \\
\text { pela Resolução RDC } 307 \text {, de } 14 \text { de novembro de } 2002 \text {. }\end{array}$ & Área Física: Regulamentação \\
\hline $\begin{array}{l}\text { Resolução RDC 45, de março de 2003; Resolução RDC } 156 \text {, } \\
\text { de } 11 \text { de agosto de 2006; Resolução RE } 2.605 \text {, de } 11 \text { de } \\
\text { agosto de 2006; Resolução RE 2.606, de } 11 \text { de agosto de } \\
\text { 2006; Resolução RDC 15, de } 15 \text { de março de } 2012 \text {. }\end{array}$ & $\begin{array}{l}\text { Produtos para saúde: regulamentação de } \\
\text { fabricação, processamento }\end{array}$ \\
\hline $\begin{array}{l}\text { Portaria 385, } 4 \text { de junho de 2003; Portaria 620, de } 7 \text { de junho } \\
\text { de } 2009 \text { (CATREM); Portaria 1.218, de } 14 \text { de agosto de } 2012 \\
\text { (CNCIRAS). }\end{array}$ & $\begin{array}{l}\text { Normativas internas: regimento; comitês de } \\
\text { assessoramento }\end{array}$ \\
\hline $\begin{array}{l}\text { Portaria 154, de } 15 \text { de junho de 2004, alterada pela } \\
\text { Resolução RDC 6, de } 14 \text { de fevereiro de } 2011 \text {; Resolução } \\
\text { RDC } 283 \text { de } 26 \text { de setembro de } 2005 \text {; Resolução RDC } 7 \text {, de } \\
24 \text { de fevereiro de } 2010 \text {; Resolução RDC 42, de } 25 \text { de outubro } \\
\text { de } 2010 \text {. }\end{array}$ & $\begin{array}{l}\text { Serviços: regulamentação técnica (diálise, idosos, } \\
\text { UTI, uso de produto alcoólico) }\end{array}$ \\
\hline $\begin{array}{l}\text { Informe Técnico 1, Infecção por Mycobacterium abscessus - } \\
\text { Diagnóstico e tratamento, fevereiro de } 2007 \text {; Informe Técnico } \\
2 \text {, Medidas para a interrupção do surto de infecção por MCR } \\
\text { e ações preventivas; Informe Técnico } 3 \text {, Alerta sobre } \\
\text { infecções por micobactéria não tuberculosa após } \\
\text { videocirurgia, março de } 2007 \text {; Informe Técnico } 4 \text {, } \\
\text { Glutaraldeído em estabelecimentos de assistência à saúde - } \\
\text { Fundamentos para a utilização, fevereiro de } 2007 \text {; } \\
\text { Investigação e Controle de Bactérias Multiresistentes, maio } \\
\text { de 2007; Ações prioritárias para prevenir e interromper } \\
\text { infecções por micobactérias não tuberculosa em } \\
\text { Estabelecimentos de Assistência a Saúde; novembro de } \\
2007 \text {; Informe Técnico 05/07, Surto de Enterococo resistente } \\
\text { à vancomicina em estabelecimentos de assistência a saúde: } \\
\text { fundamentos e esclarecimentos gerais, fevereiro de 2008; } \\
\text { Nota técnica - Assunto: micobactérias; agosto de } 2008 \text {. }\end{array}$ & $\begin{array}{l}\text { Documentos técnicos: epidemiologia } \\
\text { recomendações de práticas }\end{array}$ \\
\hline $\begin{array}{l}\text { Relatório descritivo de investigação de casos de infecções por } \\
\text { micobactérias não tuberculosas de crescimento rápido (MCR) } \\
\text { no Brasil no período de } 1998 \text { a 2009, fevereiro de 2011; } \\
\text { Boletim informativo Segurança do Paciente e Qualidade em } \\
\text { Serviços de Saúde 2011;1(1):1-12; Boletim Informativo } \\
\text { Segurança do Paciente e Qualidade Assistencial em Serviços } \\
\text { de Saúde 2011;1(2):1-11; Boletim Informativo Segurança do } \\
\text { Paciente e Qualidade Assistencial em Serviços de Saúde }\end{array}$ & Documentos técnicos: dados epidemiológicos \\
\hline
\end{tabular}




\begin{tabular}{|c|c|}
\hline $\begin{array}{l}\text { 2011;1(3):1-5; Boletim Informativo Segurança do Paciente e } \\
\text { Qualidade Assistencial em Serviços de Saúde 2012;1(4):1- } \\
\text { 22; Boletim Informativo Segurança do Paciente e Qualidade } \\
\text { Assistencial em Serviços de Saúde 2012;1(5):1-22. }\end{array}$ & \\
\hline $\begin{array}{l}\text { Diagnóstico do controle de infecção hospitalar no Brasil, maio } \\
\text { de 2005; Análise do Inquérito Nacional sobre infraestrutura, } \\
\text { recursos humanos, equipamentos, procedimentos, controle } \\
\text { de qualidade e biossegurança nos Laboratórios de } \\
\text { Microbiologia, julho de 2007; Corrente sanguínea - Critérios } \\
\text { Nacionais de Infecções Relacionadas a Assistência a Saúde, } \\
\text { setembro de 2009; Relatório sobre o recadastramento das } \\
\text { coordenações estaduais de controle de infecção hospitalar - } \\
\text { CECIH, maio de } 2012 \text {. }\end{array}$ & $\begin{array}{l}\text { Documentos técnicos: diagnóstico situacional; } \\
\text { critérios diagnósticos }\end{array}$ \\
\hline $\begin{array}{l}\text { Versão em português aprovada pelo Congresso Nacional por } \\
\text { meio do Decreto Legislativo 395/2009, publicado no DOU de } \\
\text { 10/7/2009. }\end{array}$ & Regulamento sanitário internacional (RSI) \\
\hline $\begin{array}{l}\text { Resolução RDC } 20 \text {, de } 5 \text { de maio de } 2011 \text {; Informe técnico } \\
\text { s/n junho de } 2011 \text {, atualização em } 10 \text { de agosto de } 2011 \text {. }\end{array}$ & Medicamentos: antimicrobianos \\
\hline $\begin{array}{l}\text { Portaria } 196 \text { de } 24 \text { de junho de } 1983 \text {. Diário Oficial da União } \\
\text { 1983; Portaria 930, de } 27 \text { de agosto de 1992. Diário Oficial da } \\
\text { União 1992; Lei 9.431, de } 6 \text { de Janeiro de 1997. Diário Oficial } \\
\text { da União, } 6 \text { de janeiro de 1997; Portaria } 2.616 \text { de } 12 \text { de maio } \\
\text { de 1998. Diário Oficial da União } 13 \text { de maio de 1998; Portaria } \\
\text { 1.133/GM, de } 6 \text { de julho de } 2005 \text { (CURAREM). }\end{array}$ & $\begin{array}{l}\text { Programas de prevenção de infecções: } \\
\text { regulamentação; comitês técnicos assessores }\end{array}$ \\
\hline $\begin{array}{l}\text { Portaria 15, de } 23 \text { de agosto de 1988; Portaria 05, de } 13 \text { de } \\
\text { junho de 1989; Portaria DTN 122, de } 29 \text { de novembro de } \\
\text { 1993; Portaria } 453 \text { de } 11 \text { de setembro de 1996; Portaria } \\
\text { 327/SNVS/MS, de } 30 \text { de julho de 1997; Portaria 843, de } 26 \\
\text { de outubro de } 1998 .\end{array}$ & Germicidas: regulamentação \\
\hline $\begin{array}{l}\text { Lei } 9.782 \text {, de } 26 \text { de janeiro de 1999. Diário Oficial da União, } \\
1999\end{array}$ & ANVISA: Criação \\
\hline Portaria Interministerial 482, de 16 de abril de 1999. & Óxido de etileno: regulamentação \\
\hline Norma Regulamentadora 32, 2005. & $\begin{array}{l}\text { Segurança e saúde no trabalho em serviço de } \\
\text { saúde }\end{array}$ \\
\hline \multicolumn{2}{|c|}{ LEGISLAÇÕES DO CHILE } \\
\hline LEGISLAÇÃO & ASSUNTO \\
\hline Circular $n^{\circ} 13-03$ de agosto de 2012 & Instuye sobre roles SICARS \\
\hline Exento $n^{\circ} 380$ de agosto 2015 & $\begin{array}{l}\text { Aprueba NT176 sobre Prohibición de uso en } \\
\text { varios pacientes de soluciones de uso } \\
\text { intravascular conservadas o transportadas en } \\
\text { envases únicos }\end{array}$ \\
\hline
\end{tabular}




\begin{tabular}{|c|c|}
\hline Norma Técnica $\mathrm{n}^{\circ} 175$, de 07 de agosto de 2015. & $\begin{array}{l}\text { Norma Técnica sobre Vigilancia Nacional de } \\
\text { Resistencia a los Antimicrobianos en agentes que } \\
\text { pueden producir Infecciones Asociadas a la } \\
\text { Atención en Salud (IAAS) }\end{array}$ \\
\hline Circular $n^{\circ} 11$ de 28 de maio de 2012 & $\begin{array}{l}\text { Vigilancia Nacional de Resistencia a los } \\
\text { antimicrobianos en bacterias que pueden producir } \\
\text { IAAS }\end{array}$ \\
\hline Circular $n^{\circ} 30,24$ de setembro de 2013 & $\begin{array}{l}\text { Normas para el manejo de brotes de diarrea por } C \\
\text { difficile }\end{array}$ \\
\hline Circular n 9 de 13 de março de 2013 & $\begin{array}{l}\text { Precauciones estándares para el control de } \\
\text { infecciones en la atención }\end{array}$ \\
\hline Ordinário C13 n 171 - 18 de janeiro de 2013 & $\begin{array}{l}\text { Modificaciones e Aclaraciones sobre la vigilancia } \\
\text { de IAAS }\end{array}$ \\
\hline Norma Técnica nº 350, de 24 de outubro de 2011. & $\begin{array}{l}\text { Programas de prevención y control de infecciones } \\
\text { asociadas a la atención en salud (IAAS) }\end{array}$ \\
\hline Norma N 124. Octubre, 2011. MINSAL & $\begin{array}{l}\text { Programa de prevención y control de infecciones } \\
\text { asociadas a la atención en salud. }\end{array}$ \\
\hline \multirow[t]{3}{*}{ Fevereiro de 2015} & $\begin{array}{l}\text { Manual del instrumento de "Evaluación de } \\
\text { elementos básicos de programas infecciones } \\
\text { asociadas a la atención en salud (IAAS) }\end{array}$ \\
\hline & $\begin{array}{l}\text { Plantilla de evaluación de elementos básicos de } \\
\text { programas de infecciones asociadas a la atención } \\
\text { en salud }\end{array}$ \\
\hline & Instrucciones para llenado de plantilla \\
\hline Ord. $n^{\circ} 1072,05$ de abril de 2012 . & $\begin{array}{l}\text { Instrucciones sobre evaluación del cumplimiento } \\
\text { de la Norma Técnica N¹24 en hospitales. }\end{array}$ \\
\hline Circular n 8 de 07 de maio de 2012 & $\begin{array}{l}\text { Indicaciones para el manejo de infecciones por } \\
\text { clostridium difficile }\end{array}$ \\
\hline Circular $n^{\circ} 3$ de 18 de fevereiro de 2011 & $\begin{array}{l}\text { Circular practicas de seguridad en la atención } \\
\text { prevención y control de infecciones virales y } \\
\text { hemodiálisis }\end{array}$ \\
\hline Circular $n^{\circ} 7$ de 02 de maio de 2011. & $\begin{array}{l}\text { Norma para la Prevención de Infecciones } \\
\text { Asociadas a modificaciones estructurales y otras } \\
\text { actividades que general polvo ambiental en } \\
\text { establecimientos Hospitalarios }\end{array}$ \\
\hline Circular $n^{\circ} 20$ de 02 de agosto de 2009 & $\begin{array}{l}\text { Medidas de prevención y control de infecciones } \\
\text { asociadas a la atención en salud en pacientes } \\
\text { hospitalizados con influenza estacional o } \\
\text { pandémica }\end{array}$ \\
\hline Circular $n^{\circ} 4$ de 05 de março de 2010 & $\begin{array}{l}\text { Normas de control de infecciones asociadas a la } \\
\text { atención en salud durante emergencias y } \\
\text { desastres }\end{array}$ \\
\hline
\end{tabular}




\begin{tabular}{|c|c|}
\hline Circular n 54, Diciembre 21 de 1995 & $\begin{array}{l}\text { Norma La Prohibición Del Uso De Jeringa Única } \\
\text { Para Varios Pacientes (Jeringas Multiuso) }\end{array}$ \\
\hline CIRCULAR 4F/ 45/ 8 de noviembre 1996 & $\begin{array}{l}\text { Complementa instrucciones para manejo de } \\
\text { pacientes con ADV }\end{array}$ \\
\hline $\begin{array}{llll}\text { CIRCULAR } & 46 & \text { /, } 15 \text { SEP } 1998\end{array}$ & $\begin{array}{l}\text { Recomendaciones y actualización de la Normativa } \\
\text { de Aislamiento de Pacientes del Programa de } \\
\text { Infecciones Intrahospitalarias }\end{array}$ \\
\hline CIRCULAR 3F/ 27 /25 de abril de 1990 & $\begin{array}{l}\text { Prohíbe el método de esterilización por gas de } \\
\text { formaldehido en ausencia de equipos e } \\
\text { instalaciones adecuadas }\end{array}$ \\
\hline CIRCULAR 3F/ 151/24 de septiembre de 1986 & $\begin{array}{l}\text { Prohíbe el método de esterilización por oxido de } \\
\text { etileno en ausencia de equipos e instalaciones } \\
\text { adecuadas }\end{array}$ \\
\hline CIRCULAR 4C/18/10 DE MAYO DE 1999 & $\begin{array}{l}\text { Normas para la prevención de transmisión } \\
\text { asociada a la atención en salud de agentes } \\
\text { etiológicos virales de infecciones respiratorias } \\
\text { agudas en pacientes pediátricos }\end{array}$ \\
\hline CIRCULAR N³F/ 189, 26 de octubre de 1987 & $\begin{array}{l}\text { Manejo de los brotes de infecciones } \\
\text { Gastrointestinales intrahospitalarias en Servicios } \\
\text { pediátricos }\end{array}$ \\
\hline CIRCULAR Nº 3H/ 132, 18 de Julio de 1983. & $\begin{array}{l}\text { Prohíbe uso material de infusión venosa } \\
\text { Desechable re-esterilizados }\end{array}$ \\
\hline Norma Técnica n 43 de 8 de outubro de 1999. & $\begin{array}{l}\text { Racionalización del uso de antimicrobianos en la } \\
\text { atención clínica }\end{array}$ \\
\hline & $\begin{array}{l}\text { Vigilancia, prevención y control de infecciones } \\
\text { intrahospitalarias por enterococos resistentes a } \\
\text { vancomicina }\end{array}$ \\
\hline Norma Técnica $n^{\circ} 95$ de 8 de maio de 2001. & $\begin{array}{l}\text { Normas de infecciones urinarias asociadas a } \\
\text { catéteres }\end{array}$ \\
\hline Norma Técnica nº 107 de 6 de fevereiro de 2009. & $\begin{array}{l}\text { Normas de prevención de endometritis } \\
\text { Norma endometritis puerperal }-1^{a} \text { parte } \\
\text { Norma endometritis puerperal }-2^{a} \text { parte }\end{array}$ \\
\hline Circular nº 8 de 26 de outubro de 2006 (atualização) & $\begin{array}{l}\text { Notificación de brotes } \\
\text { Formulario notificación de brotes } \\
\text { Circular sobre notificación de brotes IIH }\end{array}$ \\
\hline \multicolumn{2}{|c|}{ ISRAEL } \\
\hline LEGISLAÇÃO & ASSUNTO \\
\hline Circular $n^{\circ} 24 / 2009$ & Higiene das Mãos em Instituições de Saúde \\
\hline Circular $n^{\circ} 44 / 2009$ & $\begin{array}{l}\text { Diretrizes para tratamento e notificação de } \\
\text { infecções causadas por CRE/VRE }\end{array}$ \\
\hline Circular $n^{\circ} 10 / 2010$ & Precauções Padrão nos cuidados em saúde \\
\hline Circular $n^{\circ} 12 / 2011$ & Diretrizes para a prevenção de ICS/CVC \\
\hline
\end{tabular}




\begin{tabular}{|l|l|}
\hline Circular $n^{\circ} 24 / 2011$ & $\begin{array}{l}\text { Tratamento de resíduos }- \text { Pacientes em } \\
\text { Isolamento por Doenças Infecciosas }\end{array}$ \\
\hline Circular $n^{\circ} 49 / 2011$ & $\begin{array}{l}\text { Prevenção e Controle de Infecções em Instituições } \\
\text { de Saúde Comunitárias (ambulatórios e clínicas) }\end{array}$ \\
\hline Circular $n^{\circ} 09 / 2012$ & $\begin{array}{l}\text { Controle e Prevenção de Infecções e Resistência } \\
\text { Antimicrobiana nas Instituições de Saúde }\end{array}$ \\
\hline Circular $n^{\circ} 12 / 2012$ & $\begin{array}{l}\text { Diretrizes para diagnóstico laboratorial das } \\
\text { infecções causadas por Clostridium difficile }\end{array}$ \\
\hline Circular $n^{\circ} 16 / 2012$ & $\begin{array}{l}\text { Programa nacional para o uso racional de } \\
\text { antibióticos }\end{array}$ \\
\hline Circular $n^{\circ} 50 / 2013$ & $\begin{array}{l}\text { Orientações para a limpeza, desinfecção e } \\
\text { esterilização de endoscópios }\end{array}$ \\
\hline Circular $n^{\circ} 23 / 2014$ & $\begin{array}{l}\text { Como prevenir a propagação de Clostridium } \\
\text { difficile nas instituições de saúde }\end{array}$ \\
\hline Circular $n^{\circ} 39 / 2014$ & $\begin{array}{l}\text { Como prevenir a infecção do trato urinário em } \\
\text { pacientes hospitalizados }\end{array}$ \\
\hline Circular $n^{\circ} 01 / 2016$ & $\begin{array}{l}\text { Vacinação de estudantes e trabalhadores da área } \\
\text { da saúde }\end{array}$ \\
\hline
\end{tabular}




\subsubsection{Principais resultados dos Programas}

Em todos os cenários houve redução da ocorrência de infecções com a consolidação do programa. Os indicadores monitorados pelos sistemas de vigilância de cada país são diferentes e por este motivo seus resultados, em alguns critérios, não podem ser comparados (Quadro 2 e 3).

Quadro 2 - Indicadores Epidemiológicos incorporados aos Sistemas de Vigilância Epidemiológico dos Programas de Prevenção e Controle de Infecção do Brasil, Chile e Israel. São Paulo. 2018.

\begin{tabular}{|c|c|}
\hline & o \\
\hline$\bullet$ & Infecções em cesariana \\
\hline & $\begin{array}{l}\text { Infecções primárias de corrente sanguínea associadas ao uso de cateter venoso } \\
\text { central (IPCS/CVC) unidade de terapia intensiva adulto, pediátrica e neonatal }\end{array}$ \\
\hline • & $\begin{array}{l}\text { Infecções do trato urinário associadas ao uso de cateter vesical de demora (ITU/SVD) } \\
\text { em unidade de terapia intensiva adulto, pediátrica e neonatal }\end{array}$ \\
\hline & $\begin{array}{l}\text { Pneumonias associadas à ventilação mecânica (PAV) unidade de terapia intensiva } \\
\text { adulto, pediátrica e neonatal }\end{array}$ \\
\hline & $\begin{array}{l}\text { Resistência Microbiana (RM) em infecções primária de corrente sanguínea } \\
\text { associadas ao uso de cateter venoso central (IPCS/CVC) }\end{array}$ \\
\hline Indi & Sadores do Programa Chileno \\
\hline & $\begin{array}{l}\text { Infecções do trato urinário associadas ao uso de cateter vesical de demora (ITU/SVD) } \\
\text { em Unidades Clínicas, Cirúrgicas e UTI; }\end{array}$ \\
\hline & $\begin{array}{l}\text { Pneumonias associadas a ventilação mecânica (PAVM) em UTI adulto, pediátrica e } \\
\text { neonatal; }\end{array}$ \\
\hline$\bullet$ & Endometrite puerperal em parto vaginal e cesárea (e sem trabalho de parto); \\
\hline & $\begin{array}{l}\text { Infecções de corrente sanguínea associadas ao uso de cateter venoso central } \\
\text { (ICS/CVC) em pacientes adultos, pacientes pediátricos, em pacientes com NPT } \\
\text { (adulto e pediátrico), em pacientes com cateter umbilical permanente, em } \\
\text { neutropênicos (adultos e pediátricos), e em cateter central para hemodiálise. }\end{array}$ \\
\hline & $\begin{array}{l}\text { Infecções intestinais em lactantes, em neonatologia, em pacientes adultos com } \\
\text { nutrição enteral; }\end{array}$ \\
\hline & $\begin{array}{l}\text { Infecções de Sítio Cirúrgico (ISC) em colecistectomia laparoscópica, colecistectomia } \\
\text { por laparotomia, intervenções de hérnia inguinal adulto e infantil, em cesáreas, } \\
\text { neurocirurgias por causas tumorais, by-pass coronário, prótese de quadril, }\end{array}$ \\
\hline
\end{tabular}




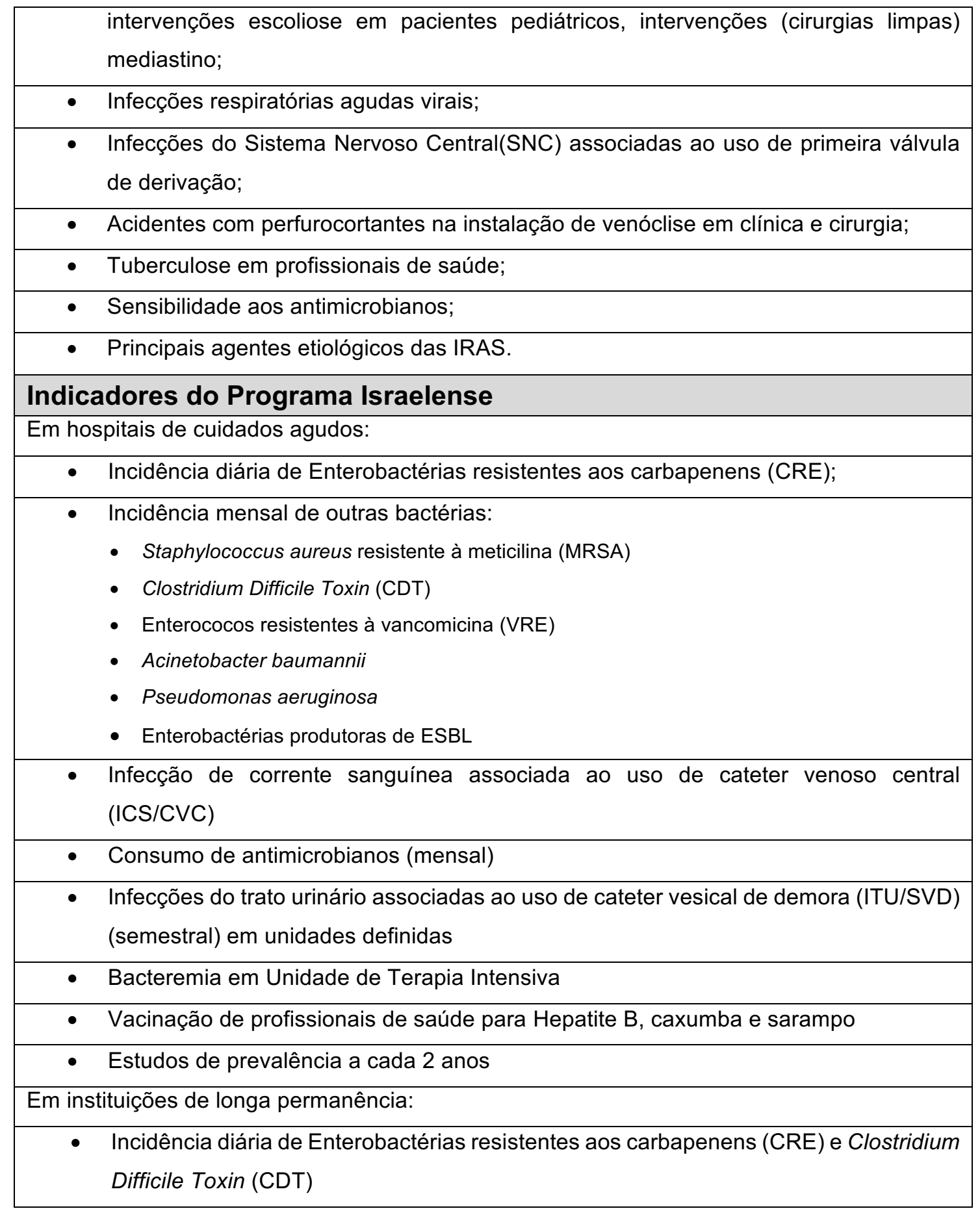

Os principais resultados brasileiros já alcançados englobam redução das Infecções de corrente sanguínea (ICS) entre 2011 a 2015 (22,9\% em UTI adulto; 22\% em UTI Pediátrica; redução em todas as categorias de peso ao nascer em UTI neonatal) (Anvisa, 2016a).

No Chile, a análise de impacto aponta redução das taxas de infecção entre 18 e $70 \%$ nos anos 2000 a 2009, evidenciando a eficácia do programa em hospitais de médio e grande porte (redução de $70 \%$ nas infecções em colecistectomia por 
laparoscopia/ 65\% nas infecções intestinais em lactantes; 58,4\% nas endometrites puerperais por partos vaginais; $32,4 \%$ nas infecções da corrente sanguínea em pediatria, entre outros) (Chile, 2017).

Os resultados do programa israelense apontam redução da ocorrência de enterococos resistentes a carbapenêmicos em torno de $60 \%$ nos primeiros cinco anos da estratégia (2007-2012). Segundo a equipe do programa, a capacidade de atingir resultados significativos em pouco tempo esteve relacionada principalmente a intervenção centralmente coordenada, a emissão de guias técnicos e diretrizes obrigatórias, o monitoramento periódico pelo sistema nacional, a atribuição de responsabilidade aos gestores hospitalares, a retroalimentação dos resultados e a visitas programadas (Schwaber e Carmeli, 2014), 
Quadro 3 - Conteúdo sumarizado dos Programas Nacionais de Prevenção e Controle de Infecção no Brasil, Chile e Israel, segundo os elementos: objetivos, foco, equipe, atividades e resultados. São Paulo. 2018.

\begin{tabular}{|c|c|c|c|c|c|}
\hline \multirow{2}{*}{ País } & \multicolumn{5}{|c|}{ Elementos do Programa } \\
\hline & OBJETIVOS & FOCO & EQUIPE & PRINCIPAIS ATIVIDADES & RESULTADOS \\
\hline 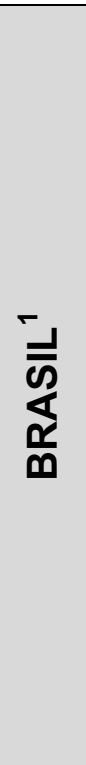 & $\begin{array}{l}\checkmark \text { Reduzir a incidência de IRAS nos } \\
\text { serviços de saúde; } \\
\checkmark \text { Objetivos específicos do período } \\
\text { (2016-2020): consolidar o sistema } \\
\text { nacional de vigilância de IRAS, reduzir } \\
\text { nacionalmente a incidência de IRAS } \\
\text { prioritárias, prevenir e controlar } \\
\text { nacionalmente a disseminação da } \\
\text { resistência microbiana no nível nacional } \\
\text { e consolidar o programa nacional. }\end{array}$ & $\begin{array}{c}\text { Hospitais de } \\
\text { cuidados } \\
\text { agudos. }\end{array}$ & $\begin{array}{c}\checkmark \text { Sete } \\
\text { profissionais } \\
\text { especialistas, } \\
\text { que incluem } \\
\text { enfermeiros, } \\
\text { farmacêuticos e } \\
\text { estatístico. }\end{array}$ & $\begin{array}{l}\checkmark \text { Publicação de guias técnicos e } \\
\text { normativas } \\
\checkmark \text { Operacionalização do Sistema } \\
\text { nacional de vigilância de IRAS - } \\
\text { monitoramento e avaliação contínua de } \\
\text { resultados; } \\
\checkmark \text { Assessoria às comissões estaduais } \\
\text { para a implantação das ações de } \\
\text { prevenção e controle de IRAS. } \\
\checkmark \text { Retroalimentação aos hospitais por } \\
\text { meio de relatórios com os resultados dos } \\
\text { dados do sistema de vigilância } \\
\text { epidemiológica }\end{array}$ & $\begin{array}{l}\text { Entre os anos de } 2011 \text { a } 2015 \\
\checkmark \quad \downarrow 22,9 \% \text { das Infecções de } \\
\text { corrente sanguínea (ICS) nas UTI } \\
\text { adulto; } \\
\checkmark \quad \downarrow 22,0 \% \text { das Infecções de } \\
\text { corrente sanguínea (ICS) nas UTI } \\
\text { Pediátrica; } \\
\checkmark \quad \downarrow \text { das Infecções de corrente } \\
\text { sanguínea (ICS)em todas as } \\
\text { categorias de peso ao nascer em } \\
\text { UTI neonatal). }\end{array}$ \\
\hline
\end{tabular}




\begin{tabular}{|c|c|c|c|c|c|}
\hline & $\begin{array}{l}\checkmark \text { Contribuir para melhorar a qualidade } \\
\text { da atenção hospitalar por meio da } \\
\text { diminuição da ocorrência de IRAS, } \\
\text { infecções que se transmitem entre } \\
\text { pacientes e profissionais de saúde e } \\
\text { custos associados; } \\
\checkmark \text { Objetivos específicos: reduzir a } \\
\text { incidência de IRAS associadas a } \\
\text { procedimentos invasivos, surtos } \\
\text { epidêmicos e exposição ocupacional; } \\
\text { reduzir a transmissão de infecção } \\
\text { ocupacional; elevar a eficiência e } \\
\text { sensibilidade do sistema de vigilância e } \\
\text { custo-benefício das atividades de } \\
\text { prevenção e controle; e reduzir dos } \\
\text { custos associados às IRAS. }\end{array}$ & $\begin{array}{l}\text { Estabelecime } \\
\text { ntos de saúde } \\
\text { que prestam } \\
\text { assistência } \\
\text { direta ao } \\
\text { paciente } \\
\text { (hospitais e } \\
\text { clínicas) }\end{array}$ & $\begin{array}{c}\checkmark \text { Dois } \\
\text { médicos e duas } \\
\text { enfermeiras }\end{array}$ & $\begin{array}{l}\checkmark \text { Publicação de guias técnicos e } \\
\text { normativas } \\
\checkmark \quad \text { Sistema nacional de vigilância de } \\
\text { IRAS - monitoramento e avaliação } \\
\text { contínua de resultados; } \\
\checkmark \text { Avaliação da sensibilidade da } \\
\text { vigilância por meio de estudos pontuais de } \\
\text { prevalência; } \\
\checkmark \quad \text { Treinamento e atividades educativas } \\
\text { para profissionais de saúde; } \\
\checkmark \text { Avaliação das práticas de atenção por } \\
\text { meio de um sistema de avaliação externo } \\
\text { regulamentado, pelo menos a cada } 3 \text { anos } \\
\text { nos hospitais públicos e privados.; } \\
\checkmark \text { Elaboração de relatórios com os } \\
\text { resultados dos hospitais. }\end{array}$ & $\begin{array}{l}\text { Entre os anos de } 2000 \text { a 2009: } \\
\checkmark \quad \downarrow 70,0 \% \text { nas infecções em } \\
\text { colecistectomia por laparoscopia; } \\
\checkmark \quad \downarrow \quad 65,0 \% \quad \text { nas infecções } \\
\text { intestinais em lactantes; } \\
\checkmark \quad \downarrow \quad 58,4 \% \text { nas endometrites } \\
\text { puerperais por partos vaginais; } \\
\checkmark \quad \downarrow \quad 32,4 \% \text { nas infecções da } \\
\text { corrente sanguínea em pediatria. }\end{array}$ \\
\hline
\end{tabular}




\begin{tabular}{|c|c|c|c|c|c|}
\hline 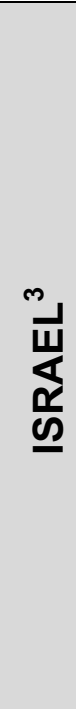 & $\begin{array}{l}\checkmark \text { Controlar e prevenir IRAS e conter a } \\
\text { resistência microbiana em todos os } \\
\text { serviços de saúde de Israel. }\end{array}$ & $\begin{array}{l}\text { Hospitais de } \\
\text { cuidados } \\
\text { agudos e de } \\
\text { longa } \\
\text { permanência. }\end{array}$ & $\begin{array}{c}\checkmark \text { Médicos, } \\
\text { enfermeiros, } \\
\text { epidemiologista } \\
\text { s, } \\
\text { microbiologistas } \\
\text { e equipe de } \\
\text { suporte de } \\
\text { dados }\end{array}$ & $\begin{array}{l}\checkmark \text { Publicação de guias técnicos e } \\
\text { normativas } \\
\checkmark \text { Sistema nacional de vigilância de IRAS } \\
\text { e resistência microbiana - monitoramento } \\
\text { e avaliação contínua de resultados; } \\
\checkmark \quad \text { Treinamento e atividades educativas } \\
\text { para profissionais de saúde; } \\
\checkmark \text { Avaliação das práticas de atenção in } \\
\text { loco, com visita periódica em hospitais } \\
\text { selecionados a cada ano; } \\
\checkmark \text { Elaboração de relatórios com os } \\
\text { resultados dos hospitais. }\end{array}$ & $\begin{array}{l}\text { Entre os anos de } 2007 \text { a 2012: } \\
\checkmark \quad \downarrow \quad 60 \% \text { na incidência de } \\
\text { enterococos resistentes a } \\
\text { carbapenêmicos. } \\
\checkmark \quad \downarrow 91 \% \text { da aquisição de hospitalar } \\
\text { de enterococos resistentes a } \\
\text { carbapenêmicos por meio cultura } \\
\text { clínica de } 55.5 \text { casos/100,000 } \\
\text { pacientes-dia } \\
\text { casos/100,000 pacientes-dia. }\end{array}$ \\
\hline
\end{tabular}

Fonte:

1 Agência Nacional de Vigilância Sanitária - Boletim Informativo Segurança do Paciente e Qualidade em Serviços de Saúde - Dados 2015. Website: http://www20.anvisa.gov.br/segurancadopaciente/

2 Documento Oficial - Ministério da Saúde do Chile - Norma n¹24, Outubro, 2011 - Programa de Controle e Prevenção de Infecção Website: http://web.minsal.cl/infecciones_intrahospitalarias/

3 Schwaber MJ, Carmeli Y. An ongoing national intervention to contain the spread of carbapenem-resistant enterobacteriaceae. Clin Infect Dis. 2014;58(5):697-7. Documento Oficial - Ministério da Saúde de Israel - Circular 09/2012 - Control and Prevention of Infections and Antimicrobial Resistance in Health Institutions. Documento Oficial - Ministério da Saúde de Israel - Circular 16/2012 - National Program for the Rational Use of Antibiotics. 


\subsection{PAREAMENTO DE CASOS: ELEMENTOS DAS POLITICAS PÚBLICAS PARA IRAS}

O ensaio de pareamento aqui realizado tem finalidade puramente analítica, visando o reconhecimento de padrões de formação e desenvolvimento dos programas. Com a organização dos dados pode-se perceber que os acontecimentos não ocorreram de forma linear entre os países. No entanto, atores e elementos comuns na formação e desenvolvimento do programa governamental foram identificados em todos os casos (Quadro 4 e 5).

Dentro da perspectiva de formação do programa, foram identificados alguns elementos comuns que tornaram o programa necessário dentro da perspectiva governamental, como: as hiperendemias, os surtos e a presença de eventos sentinelas, relacionados às IRAS (ex.: morte de um presidente eleito). Estes elementos ficaram subordinados a proposição de alternativas para solucioná-los. Estas alternativas foram projetadas por lideranças no âmbito do controle de infecção, com arsenal técnico para elaborar as propostas. Estes elementos nortearam a proposição de alternativas para a formação dos programas que foram projetadas com embasamento técnico por lideranças no âmbito do controle de infecção.

Interligando estes elementos, para que o programa de fato ingressasse na agenda governamental, um ambiente político foi demandado. Nos casos analisados, a ênfase dada pela mídia, a abertura dos órgãos do estado e o estímulo das organizações internacionais contribuiu favoravelmente para a formação deste ambiente.

A mídia explicitou um problema oculto, trazendo visibilidade social ao mesmo no Brasil e no Chile. Esta evidência pública do problema pressionou os órgãos governamentais para a intervenção. Ou seja, o destaque da mídia teve papel de influência para despertar a atenção das pessoas para o problema.

A base técnica e científica da equipe do programa foi um fator considerável para sua formação e desenvolvimento. Nos casos analisados, este conhecimento foi essencialmente gerado por meio de experiências externas ou apoio de agências externas. O uso de ferramentas de diagnóstico situacional esteve presente em momentos distintos, entretanto, quando aplicado alavancou atividades do programa. 
O envolvimento de outros níveis governamentais, complexo em nações com grande dimensão territorial, se deu de forma desigual devido à variação da situação nos diversos estados e municípios. Todavia, sem a participação destes interlocutores, a disseminação local da estratégia adotada no âmbito nacional poderia ser prejudicada.

Para a manutenção do programa, o engajamento da equipe nacional e a percepção de reconhecimento desta equipe pelos demais profissionais de prevenção e controle de IRAS foram substanciais para a legitimização das intervenções propostas. A permanência das lideranças durante tempo suficiente para consolidar esta percepção favoreceu o processo para o alcance dos objetivos em médio o longo prazo. Chile e Israel mantiveram suas lideranças desde o início do programa, mantendo uma tendência na gestão do programa. No Brasil, esta manutenção de liderança só veio ocorrer na última década, período em que houve aprimoramento do programa.

Igualmente, a formação de comissões nacionais e regionais com membros representantes da sociedade civil e do governo, somada às coalizões entre níveis governamentais foram elementos de suporte ao programa. As comissões, com participação de especialistas, assessoraram as decisões do programa, legitimando as propostas de intervenções. Enquanto as coalizões criaram canais de comunicação e apoio.

A estruturação de sistemas de vigilância epidemiológica constituiu um núcleo de sustentação do programa, permitindo acompanhar e discutir resultados. Em todos os cenários, quando a vigilância de IRAS se tornou sistemática, foi possível analisar fragilidades e oportunidades de melhoria. Em complemento, a provisão de capacitação permanente para profissionais dos hospitais e de outros níveis de governo pode ter contribuído na mitigação das fragilidades e no avanço do programa. Ainda nesse cenário, outros elementos também se destacaram, como: capacidade de auto avaliação dos programas, que se manifestou por meio da análise sistemática dos dados epidemiológicos; a avaliação de desempenho do sistema de vigilância e do programa; e a atualização das legislações. Estes elementos foram inseridos de forma diferente nos três países, à medida que os programas adquiriram maturidade. A auto avaliação já é reconhecida pela OMS como um componente essencial dos programas de controle e prevenção de IRAS (Allegranzi et al., 2011). 
Atores, grupos sociais e organizações foram essenciais no desenvolvimento dos programas (Quadro 4). No modelo de análise do triângulo de políticas de saúde, os atores ocupam posição central no desenvolvimento de uma estratégia e os papéis que desempenham na arena política pode influenciar positivamente ou negativamente seu progresso (Walt e Gilson, 1994). 
Quadro 4 - Principais atores envolvidos na elaboração dos programas nacionais de prevenção e controle de infecções relacionadas à assistência à saúde (IRAS) no Brasil, Chile e Israel. São Paulo. 2018.

\begin{tabular}{|c|c|c|}
\hline & & \\
\hline $\begin{array}{l}\text { 1) Mídia - Enfatizando a morte do presidente eleito } \\
\text { em decorrência de IRAS; } \\
\text { 2) Ministério da Saúde -responsável pelas } \\
\text { primeiras decisões e ações do programa nacional; } \\
\text { 3) ANVISA' - órgão do governo que assumiu a } \\
\text { coordenação do programa no fim da década de } \\
\text { 1990 até os dias atuais; } \\
\text { 4) CNCIRAS }{ }^{j} \text { - comissão nacional composta por } \\
\text { membros da sociedade civil e do governo } \\
\text { responsável pelas principais decisões do programa } \\
\text { na ultima década; } \\
\text { 5) CECIRAS }{ }^{k} \text { - comissões estaduais responsáveis } \\
\text { por coordenar, acompanhar e avaliar as ações do } \\
\text { programa nacional no âmbito regional. } \\
\text { 6) OPAS/OMS' - pressionou as primeiras ações do } \\
\text { programa e assessora melhorias para o programa. }\end{array}$ & $\begin{array}{l}\text { 1) Mídia - reforçou a existência de surtos em } \\
\text { algumas regiões do Chile destacando o problema } \\
\text { no país; } \\
\text { 2) Ministério da Saúde - responsável pelas } \\
\text { primeiras decisões e ações do programa nacional; } \\
\text { 3) Liderança do } \mathrm{PNCl}^{\mathrm{m}} \text { - uma liderança médica } \\
\text { coordenou as ações do programa desde a década } \\
\text { de } 1980 \text {; } \\
\text { 4) OPAS/OMS }{ }^{\text {d- }} \text { assessorou as primeiras ações do } \\
\text { programa e melhorias para o programa. } \\
\text { 5) Sociedade Chilena de Controle de Infecção e } \\
\text { Epidemiologia Hospitalar - contribuiu para a } \\
\text { promoção e difusão das boas práticas de } \\
\text { prevenção e controle de infecção regulamentadas } \\
\text { pelo programa. }\end{array}$ & $\begin{array}{l}\text { 1) Associações de Médicos Infectologistas e } \\
\text { Enfermeiros Controladores de Infecção - formou } \\
\text { uma base de profissionais qualificados e } \\
\text { atualizados para atuar em torno do problema. } \\
\text { 2) Comunidade de Médicos Infectologistas - redigiu } \\
\text { um documento para a autoridade nacional } \\
\text { apresentando o problema e motivando a criação de } \\
\text { uma força tarefa nacional; } \\
\text { 3) Diretor Geral do Ministério da Saúde - abertura } \\
\text { política para a implantação do programa nacional; } \\
\text { 4) Ministério da Saúde - responsável pelas } \\
\text { primeiras decisões e ações do programa nacional; } \\
\text { 5) Equipe e liderança do PNCl - uma equipe } \\
\text { especializada coordenou as ações do programa, } \\
\text { liderada por dois médicos; } \\
\text { 6) Profissionais das Comissões de Controle de } \\
\text { Infecção - participantes das decisões do programa; }\end{array}$ \\
\hline
\end{tabular}

\footnotetext{
${ }^{i}$ ANVISA - Agência Nacional de Vigilância Sanitária

${ }^{\mathrm{j}}$ CNCIRAS - Comissão Nacional de Prevenção e Controle de Infecção Relacionada à Assistência à Saúde

${ }^{k}$ CECIRAS - Comissão Estadual de Prevenção e Controle de Infecção Relacionada à Assistência à Saúde

' OPAS - Organização Pan-Americana da Saúde e OMS - Organização Mundial da Saúde

${ }^{\mathrm{m}} \mathrm{PNCl}$ - Programa Nacional de Controle de Infecção
} 
Nos cenários apresentados, alguns atores foram comuns: o Ministério da Saúde, como órgão responsável por conduzir as primeiras decisões e ações do programa nacional, uma liderança qualificada com equipe coordenada e as associações profissionais de especialistas em IRAS que contribuíram para a promoção e difusão das boas práticas de prevenção e controle de infecção.

No Chile e em Israel, toda coordenação do programa esteve sob a égide do Ministério da Saúde desde seu início até os dias atuais. Enquanto no Brasil, esta responsabilidade transitou para outro órgão regulatório que é a ANVISA. No Brasil e no Chile, a OPAS foi ator importante por meio do apoio a eventos de indução ao debate sobre IRAS e programas de treinamento estruturados.

No contexto brasileiro, as Comissões Nacional e Estaduais de IRAS, formadas por membros da sociedade civil e do governo, também tiveram um papel fundamental norteando decisões do programa no âmbito nacional e regional. Este papel, em Israel, foi exercido por profissionais das Comissões de Controle de Infecção que, como membros da sociedade civil, participaram ativamente nas decisões do programa.

Ao agrupar os elementos mencionados acima, foram identificados os componentes de dois núcleos estruturais dos programas nos países estudados: os núcleos de criação e de desenvolvimento e sustentabilidade (Quadro 5 e Figura 7).

\subsection{UM MODELO TEÓRICO-EXPLICATIVO}

A analise detalhada dos elementos identificados, seguidos de leitura e discussões para interpretá-los permitiu formar categorias com componentes comuns aos processos de formação e desenvolvimento e sustentabilidade dos programas em dois núcleos estruturais (Quadro 5). 
Quadro 5 - Núcleos, componentes e elementos de formação e desenvolvimento dos programas nacionais de prevenção e controle de infecções relacionadas à assistência à saúde (IRAS), proposto pelos autores. São Paulo. 2018.

\begin{tabular}{|c|c|c|c|}
\hline \multicolumn{2}{|c|}{ NÚCLEOS } & COMPONENTES & ELEMENTOS \\
\hline \multirow{3}{*}{ 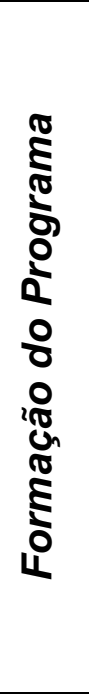 } & \multirow{3}{*}{ 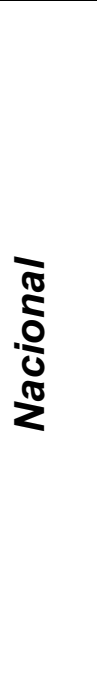 } & $\begin{array}{c}\text { Gerador } \\
\text { de } \\
\text { necessidade }\end{array}$ & $\begin{array}{l}\text { - Surtos } \\
\text { - Hiperendemias de IRAS } \\
\text { - Eventos Sentinelas (óbitos por IRAS) - óbito de celebridades }\end{array}$ \\
\hline & & $\begin{array}{c}\text { Formador } \\
\text { de Alternativas }\end{array}$ & $\begin{array}{l}\text { - Liderança motivada } \\
\text { - Disponibilidade de profissionais especializados } \\
\text { - Acesso à formação específica em controle e prevenção de IRAS } \\
\text { - Associações de Profissionais de Prevenção e Controle de } \\
\text { Infecções }\end{array}$ \\
\hline & & $\begin{array}{l}\text { Promotor } \\
\text { do Interesse } \\
\text { Social }\end{array}$ & $\begin{array}{l}\text { - Organizações Internacionais } \\
\text { - Associações Profissionais de Controle de Infecções } \\
\text { - Mídia } \\
\text { - Órgãos do Estado } \\
\text { - Ambiente Político }\end{array}$ \\
\hline \multirow{4}{*}{ 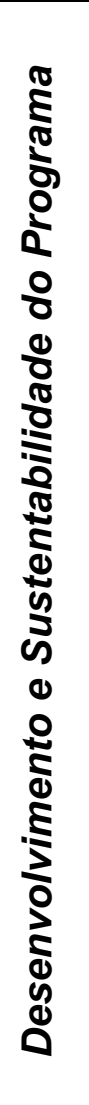 } & \multirow{4}{*}{ 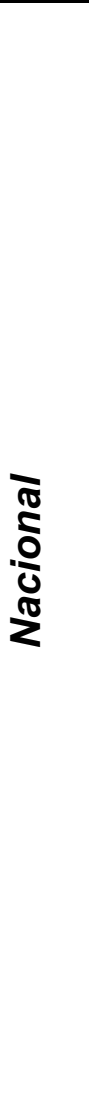 } & $\begin{array}{c}\text { Gerador } \\
\text { de Decisão }\end{array}$ & $\begin{array}{l}\text { - Disponibilidade de profissionais especializados } \\
\text { - Diagnóstico situacional do contexto de aplicação do programa } \\
\text { - Articulação entre os níveis governamentais } \\
\text { - Envolvimento de outros seguimentos da sociedade (Ex.: } \\
\text { associações profissionais, membros da sociedade civil, entre outros) }\end{array}$ \\
\hline & & $\begin{array}{c}\text { Gerador } \\
\text { de Sustentação }\end{array}$ & $\begin{array}{l}\text { - Liderança Motivada } \\
\text { - Legitimidade dos profissionais do controle e prevenção de infecção } \\
\text { - Comissões com representantes da sociedade civil e do governo } \\
\text { - Estabelecimento de coalizões entre níveis governamentais } \\
\text { - Sistemas de Vigilância Epidemiológica } \\
\text { - Recursos para a capacitação profissional permanente } \\
\text { - Divulgação dos resultados do programa }\end{array}$ \\
\hline & & $\begin{array}{c}\text { Gerador } \\
\text { de Renovação }\end{array}$ & $\begin{array}{l}\text { - Análise sistemática de resultados e divulgação de relatórios } \\
\text { - Avaliação das propriedades do sistema de vigilância } \\
\text { - Avaliação do desempenho dos serviços de saúde } \\
\text { - Atualização das legislações específicas } \\
\text { - Avaliação sistemática do programa nacional }\end{array}$ \\
\hline & & $\begin{array}{c}\text { Patrocinadores } \\
\text { do Processo }\end{array}$ & $\begin{array}{l}\text { - Líderes do Programa Nacional } \\
\text { - Profissionais especializados em prevenção e controle de infecção } \\
\text { - Associações Profissionais } \\
\text { - Organizações Internacionais } \\
\text { - Órgãos do Estado }\end{array}$ \\
\hline
\end{tabular}

Os elementos organizados revelaram dois núcleos que, embora estejam apresentados separadamente, são congruentes. O núcleo de formação do programa é composto por três componentes estratégicos que norteiam esta fase: necessidade, 
alternativas e interesse social. O núcleo de desenvolvimento e sustentabilidade por outros quatro componentes: decisão, sustentação, renovação e patrocinadores.

A partir desta relação, um modelo de interpretação foi desenhado, considerando duas dimensões: uma teórica e outra explicativa (Arredondo e Meléndez, 1992; Walt e Gilson, 1994; Weiss, 1997; Trostle et al., 1999; Elias e Patroclo, 2005; Oliveira e Teixeira, 2013). O principal fundamento do modelo foi trazer compreensão e assinalar a correlação entre as categorias temáticas identificadas na análise dos casos, delineando alternativas para a elaboração destes programas em outros cenários.

A dimensão teórica contempla dois eixos: a definição do problema e as condições mínimas para solucioná-lo. Neste sentido, recomendações baseadas em evidências foram consideradas, justificando a necessidade do programa e os componentes essenciais à sua composição. O presente estudo não se propõe a aprofundar nesta dimensão, uma vez que a OMS já conduziu um extenso trabalho para esta definição (Allegranzi et al., 2011). Contudo, apesar de sua contribuição com estes guias técnicos, não se aprofundou na condição política de desenvolvimento dos programas.

Em vista disso, a dimensão explicativa incorpora um eixo estratégico e outro sistêmico que englobam aspectos da incorporação do modelo em cada contexto (Figura 7), correlacionado com as fases de formação, consolidação, padronização, monitoramento \& avaliação dos programas (Padoveze et al., 2017). A dimensão explicativa do modelo foi construída a partir dos casos paradigmáticos estudados. Esta dimensão contempla outros dois eixos: um estratégico representado pelos núcleos e componentes identificados em convergência com a dimensão teórica; e outro sistêmico que circunda o eixo estratégico e engloba a incorporação do modelo no sistema de saúde. 
Figura 7 - Modelo Teórico Explicativo da formação dos Programas Nacionais de Prevenção e Controle de infecções relacionadas à assistência à saúde (IRAS). São Paulo. 2018.

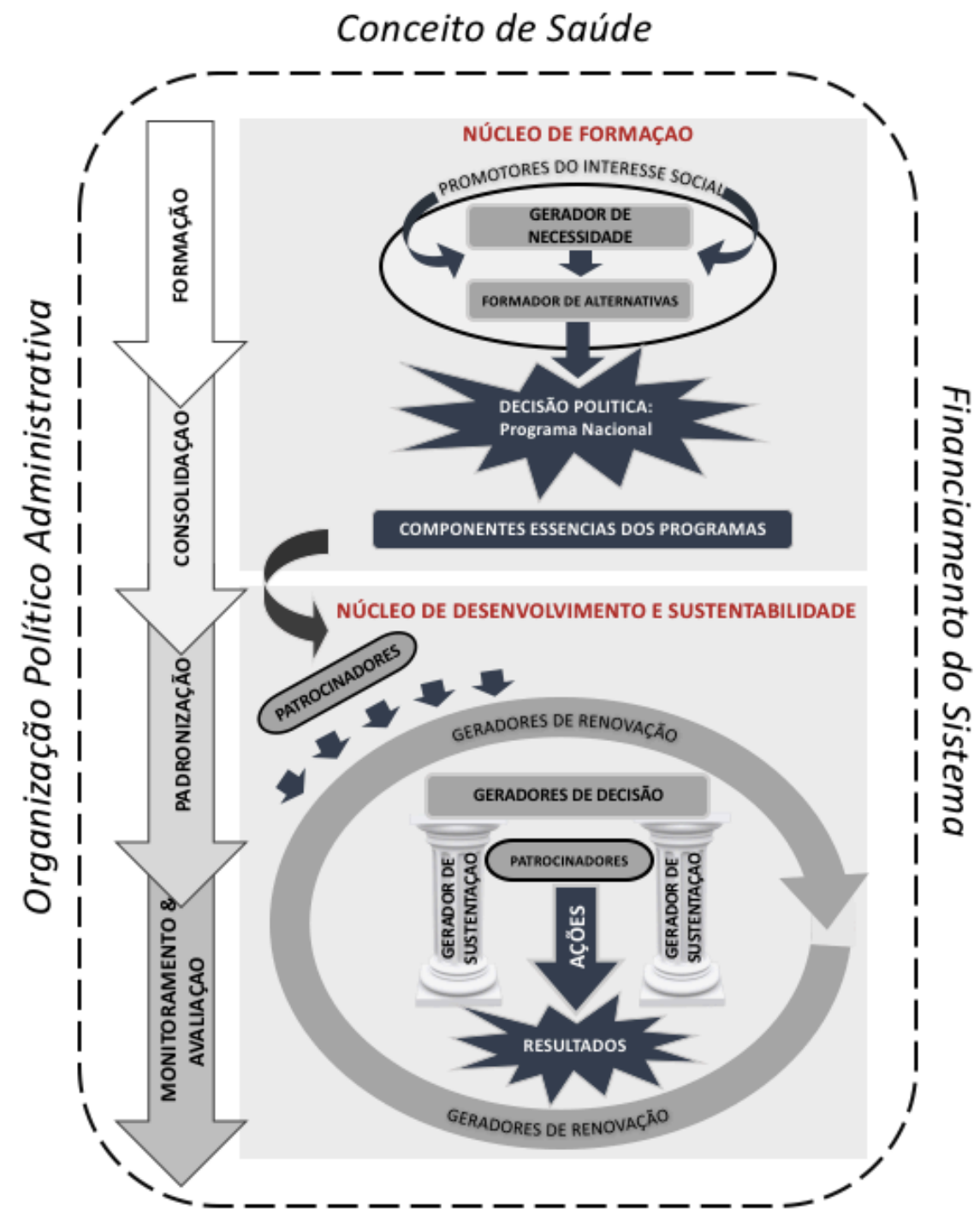

Nota: Entende-se como componentes essenciais dos programas de prevenção e controle de infecção aqueles recomendados pela Organização Mundial da Saúde (OMS). Storr J, Twyman A, Zingg W, Damani N, Kilpatrick C, Reilly J, et al. Core components for effective infection prevention and control programmes: new WHO evidence-based recommendations. Antimicrob Resist Infect Control. 2017; 6:6.

No núcleo de formação estão dispostos três componentes: no centro o gerador de necessidade, que tem relação direta com o reconhecimento do problema, e o formador de alternativas, que impulsionam oportunidades para solucionar o problema; estes dois componentes são influenciados pelos promotores do interesse social, que podem fomentar um ambiente politicamente favorável para a instalação do programa. Ainda neste núcleo, está vinculada a dimensão teórica do modelo, esta dimensão traz 
a base técnica operacional para a definição do problema e os componentes técnicos essenciais de formação dos programas (Storr et al., 2017).

No núcleo de desenvolvimento e sustentabilidade estão dispostos outros quatro componentes estratégicos. Na parte central do núcleo estão os geradores de decisão, elementos que norteiam a definição de metas e objetivos do programa, direcionando as ações. Em paralelo com as ações estão os geradores de sustentação, que suportam as iniciativas implementadas em busca de resultados. Na ausência destes, o programa pode enfraquecer e ser extinto. Circundando as ações e resultados, estão os geradores de renovação que dão condições para a análise do programa e seus impactos.

Ainda no núcleo de desenvolvimento e sustentabilidade, se encontram os patrocinadores do processo. Os patrocinadores são aqueles atores, grupos sociais ou organizações que assumem responsabilidade no seguimento do programa. São figuras que dentro dos mais variados interesses, ajudam a formar geradores de decisão, sustentação e renovação, podendo produzir pressão interna e externa para as ações do programa.

Esta distinção entre o núcleo de formação e o núcleo de desenvolvimento e manutenção é apenas um recorte didático para facilitar a compreensão do modelo, uma vez que na vida real os processos existem em forma de continuum e o fluxo das ocorrências não possui linearidade perfeita. No decurso temporal, este esquema de interpretação pode permitir a análise da maturidade do programa, considerando em paralelo as fases propostas por Padoveze et al. (2017) (formação, consolidação, padronização e monitoramento \& avaliação) (Padoveze et al., 2017).

A dimensão sistêmica complementa o modelo abordando a incorporação deste dentro do sistema de saúde. Ou seja, faz referência às relações sistemáticas do modelo com o sistema de saúde do país e com sua conjuntura econômica e política. Neste ângulo, são destacados elementos que podem também influenciar a efetivação do modelo. Neste sentido, três funções relevantes podem influenciar a organização dos programas de prevenção e controle de IRAS em um sistema de saúde:

a) Conceito de Saúde - historicamente, a formação deste conceito é o eixo organizador das práticas de atenção em saúde (Akerman et al., 2013). Os programas governamentais são respostas a sociedade para suas necessidades de saúde. As práticas, prestadores e usuários do sistema serão influenciados pela concepção sócio 
histórica de saúde, norteando o seu modelo de assistência e a regulação do sistema. Neste sentido, as ações do programa podem ser interpretadas, organizadas e potencializadas de maneira diferente, dependendo do cenário em que este se instala e dos mecanismos reguladores constituídos pelo Estado. O cuidado em saúde é interpretado com um direito nos três países. Contudo, variações desta interpretação foram percebidas, principalmente no âmbito da esfera privada, que pode comercializálo e tratá-lo com um produto.

b) Organização Político Administrativa (modelo de gestão) - a organização administrativa do Estado determina a organização estrutural do poder dentro da esfera governamental. Esta estrutura confere diferente grau de autonomia aos membros do executivo e legislativo, atribuindo e restringindo competências nas definições das políticas públicas (Bucci, 1997). Deste modo, as iniciativas dos programas governamentais serão influenciadas e ficarão condicionadas ao número de interlocutores dispostos, ao grau de autonomia atribuído a eles e sua consequente integração ou fragmentação. Variações na estrutura administrativa foram observadas nos três países: ora favorecendo a progressão do programa, ora dificultando a mesma.

c) Financiamento - para ultrapassar as barreiras postas são imprescindíveis adequar a estrutura econômico financeira para suportar as atividades do programa. À vista disso, o tipo de sistema de saúde determina a amplitude de sua atuação (sistemas universais ou segmentados). É necessário revisar as relações e atividades estabelecidas, unificar práticas comuns, e potencializar ações com alto impacto e baixo custo, limitando gastos desnecessários (Mendes e Marques, 2009; Louis, 2012). Um programa estruturado de forma adequada pode reduzir custos e ampliar o acesso ao sistema. Um grande desafio para a garantia da sustentabilidade do sistema. A discussão sobre investimentos foi fator apontado como essencial por todas as lideranças. 


\section{DISCUSSÃO}

A organização de um sistema de saúde expressa em grandes linhas os valores, a disponibilidade de recursos e as opções políticas de uma nação. A comparação destes sistemas e suas estratégias políticas revelam similaridades e fenômenos decorrentes da história e do desenvolvimento de cada país que podem colaborar com a compreensão da organização dos seus serviços e práticas de saúde (Conill, 2006). O modelo teórico-explicativo proposto no presente estudo não se propõe a ser definitivo, mas sim uma contribuição para o adensamento na reflexão sobre as políticas públicas de IRAS, tendo como elementos o estudo de caso dos países avaliados.

O contexto em que os programas nacionais se formaram sugerem distintas "razões" que impulsionaram sua entrada na agenda do governo e consequente formação. Nos casos analisados, três principais grupos de elementos associados, tornaram possível a entrada desta estratégia na agenda governamental: a evidência do problema, destacando as IRAS por meio da ocorrência de surtos e óbitos de celebridades; a oportunidade de alternativas para combatê-lo; e o apoio as iniciativas, tornando-as viáveis.

Kingdon (1984) defende que as decisões públicas são sujeitas a convergências de três fatores: o problema, as soluções e o contexto político, que quando se encontram produzem uma "janela política" que possibilita a estruturação destas ações (Buse et al., 2012; Nascimento Neto et al., 2015). A entrada de um problema na agenda governamental e a construção de uma possível intervenção devem ser dotados de legitimidade, viabilidade e suporte (Hall et al., 1975; Buse et al., 2012). Independente do cenário, as decisões públicas ficarão sujeitas a visibilidade do problema, a proposição de intervenções e a abertura política para seu desenvolvimento.

A mídia reforçou o problema, dando visibilidade ao mesmo no âmbito público. Estudiosos destacam que a mídia pode não ser capaz de moldar a forma como as pessoas pensam, mas tem um papel fundamental e grande influência no tocante aos assuntos que despertam a atenção destas pessoas (Capella et al., 2015; Mccombs e Shaw, 2017). 
O governo é influenciado por diferentes atores e grupos que possuem o poder de forma diferenciada, podendo penetrar no sistema político e exercer influência na tomada de decisão de acordo com preferências e interesses (Buse et al., 2012). Estes atores fomentam a relevância do problema de ordem pública, potencializando a captação de recursos para as primeiras alternativas, ampliando a visibilidade do problema e mobilizando o governo para seu manejo. Neste sentido, promotores do interesse social apresentam um papel fundamental. Estes atores fomentam a relevância do problema de ordem pública, potencializando a captação de recursos para as primeiras alternativas.

Com a entrada na agenda do governo, a disponibilidade de informações e o conhecimento técnico científico de profissionais em posições estratégicas foram pontos comuns que influenciaram a tomada de decisão. Programas de capacitação e intercâmbio com outros profissionais e serviços propiciam a formação de massa crítica em torno do problema, favorecendo tanto a identificação de sua magnitude quanto a proposição de alternativas (Lasswell, 1956.; Secchi, 2010; Costa e Silva, 2016).

A definição de alternativas é fortemente influenciada pela capacidade técnica da equipe que a conduz e pela clareza do problema que se pretende atacar (Lasswell, 1956.; Secchi, 2010; Costa e Silva, 2016). A oportunidade de informações, embora não determinante de uma política pública, contribui para embasar decisões e direcionar o desenvolvimento de ações (Capella, 2007; Capella et al., 2015).

A oportunidade de informações, embora não determinante de uma política pública, embasa ações e norteia o seu desenvolvimento (Capella, 2007; Capella et al., 2015). No âmbito das políticas públicas, o reconhecimento das causas de um problema não é uma tarefa tão simples, porém necessária para fundamentar suas atividades. Reunir informações científicas, buscar o consenso de especialistas e outras fontes de dados disponíveis é vital para consolidar o processo de decisão política (Stetler et al., 1998; Costa e Silva, 2016).

A vigilância de IRAS é um meio fundamental para avaliar e orientar intervenções em controle de infecção tanto no nível institucional quanto nacional. Um sistema de vigilância epidemiológica consistente além de direcionar intervenções sólidas, sustenta as práticas no decorrer do tempo (Louis, 2012; Freeman et al., 2013; Siegel e Kahn, 2014). 
No âmbito das políticas públicas, a análise detalhada das principais causas de um problema não é uma tarefa tão simples, porém necessária para fundamentar e nortear as atividades. Aplicar ferramentas de análise, reunir informações científicas, buscar o consenso de especialistas e outras fontes de dados confiáveis é vital para consolidar o processo de decisão política (Stetler et al., 1998; Costa e Silva, 2016).

Em todos os casos, embora a tomada de decisão estivesse centrada no âmbito do Ministério da Saúde, a implantação das primeiras ações do programa aconteceu de maneira distinta. Num sentido bottom-up em Israel, de um grupo de especialistas para o Ministro da Saúde (Secchi, 2010). E, no Brasil e no Chile, do governo para os demais níveis técnicos, compatível com o sentido top-down de processo (Secchi, 2010).

A implantação de políticas públicas é um processo de interação entre objetivos e ações com uma dinâmica que pode apresentar diferentes formas (Secchi, 2010; Lima e D'ascenzi, 2013). O desenvolvimento de ações pode ser imprevisível por suas particularidades: há uma infinidade de potenciais atores envolvidos com interesses diversos. Além disto, estes atores se transformam com o tempo, modificam ações, forma de pensar, interações e perspectivas, o que pode tanto avançar, quanto interromper as atividades. Neste sentido, analisar esta influência é essencial para compreender este processo (Secchi, 2010; Buse et al., 2012).

Para que políticas públicas progridam favoravelmente, as estratégias adotadas precisam ser consistentes e transparentes (Pressman e Wildavsky, 1984; Lima e D'ascenzi, 2013). Deste modo, alinhar interesses, formando coalizões, pode ser uma alternativa para fortalecê-las e sustentá-las. As coalizões permitem articulações de ações e ideias entre atores. Envolvem, no cenário de decisões e implantação de ações, diferentes protagonistas e concentram objetivos comuns, atribuindo potencial progresso com a ampliação da visão estratégica (Lima e D'ascenzi, 2013).

Juntamente, a consolidação das ações educativas por meio de capacitações dos profissionais de saúde sustenta a adoção de práticas adequadas. As capacitações foram escolhas que, no desenvolvimento dos programas foram ressaltadas como atividades vitais para perpetuar intervenções. O treinamento, segundo a OMS, é um dos componentes essenciais para a formação dos programas de prevenção e controle de IRAS. Há diversos estudos que evidenciam a necessidade de intervir na formação 
de profissionais que atuam no âmbito da saúde para atingir resultados desejados (Storr et al., 2017)

Como processo transicional, a implantação de políticas públicas demanda liderança provida de conhecimentos e informações necessárias para conduzir ações coordenadas (Secchi, 2010; Buse et al., 2012; Lima e D'ascenzi, 2013). A liderança emerge de profissionais capacitados, mas também requer outros aspectos para se solidificar, que incluem a capacidade de motivação, perseverança e constância de objetivos. Como o alcance dos objetivos do programa se dá em médio e longo prazo, profissionais capacitados, engajados e motivados, que integrem níveis de decisão e de desenvolvimento são essenciais para o sucesso das atividades (Cardo et al., 2010; Louis, 2012). Mantém-se ainda uma lacuna de pesquisa sobre qual seria o número ideal de membros para compor a equipe no nível nacional, considerando aspectos tais como número de serviços de saúde, dimensão geográfica, escalonamento dos níveis governamentais, centralização e autonomia destes níveis (Nogueira Junior, Cassimiro et al., 2014). Os exemplos analisados sugerem que se deve evitar o turnover de lideranças profissionais para evitar a quebra na continuidade das ações.

$\mathrm{Na}$ tônica da geração de renovação, a perspectiva política da avaliação é fundamental para perceber fragilidades, tendências, e possibilidades de expansão da estratégia. Como sugerem os casos estudados, gerar renovação é condição necessária para a manutenção de programas. O processo de avaliação ex post deve compreender a análise de desempenho do programa, considerando princípios como a legalidade e a eficiência administrativa (Secchi, 2010). Neste contexto, a análise de processos e resultados e a revisão de normas regulatórias devem ser ações dos programas de controle de infecção, no sentido de exigir e recomendar práticas contextualizadas e baseadas em evidência (Cardo et al., 2010).

A avaliação está intimamente conectada com a capacidade de análise dos resultados do programa, mas também foi observada sob outras perspectivas. Todos os países analisam os resultados e revisam legislações específicas do programa como parte de suas atividades. A avaliação de serviços e do sistema de vigilância também foi sistematizada em alguns cenários.

A avaliação é uma atividade voltada para a ação. A implantação desta estratégia traz informações cruciais para a identificação de fragilidades e potencialidades de uma política pública no atingimento de seus objetivos. A análise 
periódica de resultados e de processos norteia mudanças, renovando e fortalecendo a estratégia (Trevisan e Van Bellen, 2008).

Ainda, as decisões políticas são naturalmente influenciadas pelo cenário de cada país. O arranjo de um sistema de saúde é claramente influenciado pela concepção social e histórica de saúde, seja compreendida como um direito, benefício ou produto (Buse et al., 2012; Akerman et al., 2013). Esta compreensão permeia suas decisões, organização e desempenho e, consequentemente, a abertura política para a formação e desenvolvimento de programas de saúde. Assim também, a organização político-administrativa do Estado demarca o arcabouço estrutural necessário para a consolidação da estratégia (Conill, 2006).

Neste sentido, a interpretação do fenômeno e a incorporação de programas para combatê-lo pode ser evidenciada sob diferentes formas em um sistema de saúde, dependendo da interpretação sócio histórica deste conceito:

$\checkmark$ na sustentabilidade do sistema - incidindo na elevação de custos e na capacidade de ampliação do acesso aos serviços e programas;

$\checkmark$ na garantia do melhor cuidado - atingindo a perspectiva de qualidade e segurança de um produto ou o direito de uma assistência livre de danos;

$\checkmark$ e na ótica da atração e retenção de clientes - possivelmente demonstrado em modelos de seguros, na competitividade entre serviços e planos.

Nenhum sistema de saúde é puro nesta concepção de saúde, porém há uma tendência na lógica de organização e do financiamento que determinam seu modelo e consequentemente vão influenciar as decisões de práticas, recursos, financiamento e gestão (Conill, 2006). É indispensável garantir estes recursos financeiros e organização estratégica para impulsionar as ações do programa. Porém, como visto, o Estado necessita perceber o problema como prioridade de intervenção e compor sua agenda política e governamental (Secchi, 2010). É importante refletir sobre o contexto das IRAS dentro de cada sistema e dentro das diferentes interpretações supramencionadas, para direcionar abordagens e fortalecer iniciativas, contribuindo com reflexões sobre tendências e desafios futuros.

Somado ao reconhecimento do problema e a disponibilidade de recursos e financiamento para as atividades do programa, a organização político administrativa definirá a estrutura necessária para o desenvolvimento das ações nas diferentes regiões do país (Conill, 2006). Esta organização marca relações de poder e diferentes 
graus de autonomia aos executores desta estratégia (Bucci, 1997; Louis, 2012). Este esqueleto estrutural impacta diretamente nos componentes estratégicos do modelo. Ou seja, a observação desta situação também se faz necessária para o planejamento e desenvolvimento do programa, pois tais aspectos podem ser cruciais ao sucesso da estratégia. 


\section{CONCLUSÕES}

Para entender uma política é necessário compreender o processo que concedeu sua origem e desenvolvimento. A trajetória histórica dos programas nacionais de IRAS destaca fatores tanto na formação quanto no desenvolvimento e sustentação do programa. Cada país apresentou elementos, em diferentes momentos de sua história, que puderam alavancar e consolidar a estratégia nacional de prevenção e controle destas infecções. De um modo geral, o reconhecimento das IRAS como um problema, somado ao apoio de promotores do interesse social e abertura política, possibilitou a criação do programa, que demandou outros elementos para sustentá-lo e renová-lo no decorrer do tempo.

A livre manifestação destes elementos, de acordo com o contexto de cada país, caracterizou modelos de implantação com consolidação mais rápida ou mais lenta. Esta análise destacou alguns elementos que foram basilares ao progresso da estratégia, como: um diagnóstico situacional, a formação de um sistema de vigilância, a manutenção das lideranças, a capacitação das equipes, a coalizão entre níveis governamentais, o apoio de sociedades, órgãos nacionais e internacionais e a avaliação das práticas.

Embora a pesquisa tenha sido limitada a três casos, a compreensão destas experiências e a identificação de propriedades semelhantes, direcionou um modelo explicativo que norteia a análise da formação, progressão e manutenção destes programas. Cabe ainda validar o modelo, analisando sua clareza, coerência e simplicidade, para comprovar seu poder explicativo e resolutivo. Este confronto com a realidade, vai colocá-lo a prova de modo a efetuar ajustes se for necessário.

Contudo, o modelo proposto colabora com a análise dos fatores que podem influenciar o desenvolvimento de um programa nacional de IRAS, permitindo reflexões para o alcance de sua sustentabilidade. 


\subsection{IMPLICAÇÕES PARA A PRÁTICA E PARA A PESQUISA}

O modelo é inovador e se soma aos componentes técnicos que a OMS vem trabalhando nos últimos anos. Esta nova abordagem amplia a visão de formação e sustentação de um programa governamental no âmbito das IRAS, trazendo discussões e posicionamentos antes não destacados. Com esta nova abordagem, novos horizontes de investigação se colocam.

É necessário validar o modelo, colocando a prova todos os aspectos levantados com correção de possíveis equívocos de interpretação. A aplicação do modelo frente a variabilidade de culturas e distintos padrões de organização política e administrativa dos países deve permitir uma análise do seu poder resolutivo e de sua clareza de interpretação na condução desta estratégia.

Além do mais, o modelo pode nortear intervenções sistêmicas propostas por órgãos e agências governamentais no estímulo das nações na formação e consolidação destes programas nacionais. Permitindo a análise de fragilidades e potencialidades de cada país, com o alerta para riscos neste processo.

\subsection{SUGESTÕES PARA TRABALHOS FUTUROS}

O modelo desenhado coloca em discussão aspectos não destacados em pesquisas anteriores. Entretanto, algumas lacunas ainda precisam ser investigadas:

- as peculiaridades do modelo em diferentes sistemas de saúde - há especificidades do mesmo em contraposição com os aspectos constitutivos de cada sistema de saúde?

- o impacto da composição das equipes governamentais dos programas de prevenção e controle de infecção na condução da estratégia - qual a composição necessária para uma equipe no nível nacional, considerando seu número de serviços de saúde, dimensão geográfica, escalonamento dos níveis governamentais, centralização e autonomia destes níveis?

- o impacto da estrutura político administrativa do Estado na condução do programa - qual o aparato mínimo necessário para um programa nacional? Quais parâmetros devem ser considerados neste processo?; e a vinculação da 
formação e manutenção do programa a outros aspectos sistêmicos do modelo de sistema de saúde, como: regulação e mecanismos de gestão.

- a aplicação do modelo para estratégias sistêmicas regionais, continentais e até mundiais na composição e manutenção dos programas nacionais de IRAS. 


\section{REFERÊNCIAS}

AKERMAN, M. et al. Saúde e desenvolvimento: que conexões? In: CAMPOS, G. W. D. S.;BONFIM, J. R. D. A., et al (Ed.). Saúde em debate. 2: Hucitec; Fiocruz, v.170, 2013. cap. 4, p.111-136.

ALLEGRANZI, B. et al. Burden of endemic health-care-associated infection in developing countries: systematic review and meta-analysis. The Lancet, v. 377, n. 9761, p. 228-241, 2011

ALLEGRANZI, B.; NEJAD, S. B.; PITTET, D. The Burden of Healthcare-Associated Infection. In: PITTET, D.;BOYCE, J., et al (Ed.). Hand Hygiene: A Handbook for Medical Professionals Hoboken, NJ, USA: John Wiley \& Sons, Inc., 2017. p.1-7.

ANVISA. Boletim de Segurança do Paciente e Qualidade em Serviços de Saúde $n^{\circ}$ 14: Avaliação dos indicadores nacionais das Infecções Relacionadas à Assistência à Saúde (IRAS) e Resistência microbiana do ano de 2015. Agência Nacional de Vigilância Sanitária. Brasília, DF, p.83. 2016a

ANVISA Programa Nacional de Prevenção e Controle de Infecções Relacionadas à Assistência à Saúde (2016-2020). Agência Nacional de Vigilância Sanitária. Brasília, DF, 38 p. 2016b

ARAÚJO JR, J. L. C.; MACIEL FILHO, R. Developing an operational framework for health policy analysis. Revista Brasileira de Saúde Materno Infantil, v. 1, n. 3, p. 203-221, 2001.

ARAÚJO, L.; RODRIGUES, M. D. L. Modelos de análise das políticas públicas. Sociologia, Problemas e Práticas, n. 83, p. 11-35, 2017.

ARREDONDO, A.; MELÉNDEZ, V. Modelos explicativos sobre la utilización de servicios de salud: revisión y análisis. Salud pública de México, v. 34, n. 1, p. 36-49, 1992.

BALICER, R. et al. Israel: Structural and Functional Integration at the Israeli Healthcare System | SpringerLink. In: (Ed.). Handbook Integrated Care: SpringerLink, 2017. p.585-595.

BECERRIL-MONTEKIO, V. et al. Sistema de salud de Chile. Salud pública Méx, v. 53, 2011.

BIRKLAND, T. A. An introduction to the policy process: Theories, concepts and models of public policy making. Routledge, 2014. 
BLANK, R. H.; BURAU, V. Comparative health policy. Palgrave Macmillan, 2013.

BOWMAN, S. et al. Use of evidence to support healthy public policy: a policy effectiveness-feasibility loop. Bulletin of the World Health Organization, v. 90, n. 11, p. 847-853, 2012.

BRASIL. Constituição da República Federativa do Brasil. Senado Federal, Brasília 1988.

BRASIL. CnesWeb - Cadastro Nacional de Estabelecimentos de Saúde. 2017. Disponível em: < http://cnes.datasus.gov.br/Mod_Ind Unidade.asp >. Acesso em: 05/11/2017.

BRISTOL, N. Patient safety alliance to tackle hand washing worldwide. The Lancet, v. 366, n. 9490, p. 973-974, 2005.

BUCCI, M. P. D. Políticas públicas e direito administrativo. Revista de Informação Legislativa, n. 33, p. 89-98, 1997.

BUNGE, M. Teoria e realidade: São Paulo: Perspectiva, 1974.

BUSE, K.; MAYS, N.; WALT, G. Making health policy. McGraw-Hill Education (UK), 2012.

CAPELLA, A. Perspectivas teóricas sobre o processo de formulação de políticas públicas. In: (Ed.). Políticas públicas no Brasil. Rio de Janeiro: Fiocruz, v.1, 2007. p.87-124.

CAPELLA, A. C. N. et al. Análise de Políticas Públicas: uma revisão da literatura sobre o papel dos subsistemas, comunidades e redes. Novos estud. - CEBRAP, n. 101, p. $57-76,2015$

CARDO, D. et al. Moving toward elimination of healthcare-associated infections: a call to action. Infection Control \& Hospital Epidemiology, v. 31, n. 11, p. 1101-1105, 2010.

CARLILE, P.; CHRISTENSEN, C. The cycles of theory building in management research. Harvard Business School working papers. Boston, MA: HBS Press: 26 p. 2004.

CHILE. Sistema de Vigilancia de las Infecciones Intrahospitalarias. Ministerio de la Salud. 1998 
CHILE. Departamento de Estadísticas e Información de Salud. 2015. Disponível em: < http://www.deis.cl/ >. Acesso em: 18/11/2017.

CHILE. Governo do Chile. 2017. Disponível em: < http://www.gob.cl/ >. Acesso em: $18 / 11 / 2017$.

CIA. Central Intelligence Agency. 2017. Disponível em: <https://www.cia.gov/index.html>. Acesso em: 20/11/2017.

COLLINS, A. S. Preventing Health Care-Associated Infections. In: HUGHES, R. (Ed.). Patient Safety and Quality: An Evidence-Based Handbook for Nurses. Rockville (MD): Agency for Healthcare Research and Quality (US), 2008. cap. 41,

CONILL, E. Sistemas comparados de saúde. In: HUCITEC e FIOCRUZ. (Ed.). Tratado de Saúde Coletiva. São Paulo: Fiocruz, 2006. p.563-614.

COSTA, C. G. F.; SILVA, E. V. O que Realmente Importa no Processo de Tomada de Decisão Considerando Políticas Públicas Baseadas em Evidência. Revista Administração em Diálogo, v. 18, n. 2, p. 124-143, 2016.

DENZIN, N. K.; LINCOLN, Y. S. Qualitative Research. United States of America: SAGE Publications, 2017.

DYE, T. R. Understanding public policy. 14 ed. Prentice Hall Englewood Cliffs, NJ, 2013.

ELIAS, F. T. S.; PATROCLO, M. A. D. A. Utilização de pesquisas: como construir modelos teóricos para avaliação. Cienc Saude Coletiva, v. 10, n. 1, p. 215-27, 2005.

EXWORTHY, M. Policy to tackle the social determinants of health: using conceptual models to understand the policy process. Health Policy and Planning, v. 23, n. 5, p. 318-327, 2008.

FISCHER, F.; MILLER, G. J. Handbook of public policy analysis: theory, politics, and methods. crc Press, 2006.

FLEURY, S.; OUVERNEY, A. M. Política de Saúde: uma política social. Políticas e Sistema de Saúde no Brasil, Rio de Janeiro: Fiocruz, p. 23-64, 2008.

FMI. Fundo Monetário Internacional. 2017. Disponível em: <http://www.imf.org/external/index.htm>. Acesso em: 09/12/2017. 
FORTALEZA, C. M. C. B. et al. Multi-state survey of healthcare-associated infections in acute care hospitals in Brazil. Journal of Hospital Infection, v. 96, n. 2, p. 139-144, 2017.

FREEMAN, R. et al. Advances in electronic surveillance for healthcare-associated infections in the 21st Century: a systematic review. Journal of Hospital Infection, v. 84, n. 2, p. 106-119, 2013.

FREY, K. Políticas públicas: um debate conceitual e reflexões referentes à prática da análise de políticas públicas no Brasil. Planejamento e políticas públicas, n. 21, 2009.

GARNER, J. S. et al. CDC definitions for nosocomial infections, 1988. American Journal of Infection Control, v. 16, n. 3, p. 128-140, 1998.

GILSON, L. et al. Future directions for health policy analysis: a tribute to the work of Professor Gill Walt. Health Policy Plan, v. 23, n. 5, p. 291-3, 2008.

GONZALEZ, R. S. O Método Comparativo e a Ciência Política. Revista de Estudos e Pesquisas sobre as Américas, v. 2, n. 1, p. 1-12, 2008.

HALEY, R. W. et al. The efficacy of infection surveillance and control programs in preventing nosocomial infections in US hospitals. American Journal of Epidemiology, v. 121, n. 2, p. 182-205, 1985.

HALEY, R. W. Study on the Efficacy of Nosocomial Infection Control (SENIC PROJECT): Summary of Study Design. American Journal of Epidemiology, v. 111, n. 5 , p. 472-485, 1980.

HALL, P. et al. Change, choice, and conflict in social policy. London: Heinemann, 1975. 555.

IBGE. Instituto Brasileiro de Geografia e Estatística. Pesquisa nacional por amostra de domicílios contínua. Brasília, 2011.

IBGE. Instituto Brasileiro de Geografia e Estatística. 2016. Disponível em: <https://www.ibge.gov.br/>. Acesso em: 09/12/2017.

INSTITUTE OF MEDICINE. The Future of the Public's Health in the 21st Century. National Academies Press (US), 2002. 536p.

ISRAEL. Health Services - Central Bureau of Statistics. Central Bureau of Statistics 2017a. Disponível em: <http://www.cbs.gov.il/reader/cw_usr_view_SHTML?ID=590>. Acesso em: 09/12/2017. 
ISRAEL. The Electoral System in Israel. 2017b. Disponível em: $<$ http://www.knesset.gov.il/description/eng/eng_mimshal_beh.htm>. Acesso em: 03/08/2017.

KLEVENS, R. M. et al. Estimating Health Care-Associated Infections and Deaths in U.S. Hospitals, 2002. Public Health Reports, v. 122, n. 2, p. 160-166, Mar-Apr 2007.

LABRA, M. E. Política e saúde no Chile e no Brasil.Contribuições para uma comparação. Ciência \&amp; Saúde Coletiva, v. 6, n. 2, 2001.

LACERDA, R. A.; EGRY, E. Y. Hospital infections and their relation to the development of hospital care: reflections for the analysis of actual control practices. Revista latinoamericana de enfermagem, v. 5, n. 4, p. 13-23, 1997.

LACERDA, R. A.; JOUCLAS, V. M. G.; EGRY, E. Y. Infecções hospitalares no Brasil. Ações governamentais para o seu controle enquanto expressão de políticas sociais na área de saúde. Rev Esc Enferm USP, v. 30, n. 1, p. 93-115, 1996.

LAKATOS, E. M.; MARCONI, M. D. A. Fundamentos da metodologia científica. In: (Ed.). Fundamentos da metodologia científica: Altas, 2010.

LASSWELL, H. D. The decision process : seven categories of functional analysis I. College Park :: Bureau of Governmental Research, College of business and Public Administration, University of Maryland, 1956.

LEVIN, A. S.; PADOVEZE, M. C. Ciclo de Debates em Políticas Públicas para a Prevenção e Controle de IRAS e Segurança do Paciente: Relatório Final 2015. São Paulo: $\quad$ EEUSP, $2015 . \quad$ Disponível em: <http://www.ee.usp.br/evento/2014/ciclo_debates/ciclo_debates_seguranca_pacient e_IRAS_relatorio final.pdf >. Acesso em: 10/07/2017.

LIMA, L. L.; D'ASCENZI, L. Public policy implementation: analytical perspectives. Rev. Sociol. Polit., v. 21, n. 48, p. 101-110, 12/2013 2013.

LOUIS, M. S. Global health surveillance. MMWR Surveill Summ, v. 61, n. Suppl., p. 15-19, 2012.

LÜDKE, M.; ANDRÉ, M. E. D. A. Pesquisa em educação: abordagens qualitativas. Editora Pedagógica e Universitária, 1986.

MCCOMBS, M. E.; SHAW, D. L. THE AGENDA-SETTING FUNCTION OF MASS MEDIA. Public Opinion Quarterly, v. 36, n. 2, p. 176-187, 2017. 
MCKIBBEN, L. et al. Guidance on Public Reporting of Healthcare-Associated Infections: Recommendations of the Healthcare Infection Control Practices Advisory Committee. American Journal of Infection Control, v. 33, n. 4, p. 217-226, 2005.

MENDES, E. V. 25 anos do Sistema Único de Saúde: resultados e desafios. Estud. av., v. 27, n. 78, p. $27-34,2013$.

MENDES, Á.; MARQUES, R. M. O financiamento do SUS sob os "ventos" da financeirização. Ciência \& Saúde Coletiva, v. 14, n. 3, p. 841-50, 2009.

MINAYO, M. C. D. S. et al. Pesquisa social: teoria, método e criatividade. Vozes, 2013.

NASCIMENTO NETO, P. et al. Análise de políticas públicas: entre a modelagem e a realidade da política habitacional brasileira. Revista de Administração Pública RAP, v. 49, n. 4, 2015.

NOGUEIRA JUNIOR, C. et al. Characterization of epidemiological surveillance systems for healthcare-associated infections ( $\mathrm{HAl}$ ) in the world and challenges for Brazil. Cad Saude Publica, v. 30, n. 1, p. 11-20, Jan 2014.

NOGUEIRA JUNIOR, C.; PADOVEZE, M. C.; LACERDA, R. A. Sistemas governamentais de vigilância de infecções relacionadas à Assistência à Saúde no Brasil. Rev Esc Enferm USP, v. 48, n. 4, p. 656-61, 2014.

NUNES, E. D.; UNIVERSIDADE ESTADUAL DE CAMPINAS, S. P., BRASIL. A trajetória das ciências sociais em saúde na América Latina: revisão da produção científica. Revista de Saúde Pública, v. 40, n. spe, p. 64-72, 2006.

OECD. The Organisation for Economic Co-operation and Development. Israel and the OECD. 2017. Disponível em: < http://www.oecd.org/israel/israel-and-oecd.htm >. Acesso em: 04/08/2017.

OLIVEIRA, S. R. A.; TEIXEIRA, C. F. Avaliação da regionalização do SUS: construção do modelo teórico-lógico. Revista Baiana de Saúde Pública, v. 37, n. 1, p. 236, 2013.

PADOVEZE, M. et al. Public policies on healthcare associated infections: a case study of Brazil and UK. Revista de Saúde Pública, v. 51, n. 119, 2017.

PADOVEZE, M. C.; FORTALEZA, C. M. C. B. Healthcare-associated infections: challenges to public health in Brazil. Revista de saude publica, v. 48, n. 6, p. 9951001, 2014.

PAIM, J.; TEIXEIRA, C. Política, planejamento e gestão em saúde: balanço do estado da arte. Revista de Saúde Pública, v. 40, p. 73-78, 2006. 
PAIM, J. et al. The Brazilian health system: history, advances, and challenges. The Lancet, v. 377, n. 9779, p. 1778-1797, 2011.

PETERS, D. H. The application of systems thinking in health: why use systems thinking? Health Research Policy and Systems, v. 12, n. 1, p. 51, 2014-08-26 2014.

PRESSMAN, J.; WILDAVSKY, A. Implementation. 3 ed. University of California: Berkeley, 1984.

RODRIGUES, M. M. A. Políticas públicas. 1 ed. São Paulo: Publifolha, 2010. 92 p.

ROSEN, B.; WAITZBERG, R.; MERKUR, S. Israel: Health System Review. WHO Regional Office for Europe, p.212. 2015

RUA, M. G. Análise de políticas públicas: conceitos básicos [Public policy analysis: basic concepts]. $O$ estudo da política: tópicos selecionados [The study of politics: selected topics]. Brasília: Paralelo, v. 15, 1998.

SCHMITTER, P. C. Reflexões sobre o conceito de política. Curso de Introdução à Ciência Política-Unidade I. Brasília: UnB, p. 29-35, 1982.

SCHNEIDER, S.; SCHMITT, C. J. O uso do método comparativo nas ciências sociais. Cadernos de Sociologia, v. 9, p. 49-87, 1998.

SCHRAIBER, L. B. Necessidades de saúde, políticas públicas e gênero: a perspectiva das práticas profissionais. Ciência \& Saúde Coletiva, v. 17, p. 2635-2644, 2012.

SCHWABER, M. J.; CARMELI, Y. An ongoing national intervention to contain the spread of carbapenem-resistant enterobacteriaceae. Clin Infect Dis, v. 58, n. 5, p. 697-703, Mar 2014.

SCHWABER, M. J.; CARMELI, Y. The Impact of a Carbapenem-Resistant Enterobacteriaceae Outbreak on Facilitating Development of a National Infrastructure for Infection Control in Israel. Clinical Infectious Diseases, v. 65, n. 12, p. 2144-2149, 2017.

SCHWABER, M. J. et al. Containment of a Country-wide Outbreak of CarbapenemResistant Klebsiella pneumoniae in Israeli Hospitals via a Nationally Implemented Intervention. Clinical Infectious Diseases, v. 52, n. 7, p. 848-855, 2011.

SECCHI, L. Políticas públicas: conceitos, esquemas de análise, casos práticos. São Paulo: Cengage Learning, v. 133, 2010. 
SETO, Wing Hong et al. Core components for infection prevention and control programs: a World Health Organization network report. Infection Control \& Hospital Epidemiology, v. 31, n. 9, p. 948-950, 2010.

SIEGEL, S.; KAHN, K. L. Regional interventions to eliminate healthcare-associated infections. Med Care, v. 52, n. 2 Suppl 1, p. S46-53, 2014.

SOUZA, C. Políticas públicas: uma revisão da literatura. Sociologias, p. 20-45, 2006.

STETLER, C. B. et al. Evidence-Based Practice and the Role of Nursing Leadership : Journal of Nursing Administration. Journal of Nursing Administration, v. 28, n. 7/8, p. 45-53, 1998.

STONE, P. W.; BRACCIA, D.; LARSON, E. Systematic review of economic analyses of health care-associated infections. American Journal of Infection Control, v. 33, n. 9, p. 501-509, 2005.

STORR, J. et al. Core components for effective infection prevention and control programmes: new WHO evidence-based recommendations. Antimicrobial Resistance \& Infection Control, v. 6, n. 1, p. 6, 2017-01-10 2017.

THE WORLD BANK. The World Bank Group. 2017. Disponível em: < http://www.worldbank.org/en/who-we-are >. Acesso em: 13/11/2017.

TREVISAN, A. P.; VAN BELLEN, H. M. Avaliação de políticas públicas: uma revisão teórica de um campo em construção. Revista de Administração Pública - RAP, v. 42, n. 3, 2008.

TROSTLE, J.; BRONFMAN, M.; LANGER, A. How do researchers influence decisionmakers? Case studies of Mexican policies. Health policy and planning, v. 14, n. 2, p. 103-114, 1999.

VAITSMAN, J.; MENDES RIBEIRO, J.; DE VASCONCELOS COSTA LOBATO, L. Análise de políticas, políticas de saúde e a Saúde Coletiva. Physis - Revista de Saúde Coletiva, v. 23, n. 2, 2013.

VELLOSO, M. P. et al. INTERDISCIPLINARIDADE E FORMAÇÃO NA ÁREA DE SAÚDE COLETIVA. Trabalho, Educação e Saúde, v. 14, n. 1, p. 257-271, 03/2016 2016.

VIANA, N. S.; SOARES, C. B.; CAMPOS, C. M. S. Reprodução social e processo saúde-doença: para compreender o objeto da saúde coletiva. Soares CB, Campos CMS organizadores. Fundamentos de saúde coletiva eo cuidado de enfermagem. Barueri: Manole, p. 107-42, 2013. 
WALT, G.; GILSON, L. Reforming the health sector in developing countries: the central role of policy analysis. Health policy and planning, v. 9, n. 4, p. 353-370, 1994.

WALT, G. et al. 'Doing'health policy analysis: methodological and conceptual reflections and challenges. Health policy and planning, v. 23, n. 5, p. 308-317, 2008.

WEBER, D. J.; SICKBERT-BENNETT, E. E.; RUTALA, W. A. Healthcare-associated infections. In: ABUBAKAR, I.;TED, C., et al (Ed.). Infections Diseases Epidemiology. 1. London, UK: Oxford University, 2016. cap. 21, p.301-310.

WEISS, C. H. How can theory-based evaluation make greater headway? Evaluation review, v. 21, n. 4, p. 501-524, 1997.

WORLD HEALTH ORGANIZATION. Health 21: An introduction to the health for all policy framework for the WHO European Region. 1998.

WORLD HEALTH ORGANIZATION. World Alliance for Patient Safety Progress Report 2006-2007. World Health Organization. 2008

WORLD HEALTH ORGANIZATION. Closing the gap: policy into practice on social determinants of health: discussion paper. World Health Organization. Geneva. $2011 \mathrm{a}$

WORLD HEALTH ORGANIZATION. Core components for infection prevention and control programmes. 2011b

WORLD HEALTH ORGANIZATION. How clean hands have helped save lives in Chile. 2017. Disponível em: < http://www.who.int/features/2017/clean-handschile/en/ > . Acesso em: 22/11/2017.

ZIMLICHMAN, E. et al. Health care-associated infections: A meta-analysis of costs and financial impact on the us health care system. JAMA Internal Medicine, v. 173, n. 22, p. 2039-2046, 2013. 


\title{
APÊNDICES
}

\section{APÊNDICE A - CARTA CONVITE}

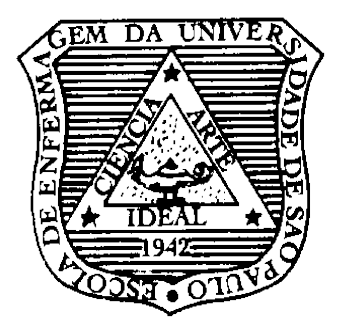

\author{
UNIVERSIDADE DE SÃO PAULO \\ ESCOLA DE ENFERMAGEM \\ Departamento de Enfermagem Saúde Coletiva
}

Av. Dr. Enéas de Carvalho Aguiar, 419 - Cerqueira César CEP

05403-000 - São Paulo - SP

Tel.: (11) 3061-7652 - FAX (11) 3061-7662

São Paulo,

de de

Prezado

Estamos desenvolvendo a pesquisa intitulada: "Políticas Públicas para Prevenção e Controle de Infecções relacionadas à Assistência à Saúde (IRAS): Concepção de um Modelo Teórico", que será executada pelo aluno de doutorado Cassimiro Nogueira Junior, matriculado no Programa de Pós-Graduação em Enfermagem da Escola de Enfermagem da Universidade de São Paulo, sob minha orientação.

Para o desenvolvimento deste estudo, pretendemos descrever e comparar a trajetória de algumas nações no planejamento e desenvolvimento de ações governamentais para a prevenção e controle de IRAS.

Através desta análise, desejamos ampliar nossa visão sobre o fenômeno, o que deverá contribuir para o desenvolvimento de um modelo teórico explicativo que possa apoiar nações cujos programas de prevenção e controle de IRAS ainda se encontram incipientes ou inexistentes.

Por meio de revisão de literatura, identificamos nações que poderiam ser consideradas como modelo para este estudo, por sua reconhecida tradição nas práticas de controle e prevenção de infecção, entre elas o

Deste modo, solicitamos sua autorização para uma visita técnica com vistas a obter informações mais detalhadas que permitam um maior conhecimento referente a estrutura, processos e ações desenvolvidas pelo Programa Nacional de Prevenção e Controle de IRAS do 
Estamos à disposição para fornecer informações e esclarecer dúvidas referentes ao projeto.

Aguardamos seu breve retorno.

Atenciosamente,

Profa. Dra. Maria Clara Padoveze

Departamento de Enfermagem em Saúde Coletiva 


\title{
APÊNDICE B - PROGRAMAS DA VISITA AO CHILE
}

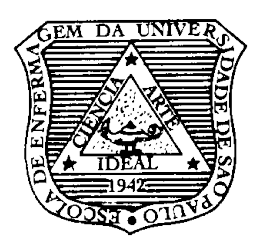

\author{
UNIVERSIDADE DE SÃO PAULO \\ ESCOLA DE ENFERMAGEM \\ Departamento de Enfermagem Saúde Coletiva \\ Av. Dr. Enéas de Carvalho Aguiar, 419 - Cerqueira César \\ CEP 05403-000 - São Paulo - SP \\ Tel.: (11) 3061-7652 - FAX (11) 3061-7662
}

\section{PROGRAMA DE LA VISITA TECNICA}

\section{Participante de São Paulo, Brasil:}

- Cassimiro Nogueira Junior, RN, MsC

Estudiante de doctorado, inscrito en el Programa de Estudios de Posgrado en Enfermería de la Escuela de Enfermería de la Universidad de São Paulo (EEUSP)

Institución a visitar: Control de infecciones, Departamento de Calidad y Seguridad del Paciente, Subsecretaría de Redes Asistenciales, Ministerio de Salud del Chile.

Contato: Dr. Fernando Otaíza O'Ryan, MSc

Periodo de visita: 14 - 18 de marzo 2016

Objetivo: Obtener informaciones más detalladas que permitan un mayor conocimiento sobre la estructura, los procesos y las acciones desarrolladas por el Programa Nacional de Prevención y Control de Infecciones asociadas a la Atención en Salud (IAAS) en Chile.

Justificación: Las Infecciones asociadas a la Atención en Salud (IAAS) son un fenómeno histórico y social, que provocan muchos impactos en el bienestar, económicos y jurídicos, lo que representa una causa importante de morbilidad y mortalidad y un desafío fundamental para mejorar la calidad de la atención de las personas. El reconocimiento y el compromiso de las diversas naciones de todo el mundo para desarrollar políticas públicas para prevenir y controlar IAAS son claves para promover la seguridad en la asistencia. En esta perspectiva, algunas experiencias exitosas están haciendo realidad en todo el mundo y pueden ser consideradas como referencias. Sin embargo, la estructuración de estas acciones 
dentro del gobierno, aunque esencial, es todavía un escenario de gran parte inexplorado. Por eso se propone un estudio que busca implementar la investigación de las políticas referentes a IAAS empleadas en países específicos con la intención de fomentar reflexiones para construir un modelo teórico explicativo que contribuye con la formación de estas políticas públicas en otros países.

\section{Agenda Propuesta, Marzo, 2016}

\begin{tabular}{|l|l|}
\hline Fechas & \multicolumn{1}{|c|}{ Actividades } \\
\hline $14 / 03$ & $\begin{array}{l}\text { Mañana: Visita Introductoria - Primer contacto con el personal y la } \\
\text { estructura del Programa Nacional de Control de Infecciones Chile. } \\
\text { Sugerencia: entrevista con el responsable del programa. } \\
\text { Tarde: Conocer el proceso histórico de la formación y el desarrollo } \\
\text { del programa nacional para la prevención y control de las IAAS y el } \\
\text { sistema de salud en Chile. Sugerencia: entrevista con miembro del } \\
\text { equipo con conocimiento del histórico del programa. }\end{array}$ \\
\hline $15 / 03$ & $\begin{array}{l}\text { Mañana y Tarde: Caracterización del programa actual - sus } \\
\text { objetivos prioritarios, los mecanismos utilizados para inducir } \\
\text { comportamientos, estructura gubernamental para la implementación } \\
\text { del programa de prevención y control de las IAAS (directrices } \\
\text { técnicas principales, recursos humanos, vigilancia, apoyo de } \\
\text { laboratorio, temas ambientales, monitoreo / evaluación, y la interfaz } \\
\text { con otros programas). }\end{array}$ \\
\hline $16 / 03$ & $\begin{array}{l}\text { Mañana y Tarde: Identificación de los principales resultados } \\
\text { obtenidos por el programa, incluso las principales facilitadores y } \\
\text { dificultades en el ruta del programa. Conocer la red de apoyo al } \\
\text { programa, las principales partes interesadas en la ejecución de las } \\
\text { acciones. Los principales desafíos para el diseño y la expansión de } \\
\text { esta política nacional. }\end{array}$ \\
\hline $\begin{array}{l}\text { Mañana Y Tarde: Identificación de las actividades del programa } \\
\text { referente a: a) investigación de brotes relacionados con las } \\
\text { infecciones asociadas a la salud; b) las estrategias para poner en } \\
\text { práctica las medidas de prevención a nivel local, regional y nacional; }\end{array}$ \\
\hline Jueves
\end{tabular}




\begin{tabular}{|l|l|}
\hline & $\begin{array}{l}\text { c) Red Nacional de Seguranza do Paciente; d) la resistencia a los } \\
\text { antimicrobianos; e) investigaciones sobre prevención de infecciones } \\
\text { asociados con los cuidados de la salud; f) estrategias de } \\
\text { comunicación a nivel local, regional y nacional; g) Plan nacional para } \\
\text { prevenir las infecciones asociadas a la salud. }\end{array}$ \\
\hline $18 / 03$ & $\begin{array}{l}\text { Mañana: Consolidación de informaciones y lectura de documentos } \\
\text { (actividad individual). } \\
\text { Tarde: Resumen y validación de la comprensión de las } \\
\text { informaciones obtenidas. Finalización de la visita. Sugerencia: } \\
\text { entrevista con el responsable del programa. }\end{array}$ \\
\hline
\end{tabular}

São Paulo, 21 de diciembre 2015 


\title{
APÊNDICE C - PROGRAMA DA VISITA A ISRAEL
}

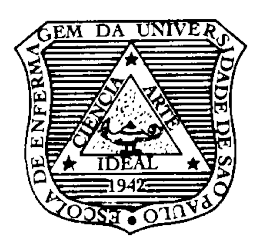

\author{
UNIVERSIDADE DE SÃO PAULO \\ ESCOLA DE ENFERMAGEM \\ Departamento de Enfermagem Saúde Coletiva \\ Av. Dr. Enéas de Carvalho Aguiar, 419 - Cerqueira César \\ CEP 05403-000 - São Paulo - SP \\ Tel.: (11) 3061-7652 - FAX (11) 3061-7662
}

\section{TECHNICAL VISIT PROGRAM}

\section{Participant of São Paulo, Brazil:}

Cassimiro Nogueira Junior, RN, MsC, PhD Student, enrolled in São Paulo University Postgraduate Program in Nursing

Institution to visit: National Institute for Infection Control and Antibiotic Resistance Ministry of Health - State of Israel - Tel Aviv

\section{Contact:}

Prof. Yehuda Carmeli - Head for the National Institute for Infection Control and Antibiotic Resistance.

Dr. Mitchell Schwaber - Director of the National Center for Infection Control of the Israel Ministry of Health

Visiting Period: 04th - 08th September, 2016

Purpose of the visit: Get more detailed information that allow a better understanding of the structure, processes and actions developed by the National Program for Infection Control in Israel

Justification: Healthcare associated Infections (HAl) is a historical and social phenomenon, which cause many impacts on welfare, economic and legal, which represents a major cause of morbidity and mortality and a key challenge to improve the quality of care. Recognition and commitment of the various nations around the world to develop public policies to prevent and control of HAls are key to promote safety in healthcare. In this perspective, some successful experiences are coming true 
around the world and can be considered as references. However, the structuring of these actions within the government, though essential, is still a largely unexplored scenario. For this reason, we purpose a study that aims to investigate the structuring of public policies to prevent and control HAl around the world with the intention of encouraging reflections to build an explanatory theoretical model that contributes to the formation of these public policies in other countries.

\section{Proposed Agenda, September, 2016}

\begin{tabular}{|c|l|}
\hline Date & \multicolumn{1}{|c|}{ Activities } \\
\hline $04^{\text {th }}$ Sep & $\begin{array}{l}\text { Morning: Introductory Visit - First contact with staff and structure of } \\
\text { the National Infection Control Program Chile. Suggestion: interview } \\
\text { with the program director. } \\
\text { Afternoon: Knowing the historical process of the formation and } \\
\text { development of the National Program for Prevention and Control of } \\
\text { HAl and the Health System in Israel. Suggestion: interview with team } \\
\text { member with knowledge of the history of the program. }\end{array}$ \\
\hline $05^{\text {th }}$ Sep & $\begin{array}{l}\text { Morning and Afternoon: Characterization of the current program - } \\
\text { its priorities, the mechanisms used to induce behaviors, } \\
\text { governmental structure for the implementation of the program of } \\
\text { prevention and control of HAl (main technical guidelines, human } \\
\text { resources, surveillance, laboratory support, environmental issues, } \\
\text { monitoring / evaluation, and interface with other programs). }\end{array}$ \\
\hline $06^{\text {th } \text { Sep }}$ & $\begin{array}{l}\text { Morning and Afternoon: Identification of the main results of the } \\
\text { program, including the main advantages and constraints of this } \\
\text { program. Knowing the program's support network and the key } \\
\text { stakeholders in the deployment of the actions, the main challenges } \\
\text { for the design and expansion of this national policy. }\end{array}$ \\
\hline $07^{\text {th }}$ Sep & $\begin{array}{l}\text { Morning and Afternoon: Identification of program activities relating } \\
\text { to: a) outbreak investigation related to healthcare- } \\
\text { associated infections; b) strategies to implement prevention } \\
\text { measures at local, regional and national levels; c) National } \\
\text { Network of Patient Safety; d) Antimicrobial Resistance; e) }\end{array}$ \\
\hline
\end{tabular}




\begin{tabular}{|l|l|}
\hline & $\begin{array}{l}\text { investigations on prevention of HAl; f) communication strategies at } \\
\text { local, regional and national levels; g) National Plan to prevent } \\
\text { healthcare-associated infections. }\end{array}$ \\
\hline $08^{\text {th }}$ Sep & $\begin{array}{l}\text { Morning: Consolidation of information and reading documents } \\
\text { (individual activity). } \\
\text { Afternoon: Summary and validation of the information obtained. } \\
\text { Ending of the visit. } \\
\text { Suggestion: interview with the program manager. }\end{array}$ \\
\hline
\end{tabular}

São Paulo, August 22, 2016 


\title{
APÊNDICE D - PROGRAMA DA VISITA AO BRASIL
}

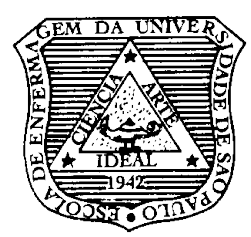

\author{
UNIVERSIDADE DE SÃO PAULO \\ ESCOLA DE ENFERMAGEM \\ Departamento de Enfermagem Saúde Coletiva \\ Av. Dr. Enéas de Carvalho Aguiar, 419 - Cerqueira César \\ CEP 05403-000 - São Paulo - SP \\ Tel.: (11) 3061-7652 - FAX (11) 3061-7662
}

\section{PROGRAMA PROPOSTO - VISITA TÉCNICA ANVISA - Brasília - DF}

\section{Participante de São Paulo, Brasil:}

- Cassimiro Nogueira Junior, RN, MsC

Estudante de Doutorado, matriculado no Programa Pos-Graduaçao em Enfermagem da Escola de Enfermagem da Universidade de São Paulo (EEUSP)

Orientadora: Profa. Dra. Maria Clara Padoveze.

Instituição a visitar: Gerência de Vigilância e Monitoramento em Serviços de Saúde - GVIMS / Gerência Geral de Tecnologia em Serviços de Saúde - GGTES Agência Nacional de Vigilância Sanitária - ANVISA.

Contato: Magda M. de Miranda Costa

Periodo de visita: 13 e 14 de março de 2017.

Objetivo: obter informações mais detalhadas que permitam uma melhor compreensão da estrutura, processos e ações desenvolvidas pelo Programa Nacional de Prevenção e Controle das Infecções relacionadas a assistência à saúde (IRAS) no Brasil.

Justificativa: As Infecções relacionadas a assistência à saúde (IRAS) constituem um fenômeno histórico e social, que causa diversos impactos económicos, sociais e jurídicos, representando uma das principais causas de morbidade e mortalidade e um dos principais desafios para melhorar a qualidade da assistência a saúde. O reconhecimento e o compromisso das diversas nações para desenvolver políticas públicas de prevenção e controle de infecções são fundamentais para promover a 
segurança na assistência. Nesta perspectiva, algumas experiências bem sucedidas estão se tornando realidade em todo o mundo. No entanto, a estruturação dessas ações dentro do governo, embora essencial, ainda é um cenário pouco explorado. Assim, este estudo busca explorar o planejamento e a implantação de políticas públicas sobre IRAS em alguns países, com a intenção de estimular reflexões para construir um modelo teórico explicativo que contribua para a formação desta estratégia em outros países.

Agenda Proposta*, Março, 2017

\begin{tabular}{|c|c|}
\hline Datas & Atividades \\
\hline Segunda & $\begin{array}{l}\text { Manhã: } \\
\text { 1. Conhecer a estrutura do programa e o modelo de } \\
\text { Implantação da Política } \\
\text { 2. Entender a Participação da Organização Mundial da Saúde } \\
\text { (OMS) e de outras Cooperações Nacionais e Internacionais. } \\
\text { 3. Compreender a inserção do fenômeno na agenda política e } \\
\text { na agenda formal do país - Questão da Segurança do } \\
\text { Paciente. } \\
\text { Tarde: } \\
\text { 4. Conhecer as metas e objetivos prioritários do programa / e } \\
\text { entender a prospecção de tendências presentes ou } \\
\text { historicamente identificadas. } \\
\text { 5. Conhecer a sistema de saúde do país envolvida na } \\
\text { definição de ações - Relação da ANVISA com o MS na } \\
\text { definição das ações. } \\
\text { 6. Distinguir os critérios definidos para a avaliar a política e } \\
\text { conhecer o processo de monitoramento de resultados. }\end{array}$ \\
\hline $14 / 03$ & $\begin{array}{l}\text { Manhã: } \\
\text { 1. Caracterizar do plano de ação do programa e Identificação } \\
\text { dos atores envolvidos no processo, sua posição, papel e } \\
\text { relação com a política. } \\
\text { 2. Identificar os principais resultados e principais interfaces do } \\
\text { programa e como elas ocorrem } \\
\text { Tarde: } \\
\text { 3. Finalização da visita. Identificar as principais adversidades } \\
\text { encontradas na implantação e manutenção do programa. } \\
\text { 4. Reconhecer as fragilidades e principais deficiências do } \\
\text { programa } \\
\text { 5. Discutir os principais desafios e tendências para a } \\
\text { manutenção e expansão do programa. }\end{array}$ \\
\hline
\end{tabular}


* Trata-se de um programa sugerido. Fica a critério da GVIMS a distribuiçao de datas e períodos conforme a conveniencia da instituiçao.

São Paulo, 13 fevereiro 2017. 


\section{APÊNDICE E - INSTRUMENTO DE COLETA DE DADOS}

\section{INSTRUMENTO NORTEADOR DA COLETA DE DADOS}

\section{O Programa Nacional de Prevenção e Controle de IRAS (PNPCl)}

\section{CONTEXTO}

\subsection{Fatores Situacionais}

$\checkmark$ Situações ou eventos que despertaram a atenção para as IRAS como problema de saúde pública

$\checkmark$ Alterações de regulamentos ou mudanças no sistema de saúde que colocaram as IRAS como problema relevante para a sociedade.

\subsection{Fatores Estruturais}

$\checkmark$ Demografia e Condições de Saúde do País

$\checkmark$ Sistema Político e Econômico - A inserção da Política de Saúde do País (modelo de proteção social)

$\checkmark$ Sistema de Saúde do País (componentes, estrutura e cobertura, financiamento/recursos, participação social, avaliação)

$\checkmark$ Recursos Tecnológicos e Inovações das Políticas de Saúde

\subsection{Fatores Culturais}

$\checkmark$ Posições de Minorias Étnicas ou Linguísticas

$\checkmark$ Interferência de Fatores Religiosos

$\checkmark$ Outros fatores culturais / Movimentos Sociais

\subsection{Fatores Externos ou Internacionais}

$\checkmark$ Participação da Organização Mundial da Saúde (OMS)

$\checkmark$ Outras Cooperações Internacionais

\section{PROCESSO}

\subsection{Etapa 1 - Identificação e Formação de Agenda}


$\checkmark$ Compreensão das IRAS como problema público (eventos, pressão social, grupos envolvidos) - Identificando atores envolvidos.

$\checkmark$ Como o problema tornou parte da agenda política e da agenda formal do país (Teoria do Equilíbrio Pontuado - Momentos de mudança na agenda)

\subsection{Etapa 2 - Escopo}

$\checkmark$ Como foram definidas as primeiras alternativas (metas e objetivos prioritários) / prospecção de tendências presentes ou historicamente identificadas

$\checkmark$ Em que âmbito do sistema de saúde do país aconteceram as primeiras discussões

$\checkmark$ Como foi a elaboração do plano de ação (elaborar a árvore de decisão)

\subsection{Etapa 3 - Tomada de Decisão}

$\checkmark$ Estrutura do sistema de saúde do país envolvida na definição de ações

$\checkmark$ Tomadores de decisão envolvidos neste processo

$\checkmark$ Identificando interesses, posições e compromissos neste processo (Mapa de Posições e nível de poder na estrutura política)

$\checkmark$ Modelo de Tomada de Decisão $(\mathrm{P}>\mathrm{S} / \mathrm{P}<>\mathrm{S} / \mathrm{P}<\mathrm{S})$

$\checkmark$ Definição do âmbito de aplicação desta política

\subsection{Etapa 4 - Implementação e Impactos}

$\checkmark$ Componentes da implantação da política

- Gestão e organização da política

- Orientações técnicas formuladas

- Recursos humanos recrutados

- Sistema de Vigilância

- Suporte laboratorial

- Relação com o meio ambiente

- Monitoramento / avaliação

- Interface com outros programas

$\checkmark$ Modelo de Implantação da Política (Top-Down ou Bottom-Up) 


\subsection{Etapa 5 - Avaliação}

$\checkmark$ Como foi a definição de Indicadores e Padrão de Avaliação

$\checkmark$ Critérios utilizados para a avaliar esta política

$\checkmark$ Como acontece o monitoramento da Política

$\checkmark$ Alcance de metas e objetivos (Padrões absolutos, históricos e normativos comparação)

\subsection{Etapa 6 - Análise de Lacunas}

$\checkmark$ Identificação das fragilidades e principais deficiências do programa

$\checkmark$ Análise dos impactos negativos e dificuldades na implantação de melhorias e inovação das políticas propostas.

\section{CONTEÚDO}

3.1. O Programa Nacional de Prevenção e Controle de IRAS (PNPCI) Definição

$\checkmark$ Caracterizar o conteúdo principal desta política (sua definição teórica e prática)

\subsection{Legislações que fundamentam o PNPCI}

$\checkmark$ Apontar as principais legislações que fundamentaram a criação e manutenção do programa.

\subsection{Principais Metas e Objetivos}

$\checkmark$ Apontar as principais metas e objetivos do programa.

\subsection{Ações do Programa}

$\checkmark$ Caracterizar o plano de ação do programa.

\subsection{Cenário de Atuação do PNPCI}

$\checkmark$ Reconhecer o âmbito de aplicação do programa.

\subsection{Atores envolvidos no PNPCI}


$\checkmark$ Identificar os atores envolvidos no processo, sua posição, papel e relação com a politica.

\subsection{Processo de Avaliação e Principais Indicadores do PNPCI}

$\checkmark$ Identificar indicadores de programa (e critérios de comparação)

$\checkmark$ Identificar processo de avaliação, monitoramento e comparação.

\subsection{Resultados do PNPCI}

Apontar os principais resultados alcançados pelo programa

\subsection{Interfaces do PNPCI}

Apontar as principais interfaces do programa e como elas ocorrem

\subsection{Desafios e Tendências para a expansão do PNCPI}

$\checkmark$ Discutir os principais desafios e tendências para a manutenção e expansão do programa.

\subsection{Adversidades da implantação do PNPCI}

$\checkmark$ Apontar as principais adversidades encontradas na implantação e manutenção do programa. 


\section{ANEXO 1 - APROVAÇÃO CEP/EEUSP}

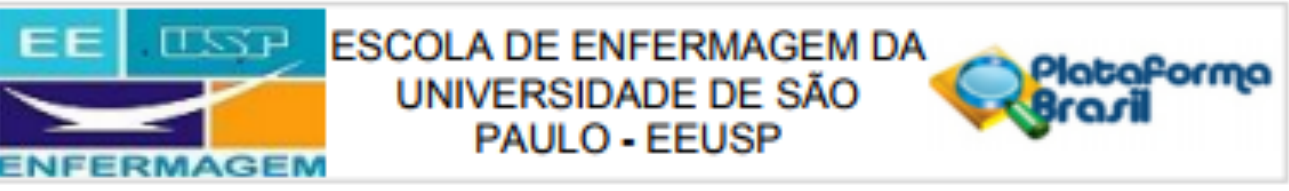

PARECER CONSUBSTANCIADO DO CEP

\section{DADOS DO PROJETO DE PESQUISA}

Titulo da Pesquisa: POLITICAS PÚBLICAS PARA PREVENÇĀO E CONTROLE DE IRAS: CONCEPÇĀO DE UM MODELO TEORICO PARA SUA ESTRUTURAÇAO

Pesquisador: CASSIMIRO NOGUEIRA JUNIOR

Area Temática:

Versảo: 1

CAAE: 52376516.9.0000.5392

Instituiçāo Proponente: Escola de Enfermagem da Universidade de Săo Paulo - EEUSP

Patrocinador Principal: MINISTERIO DA CIENCIA TECNOLOGIA E INONACAO

\section{DADOS DO PARECER}

Número do Parecer: 1.400 .148

\section{Apresentaçăo do Projeto:}

Tratsose de um projeto de Doutorado vinculado à Escola de Enfermagem da Universidade de Sto Paulo na área de concentraçấo - Cuidado em Saúde.

O projeto refere-se à análise das politicas públicas voltadas à prevençăb das infecçס̄es relacionadas aै assistetncia à saúde (IRAS), as quais șâo responsáveis pelo aumento da causa de morbimortalidade, sendo atualmente um dos principais desafios para mehoria da qualidade assistencial.

Tratasse de um estudo exploratbrio, descrifivo e explicativo, de abordagem qualitativa, baseado no modelo de "triângulo da politica pública de saúde" (Walt e Gison, 1994) para a and́lise das politicas públicas de prevençăo e controle de IRAS, combinando os métodos: descrifivo-comparativo e descritivo-analitico. A coleta dos dados será realizada em trés paises pré-selecionados (Chile, Estados Unidos e lsrael) com base em critérios de inclustăo e exclusto definidos no protocolo da pesquisa. A populaçăo será composta por nove gestores que integram as equipes governamentais, responstiveis pelos programas.

Apresenta o cronograma de execuçâo do projeto com término previsto para janeiro de 2018. $O$ orçamento perfaz um total de R\$ $36.128,00$ e recebeu financiamento do Ministério da Ciéncia, Teconologia e Inovaça.

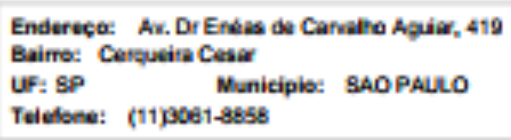

CEP: $05.408-000$

E-mal: expectias.tr 


EE
ENFERMAGEM
$\begin{gathered}\text { UNIVERSIDADE DE SÄO DA } \\ \text { PAULO-EEUSP }\end{gathered}$

Coranuapla to Precar: 1.400.140

Objetivo da Pesquisa:

Objetivo geral:

Construir um modelo teórico explicativo para a formaçâo de políficas públicas direcionadas à prevençăo e controle de IRAS.

Objetivos Especificos:

1. Descrever a trajetória histórica de formaçăo das polificas públicas para a prevençăo e controle de IRAS em paises com reconhecida tradiçăo elou em processo de ascensâo nesta ärea.

2. Caracterizar e comparar os modelos de prevençba e controle de IRAS em nivel governamental nos paises definidos, considerando seu conteúdo, contexto e processo.

3. Construir uma matriz explicativa dos modelos analisados para a prevença e controle de IRAS em nivel governamental.

\section{Avaliaçăo dos Riscos e Beneficios:}

O projeto apresenta baixo risco aos responsáveis pelos programas de prevençâo e controle de IRAS nos paises selecionados e pode estar relacionado ao desconforto em receber a visita do pesquisador para o acesso aos documentos públicos e demais registros sobre o processo de implementaçấo dessas politicas no campo da saúde pública. Quanto aos beneficios poderá contribuir no aperfeiçoamento das politicas de prevençâso e controle de IRAS, com vistas a melhoria da qualidade da atenç̧a à saúde em diferentes contextos.

Comentários e Consideraçōes sobre a Pesquisa:

O projeto é relevante para produçăo de conhecimento cientifico sobre o tema em questăo. Seră desemolvido em tres fases: a) pesquisa bibliografica e documentat; b) imersato nos programas nacionais de prevençâso e controle de IRAS; e c) construçăo de um modelo teórico explicativo das politicas públicas consonantes a tema.

O pesquisador informou que para o desemolvimento da segunda fase, solicitard a autorizaçato formal, por meio de carta convite as autoridades dos paises selecionados. Constam do projeto, o modelo da carta convite e a carta de aceite do Ministério da Saúde do Chile.

Consideraçōes sobre os Termos de apresentaçẩo obrigatória:

O pesquisador solicitou a dispensa do Termo de Consentimento Livre e Esclarecido (TCLE). Justifica que serbo coletados dados secundários, no caso documentos públicos referentes aos programas nacionais de controle e prevençało de IRAS nos paises selecionados; e que nấo será solicitado aos

Endereço: Ax. Dr Enéas de Carnatha Agaiar, 419

Bairre: Cerqueita Cesar

UF: SP Nunicipis: SAOPALLO

CEP: $05.400-000$

Telebene: (11)36a1-8658

E-mal: expedgusp.tr 


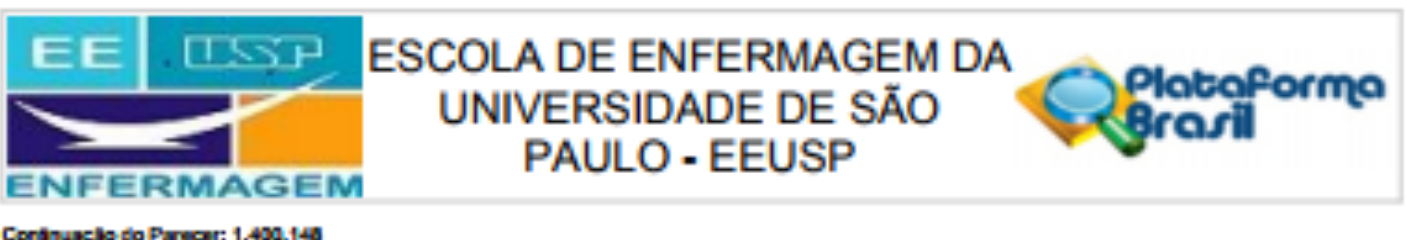

Conanuacla to Precar: 1.450.14a

gestores nenhum tipo de julgamento sobre a estruturaçăo e o desenvolvimento das politicas locais.

Recomendaçōes:

Năo há recomendą̧oes.

Conclusōes ou Pendéncias e Lista de Inadequaçōes:

O protocolo de pesquisa nâto apresenta b́bices éticos que impeçam a sua realizaçâo.

Consideraçōes Finais a critério do CEP:

- Este CEP informa a necessidade de registro dos resultados parciais e finais na Plataforma Brasì;

- Esta aprovaçăo nâo substitui a autorizaçấo da instituiçâo coparticipante, antes do inicio da coleta de dados.

Este parecer foi elaborado baseado nos documentos abaixo relacionados:

\begin{tabular}{|c|c|c|c|c|}
\hline Tipo Documento & Arquivo & Postagem & Ausar & Situsçà \\
\hline $\begin{array}{l}\text { Informaços Bassicas } \\
\text { do Proieto }\end{array}$ & $\begin{array}{l}\text { PB_INFORMACOES_BASICAS_DO_P } \\
\text { ROÄETO 660821.pdf }\end{array}$ & $\begin{array}{c}09 / 01 / 2016 \\
18: 40: 39\end{array}$ & & Aceilo \\
\hline Outros & apendice1_cartaconvite.doc & $\begin{array}{c}09 / 01 / 2016 \\
18 \times 40: 16\end{array}$ & $\begin{array}{l}\text { CASSIMIRO } \\
\text { NOGUEIRA JUNIOR }\end{array}$ & Aceilo \\
\hline Outras & anexo1_cartachile.pdf & $\begin{array}{c}09 / 01 / 2016 \\
18 \times 39: 12\end{array}$ & $\begin{array}{l}\text { CASSIMIRO } \\
\text { NOGUEIRA JUNOR }\end{array}$ & Aceilo \\
\hline $\begin{array}{l}\text { Projeto Detal hadof } \\
\text { Brochura } \\
\text { Investigador }\end{array}$ & Projetodetalnado.doc & $\begin{array}{c}0: 01 / 22016 \\
18: 37: 64\end{array}$ & $\begin{array}{l}\text { CASSIMIRTO } \\
\text { NOGUEIRA JUNIOR }\end{array}$ & Aceño \\
\hline Folha de Rosit & folhaDeRosto.pdf & $\begin{array}{c}09 / 01 / 2016 \\
18: 33: 63\end{array}$ & $\begin{array}{l}\text { CASSIMIRO } \\
\text { NOGUEIRA JUNIOR }\end{array}$ & Aceino \\
\hline
\end{tabular}

Situaçăło do Parecer:

Aprovado

Necessita Apreciaçăo da CONEP:

Nabo

Endereça: Ar. Dr Enés de Carvaltha Agaior, 419

Bairre: Cerqueita Cesar

UF: SP Nunicipis: SAOPALLO

CEP: $05.408-000$

Telebene: (11)36e1-86s8

E-mal: expeeguaptr 


EE . TSPP
ENFERMAGEM DE ENFERMAGEM DA
$\begin{gathered}\text { UNIVERSIDADE DE SÄO } \\ \text { PAULO - EEUSP }\end{gathered}$

Conanuapla to Precar: 1,400.14a

SAO PALLO, 01 de Fevereiro de 2016

Assinado por:

Lisabelle Mariano Rossato

(Coordenador)

Endereço: Ax. Dr Enè de Carnalto Agaiar, 419

Baime: Cerqueita Cesar
UF: SP Nunicipis: SAOPALLO

Telelone: (11)3681-8658

CEP: $05.400-000$

E-mal: expection.tr

Payina st of on 